MICHELE RODRIGUES

CARACTERIZAÇÃO ELÉTRICA DE CAPACITORES OBTIDOS ATRAVÉS DE TECNOLOGIA ULTRA-SUBMICROMÉTRICA 
MICHELE RODRIGUES

\title{
CARACTERIZAÇÃO ELÉTRICA DE CAPACITORES OBTIDOS ATRAVÉS DE TECNOLOGIA ULTRA-SUBMICROMÉTRICA
}

\author{
Dissertação apresentada à Escola \\ Politécnica da Universidade de São Paulo \\ para a obtenção do título de Mestre em \\ Engenharia.
}

Área de Concentração:

Engenharia Eletrônica / Microeletrônica

Orientador:

Prof. Dr. João Antonio Martino

São Paulo 
AUTORIZO A REPRODUÇÃO E DIVULGAÇÃO TOTAL OU PARCIAL DESTE TRABALHO, POR QUALQUER MEIO CONVENCIONAL OU ELETRÔNICO, PARA FINS DE ESTUDO E PESQUISA, DESDE QUE CITADA A FONTE.

Rodrigues, Michele

Caracterização elétrica de capacitores obtidos através de tecnologia ultra-submicrométrica / M. Rodrigues. -- São Paulo, 2006.

p.96

Dissertação (Mestrado) - Escola Politécnica da Universidade de São Paulo. Departamento de Engenharia de Sistemas Eletrônicos.

1.Capacitores 2.Circuitos integrados MOS 3.Microeletrônica I.Universidade de São Paulo. Escola Politécnica. Departamento de Engenharia de Sistemas Eletrônicos II.t. 
Dedico este trabalho ao meu pai Moacir por fazer de mim uma lutadora e ser meu herói.

Á minha mãe Maria Célia pela força com que nos carrega.

Ao meu amado Wilson pelo apoio e incentivo na luta dos meus sonhos e ideais.

Divido com vocês a glória desta conquista. 


\section{AGRADECIMENTOS}

Ao mestre Prof. Dr. João Antonio Martino pela atenciosa orientação, com quem pude aprender o que é paixão à pesquisa.

Ao professor e amigo Dr. Victor Sonnenberg, não só pela coorientação, mas também pela amizade, compreensão, incentivo e confiança depositada.

Aos estimados professores Dr. Marcelo Antonio Pavanello e Dr. Aparecido Sirley Nicolett, pelas inestimáveis orientações, participações e sugestões mesmo que distantes.

A todos os meus queridos e especiais amigos do grupo SOI-CMOS pelas eternas discussões, e por sempre estarem dispostos a ajudar.

Ao Laboratório de Sistemas Integráveis da Escola Politécnica da Universidade de São Paulo, pela disponibilidade da infra-estrutura necessária para essa atividade de pesquisa e ao CNPq, pelo apoio financeiro inestimável, que permitiu a realização deste trabalho.

Aos meus pais e irmã, pelo grande apoio, incentivo, compreensão e dedicação durante a realização deste sonho profissional e de tantos outros.

Ao meu amado Wilson pela imensa compreensão nos momentos de ausência, pela sábias palavras de conselho e pelo amor incondicional.

À Iraídes e a Aline pela atenção e preocupação à mim dedicada.

À querida Denice que mesmo à distância contribuiu para minha formação pessoal e profissional.

À grande amiga Claudia pela amizade sem limites e barreiras.

A tantas outras pessoas que, de alguma forma, colaboraram para a realização deste trabalho e que, de forma involuntária, foram aqui omitidas. 
"Não podemos resolver problemas utilizando o mesmo tipo de raciocínio que utilizamos, quando os criamos." 


\section{RESUMO}

RODRIGUES, M. Caracterização elétrica de capacitores obtidos através de tecnologia ultra-submicrométrica. 2006. f. Dissertação (Mestrado) - Escola Politécnica, Universidade de São Paulo, São Paulo, 2006.

Apresentamos neste trabalho um estudo do efeito da depleção do silício policristalino e da corrente de tunelamento em dispositivos com óxidos de porta finos. Utilizamos curvas características da capacitância em função da tensão de porta $(\mathrm{C}-\mathrm{V})$, para analisar a degradação causada por estes efeitos.

Quanto ao efeito da depleção do silício policristalino a capacitância total na região de inversão apresenta uma redução conforme a concentração de dopantes do silício policristalino diminui. Este efeito foi observado em curvas $\mathrm{C}-\mathrm{V}$ tanto de alta como de baixa freqüência, sendo esta última mais afetada.

A corrente de tunelamento através do óxido de porta apresentou uma influência na largura da região de depleção no silício, que aumentou devido ao tunelamento de portadores do substrato. Como resultado, uma diminuição na capacitância do silício foi observada, fazendo a curva C-V diminuir na região de inversão. Quando considerado o efeito de depleção no silício policristalino junto com o efeito do tunelamento, observou-se que na região da porta houve um excesso de portadores, causando uma diminuição na região de depleção do silício policristalino. Neste caso a curva $\mathrm{C}-\mathrm{V}$ sofreu uma maior redução, tornando-se difícil separar os dois efeitos. A curva $\mathrm{C}-\mathrm{V}$ de baixa freqüência foi a mais atingida, pois como os portadores tem tempo de resposta, pode-se observar a influência da corrente de tunelamento nas cargas de inversão.

Apresentamos ainda um novo método para a determinação da concentração de dopantes no substrato e no silício policristalino, através de curvas $\mathrm{C}-\mathrm{V}$ de alta frequiência. Simulações numéricas bidimensionais e medidas experimentais foram utilizadas para validação do método. Os resultados obtidos indicam que o método proposto apresenta um grande potencial, tendo como principal vantagem a simplicidade de aplicação.

Palavras-chave: capacitor, MOS, óxido de porta fino, efeito de depleção do Si-poli, corrente de tunelamento, simulação bidimensional, curva C-V. 


\begin{abstract}
RODRIGUES, M. Electrical characterization of capacitors obtained through extremesubmicrometer technology. 2006. f. Dissertation (Master) - Escola Politécnica, Universidade de São Paulo, São Paulo, 2006.
\end{abstract}

In this work we present the study of polysilicon depletion and the gate tunneling current effects in thin-gate oxide devices. Characteristic curves of capacitance as a function of the gate voltage $(\mathrm{C}-\mathrm{V})$ were used to analyze the degradation caused for these effects.

Regarding the poly depletion effect, a reduction of the total capacitance in the inversion region was verified as the polysilicon doping concentration decreases. This effect was observed in $\mathrm{C}-\mathrm{V}$ curves in high and low frequency, being the last one more affected.

The gate tunneling current presented an influence on the width of the depletion silicon region, which increased due to the carriers tunneling from the substrate. As a result, a reduction in the silicon capacitance was observed, causing the $\mathrm{C}-\mathrm{V}$ curve reduction in the inversion region. When the polysilicon depletion effect is considered together with the tunneling effect, it was observed that there is a carriers excess in the gate region, causing a reduction of the polysilicon depletion region width. In this case, the $\mathrm{C}-\mathrm{V}$ curve suffered a larger reduction, making difficult to separate both effects. The most affected characteristic was the $\mathrm{C}-\mathrm{V}$ curve at low frequency, due to existence of the carrier response time that allows observing the influence of the tunneling current in inversion charges.

A new method for the determination of the doping concentration of substrate and polysilicon was also presented, through $\mathrm{C}-\mathrm{V}$ curves at high frequency. Two-dimensional simulations and experimental measurements were used to validate the method. The obtained results indicate that the propose method present a higher potential, having as principal advantage the simplicity of application.

Keywords: MOS capacitor, thin gate oxide, polysilicon depletion effect, tunneling current, C-V curve, two-dimensional simulation. 


\section{LISTA DE FIGURAS}

Figura 1.1 - Lei de Moore ${ }^{1}$

Figura 1.2 - Impacto da Lei de Moore na (a) capacidade de processamento e no (b) custo dos transistores $^{2}$.

Figura 1.3 - Evolução da espessura do óxido de porta $\left(\mathrm{t}_{\mathrm{ox}}\right)$ com o comprimento de canal $(\mathrm{L})^{5}$.

Figura 2.1 Representação esquemática do processo de fabricação de um capacitor MOS com porta de Si-poli indicando a região menos dopada junto ao óxido.

Figura 2.2 - a) Modelo equivalente de capacitâncias e o b) perfil transversal do capacitor MOS com porta de metal.

Figura 2.3 - (a) Modelo equivalente de capacitâncias e o (b) perfil transversal de um capacitor MOS com porta de Si-poli. 25

Figura 2.4 - Diagrama de faixas de energia para um capacitor MOS na condição de acumulação.

Figura 2.5 - Diagrama de faixas de energia para um capacitor MOS na condição de faixa plana. 27

Figura 2.6 - Diagrama de faixas de energia para um capacitor MOS na condição de depleção.

Figura 2.7 - Diagramas de faixas de energia para uma capacitor MOS na condição de inversão forte.

Figura 2.8 - Estrutura Si-poli / óxido / substrato com a representação das quedas de potenciais.

Figura 2.9 - Diagrama de faixas de energia de uma estrutura Si-poli N+/ óxido / substrato P.30

Figura 2.10 - Curvas $\mathrm{V}_{\mathrm{Tp}}$ em função de $\mathrm{N}_{\text {poli }}$, indicando o aumento da tensão de limiar com a redução de $\mathrm{N}_{\text {poli }}{ }^{12}$.

Figura 2.11 - Curva $\mathrm{C}$ x $\mathrm{V}_{\mathrm{G}}$ normalizada em função de $\mathrm{C}_{\mathrm{ox}}$ operando em alta freqüência para um capacitor MOS, indicando a influência do efeito de depleção no Si-poli....... 33 
Figura 2.12 - Curva $C \times V_{G}$ normalizada em função de $C_{o x}$ em baixa freqüência de um capacitor MOS, indicando a influência do efeito de depleção do Si-poli............. 34

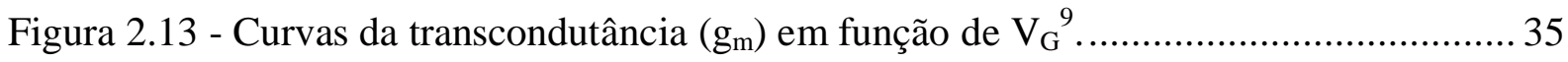

Figura 2.14 - Curva da degradação da corrente de dreno $\left(\mathrm{I}_{\mathrm{D}}\right)$ em função de $\mathrm{N}_{\text {poli }}{ }^{20} \ldots \ldots \ldots \ldots . . . . . .35$

Figura 2.15 - Diagrama de faixas exemplificando os três principais tipos de injeção de portadores através do isolante. ............................................................... 37

Figura 2.16 - Diagramas de faixas de energia de uma estrutura Si-poli N+ / óxido / substrato P no caso da corrente de (a) tunelamento por Fowler-Nordheim e de (b) tunelamento direto.

Figura 2.17 - Curvas da densidade da corrente de tunelamento $\left(\mathrm{J}_{\mathrm{G}}\right)$ em função da tensão aplicada à porta $\left(\mathrm{V}_{\mathrm{G}}\right)$ para $\mathrm{t}_{\mathrm{ox}}$ variando de $2,9 \mathrm{a} 6,2 \mathrm{~nm}^{27}$ 38

Figura 2.18 - Diagrama de faixas de energia de uma estrutura nMOSFET com substrato P e porta de Si-poli $\mathrm{N}+$, e os mecanismos da corrente de tunelamento direto ${ }^{28}$ 39

Figura 2.19 - Curva $\mathrm{C}$ x $\mathrm{V}_{\mathrm{G}}$ normalizada em função de $\mathrm{C}_{\mathrm{ox}}$ de alta freqüência, demonstrando a influência da corrente de tunelamento.

Figura 2.20 - Curva $C \times V_{G}$ normalizada em função de $C_{o x}$ de baixa freqüência, demonstrando a influência da corrente de tunelamento.

Figura 2.21 - Curvas de $\mathrm{V}_{\mathrm{ox}}$ em função de $\mathrm{V}_{\mathrm{G}}$, para diferentes $\mathrm{N}_{\mathrm{poli}}$ e $\mathrm{t}_{\mathrm{ox}}{ }^{32}$ 42

Figura 2.22 - Curva da densidade da corrente de tunelamento $\left(\mathrm{J}_{\mathrm{G}}\right)$ em função de $\mathrm{V}_{\mathrm{G}}$, para diferentes espessuras no óxido de porta e concentrações no Si-poli.

Figura 2.23 - Curvas C-V de uma estrutura Si-poli N+ / $\mathrm{SiO}_{2} /$ Substrato P em (a) alta e (b) baixa freqüência.

Figura 2.24 - Relação de $\mathrm{t}_{\mathrm{ox}}$ em função das dimensões dos dispositivos, fazendo uma análise da necessidade de novos matérias de porta para substituição do $\mathrm{SiO}_{2}{ }^{4}$.

Figura 2.25 - Comparação entre uma (a) estrutura convencional com dielétrico de porta óxido de silício $\left(\mathrm{SiO}_{2}\right)$ e (b) uma estrutura com dielétrico de porta High-k.

Figura 2.26 - Curva da corrente de porta $\left(\mathrm{J}_{\mathrm{G}}\right)$ em função da espessura equivalente do óxido de porta $(\text { EOT })^{3}$. 46 
Figura 3.1 . Curvas $\mathrm{C} \times \mathrm{V}_{\mathrm{G}}$ simuladas para um capacitor com porta de Si-poli N+, operando em alta freqüência.

Figura 3.2 - Curvas $\mathrm{C}$ x $\mathrm{V}_{\mathrm{G}}$ simuladas para um capacitor com porta de Si-poli N+, operando em baixa frequiência.

Figura 3.3 - Curvas do Potencial e da concentração dos portadores, ambas em função da profundidade, para uma estrutura $\mathrm{Si}$-poli $\mathrm{N}+/ \mathrm{SiO}_{2} / \mathrm{Substrato} \mathrm{P}$ e com diferentes tensões de porta (a) $\mathrm{V}_{\mathrm{G}}=0,5 \mathrm{~V}$, (b) $\mathrm{V}_{\mathrm{G}}=1,5 \mathrm{~V}$ e (c) $\mathrm{V}_{\mathrm{G}}=4 \mathrm{~V}$. 52

Figura 3.4 - Curvas $\mathrm{C} \times \mathrm{V}_{\mathrm{G}}$ simuladas para um capacitor com porta de Si-poli $\mathrm{P}+$, operando em alta freqüência.

Figura 3.5 - Curvas $\mathrm{C}$ x $\mathrm{V}_{\mathrm{G}}$ simuladas para um capacitor com porta de alumínio e porta de $\mathrm{Si}$ poli $\mathrm{P}+$, operando em baixa freqüência.

Figura 3.6 - Curvas do Potencial em função da Profundidade, para uma estrutura Si-poli $\mathrm{P}+/ \mathrm{SiO}_{2} / \mathrm{Sub}$. $\mathrm{P}$, com tensões de porta de (a) $\mathrm{V}_{\mathrm{G}}=0 \mathrm{~V}$, (b) $\mathrm{V}_{\mathrm{G}}=-1,5 \mathrm{~V}$ e (c) $\mathrm{V}_{\mathrm{G}}=-4 \mathrm{~V}$.

Figura 3.7 - Simulação do perfil bidimensional de uma estrutura Alumínio/ $\mathrm{SiO}_{2} / \mathrm{Substrato} \mathrm{P}$, onde (a) é sem corrente de tunelamento direto e (b) é com tunelamento, para $\mathrm{V}_{\mathrm{G}}=3 \mathrm{~V}$

Figura 3.8 - Curvas da largura da região de depleção $\left(\mathrm{d}_{\mathrm{Si}}\right)$ e da capacitância do silício $\left(\mathrm{C}_{\mathrm{Si}}\right)$, ambas em função de $V_{G}$, para $t_{o x}=2,2 n m$. 58

Figura 3.9 - Curvas C-V em alta freqüência, demonstrando a influência da corrente de tunelamento direto (TD), para um capacitor MOS tipo P com porta de alumínio, $\mathrm{t}_{\mathrm{ox}}=2,2 \mathrm{~nm} \mathrm{e} \mathrm{N}_{\mathrm{a}}=1 \times 10^{18} \mathrm{~cm}^{-3}$ 59

Figura 3.10 - Curvas C-V em baixa frequiência, demonstrando a influência da corrente de tunelamento direto (TD), para um capacitor MOS tipo P com porta de alumínio, $\mathrm{t}_{\mathrm{ox}}=2,2 \mathrm{~nm} \mathrm{e} \mathrm{N}_{\mathrm{a}}=1 \times 10^{18} \mathrm{~cm}^{-3}$. 60

Figura 3.11 - Curvas da densidade de corrente $\left(\mathrm{J}_{\mathrm{G}}\right)$ em função de $\mathrm{V}_{\mathrm{G}}$, para diferentes $\mathrm{t}_{\mathrm{ox}} \ldots . . .61$

Figura 3.12 - Curva da densidade de corrente de tunelamento $\left(\mathrm{J}_{\mathrm{G}}\right)$ em função de $\mathrm{V}_{\mathrm{G}}$, para diferentes concentrações de dopantes no Si-poli. 
Figura 3.13 - Simulação do perfil bidimensional de uma estrutura Sipoli N+/SiO2/Substrato P, onde (a) é sem corrente de tunelamento direto e (b) é com tunelamento, para $\mathrm{V}_{\mathrm{G}}=3 \mathrm{~V}$

Figura 3.14 - Curvas da largura da região de depleção máxima no Si-poli $\left(\mathrm{d}_{\text {polimáx }}\right)$ e no silício $\left(\mathrm{d}_{\text {Simáx }}\right)$ em função da concentração de dopantes no Si-poli $\left(\mathrm{N}_{\text {poli }}\right)$ com e sem tunelamento TD. 64

Figura 3.15 - Curvas da largura da região de depleção máxima no silício em função de $\mathrm{N}_{\text {poli }}$, para diferentes espessuras de óxido de porta.

Figura 3.16 - Curvas C-V com (a) porta de alumínio, (b) porta Si-poli N+ e (c) porta Si-poli $\mathrm{N}+\mathrm{e}$ modelo de tunelamento, com $\mathrm{t}_{\mathrm{ox}}=2,2 \mathrm{~nm}, \mathrm{~N}_{\mathrm{a}}=1 \times 10^{18} \mathrm{~cm}^{-3}$ e alta freqüência de operação 65

Figura 3.17 - Ampliação da curva C-V da Figura 3.16 na região de inversão. 66

Figura 3.18 - Variação da curva C-V de alta freqüência, com a diminuição na concentração de dopantes do Si-poli N+ e com a corrente de tunelamento.

Figura 3.19 - Curvas das capacitância presentes em uma estrutura Si-poli N+/ $\mathrm{SiO}_{2} /$ Substrato $\mathrm{P}$ em função de $\mathrm{N}_{\text {poli }}$, sob o efeito da corrente de tunelamento direto. 68

Figura 3.20 - Curvas do Potencial em função da profundidade, para uma estrutura Sipoli $\mathrm{N}+/ \mathrm{SiO} 2 /$ Substrato $\mathrm{P}$, com tensões de porta de (a) $\mathrm{V}_{\mathrm{G}}=0,5 \mathrm{~V}$, (b) $\mathrm{V}_{\mathrm{G}}=1,5 \mathrm{~V}$ e (c) $\mathrm{V}_{\mathrm{G}}=3,0 \mathrm{~V}$

Figura 3.21 - Curva do Potencial em função da Profundidade, demonstrando a influência da corrente de tunelamento direto no potencial de superfície do silício $\left(\phi_{\mathrm{S}}\right)$.

Figura 3.22 - Variação da curva C-V de baixa freqüência, com a diminuição na concentração de dopantes do Si-poli N+e com a corrente de tunelamento. 70

Figura 4.1 - Curva C-V normalizada em função de $C_{o x}$ de uma estrutura Si-poli N+ / óxido / substrato, operando em alta freqüência.

Figura 4.2 - (a) Modelo equivalente de capacitâncias e a representação de C1 e C2, e (b) o perfil de um capacitor MOS com porta de Si-poli. 72

Figura 4.3 - Curva C-V normalizada em função de $C_{o x}$ e a respectiva segunda derivada de um capacitor MOS com porta de Si-poli N+. ... 


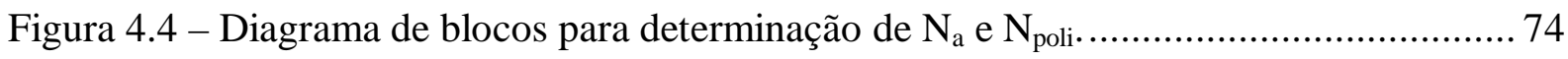

Figura 4.5 Curvas simuladas do potencial em função da profundidade, onde para (a)

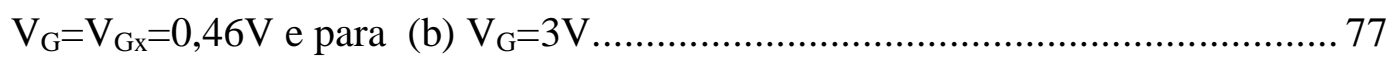

Figura 4.6 - Curva C-V experimental e sua respectiva segunda derivada.......................... 78 


\section{LISTA DE TABELAS}

Tabela 2.1 - Constante dielétrica $(\mathrm{K})$ de novos dielétricos de porta ${ }^{5}$

Tabela 3.1 - Modelos físicos utilizados nos arquivos de simulação. 48

Tabela 3.2 - Valores da largura máxima da região de depleção $\left(\mathrm{d}_{\text {Simáx }}\right)$ para diferentes $\mathrm{t}_{\mathrm{ox}}$ sob influência do tunelamento de corrente.

Tabela 4.1 - Valores de $\mathrm{C} 1, \mathrm{C} 2$ e $_{\mathrm{ox}}$ extraídos das simulações e os valores de $\mathrm{N}_{\mathrm{a}}$ e $\mathrm{N}_{\text {poli }}$ determinados pelo método proposto. 75

Tabela 4.2 - Erro percentual máximo na extração de $\mathrm{N}_{\mathrm{a}}$ e $\mathrm{N}_{\text {poli. }}$ 76

Tabela 4.3 - Comparação entre os potenciais de superfície no silício e no Si-poli, para

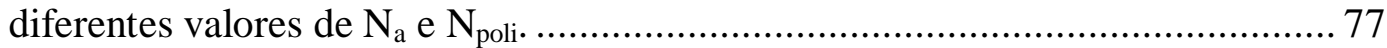




\section{LISTA DE SÍMBOLOS}
A
Área do capacitor $\left[\mathrm{cm}^{2}\right]$
$a_{v}$
Termo que representa a inserção do efeito da depleção do silício policristalino no cálculo da tensão de limiar
$\mathrm{C} 1$
Capacitância medida na curva C-V que não considera o efeito da depleção no silício policristalino por unidade de área $\left[\mathrm{F} / \mathrm{cm}^{2}\right]$
Capacitância medida na curva $\mathrm{C}-\mathrm{V}$ que considera o efeito da depleção no silício policristalino por unidade de área $\left[\mathrm{F} / \mathrm{cm}^{2}\right]$
$\mathrm{C}_{\mathrm{d}} \quad$ Capacitância de depleção da camada do silício por unidade de área $\left[\mathrm{F} / \mathrm{cm}^{2}\right]$
$\mathrm{C}_{\mathrm{dpoli}}$ Capacitância de depleção do silício policristalino por unidade de área $\left[\mathrm{F} / \mathrm{cm}^{2}\right]$
$\mathrm{C}_{\mathrm{FB}}$
Capacitância de faixa plana por unidade de área $\left[\mathrm{F} / \mathrm{cm}^{2}\right]$
$\mathrm{C}_{\mathrm{inv}}$
Capacitância de inversão da camada do silício por unidade de área $\left[\mathrm{F} / \mathrm{cm}^{2}\right]$
$\mathrm{C}_{\text {invpoli }}$
$\mathrm{C}_{\min }$
Capacitância de inversão do silício policristalino por unidade de área $\left[\mathrm{F} / \mathrm{cm}^{2}\right]$
$\mathrm{C}_{\mathrm{o}}$ Capacitância mínima $\left[\mathrm{F} / \mathrm{cm}^{2}\right]$
$\mathrm{C}_{\mathrm{ox}}$
Capacitância do óxido de porta [F]
$\mathrm{C}_{\text {poli }}$
Capacitância do óxido de porta por unidade de área $\left[\mathrm{F} / \mathrm{cm}^{2}\right]$
$\mathrm{C}_{\text {polimáx }}$
Capacitância da camada do silício policristalino por unidade de área $\left[\mathrm{F} / \mathrm{cm}^{2}\right]$
Capacitância máxima da camada do silício policristalino por unidade de área $\left[\mathrm{F} / \mathrm{cm}^{2}\right]$
$\mathrm{C}_{\mathrm{Si}} \quad$ Capacitância da camada do silício por unidade de área $\left[\mathrm{F} / \mathrm{cm}^{2}\right]$
$\mathrm{C}_{\text {Simáx }} \quad$ Capacitância máxima da camada do silício por unidade de área $\left[\mathrm{F} / \mathrm{cm}^{2}\right]$
$\mathrm{C}_{\mathrm{T}}$ capacitância total presente em um capacitor MOS por unidade de área $\left[\mathrm{F} / \mathrm{cm}^{2}\right]$
$\mathrm{C}_{\mathrm{x}} \quad$ capacitância que indica o início da depleção na região do silício policristalino $\left[\mathrm{F} / \mathrm{cm}^{2}\right]$
$\mathrm{d}_{\mathrm{Si}} \quad$ Largura da região de depleção no silício [nm]
d $\quad$ Largura máxima da região de depleção no silício [nm]
$\mathrm{d}_{\text {poli }}$
Largura da região de depleção na silício policristalino [nm]
$\mathrm{d}_{\text {polimáx }}$
Largura máxima da região de depleção na silício policristalino [nm]
$\mathrm{E}_{\mathrm{C}}$
Nível energético do extremo inferior da Faixa de Condução [eV]
$\mathrm{E}_{\mathrm{F}} \quad$ Nível de Fermi $[\mathrm{eV}]$ 


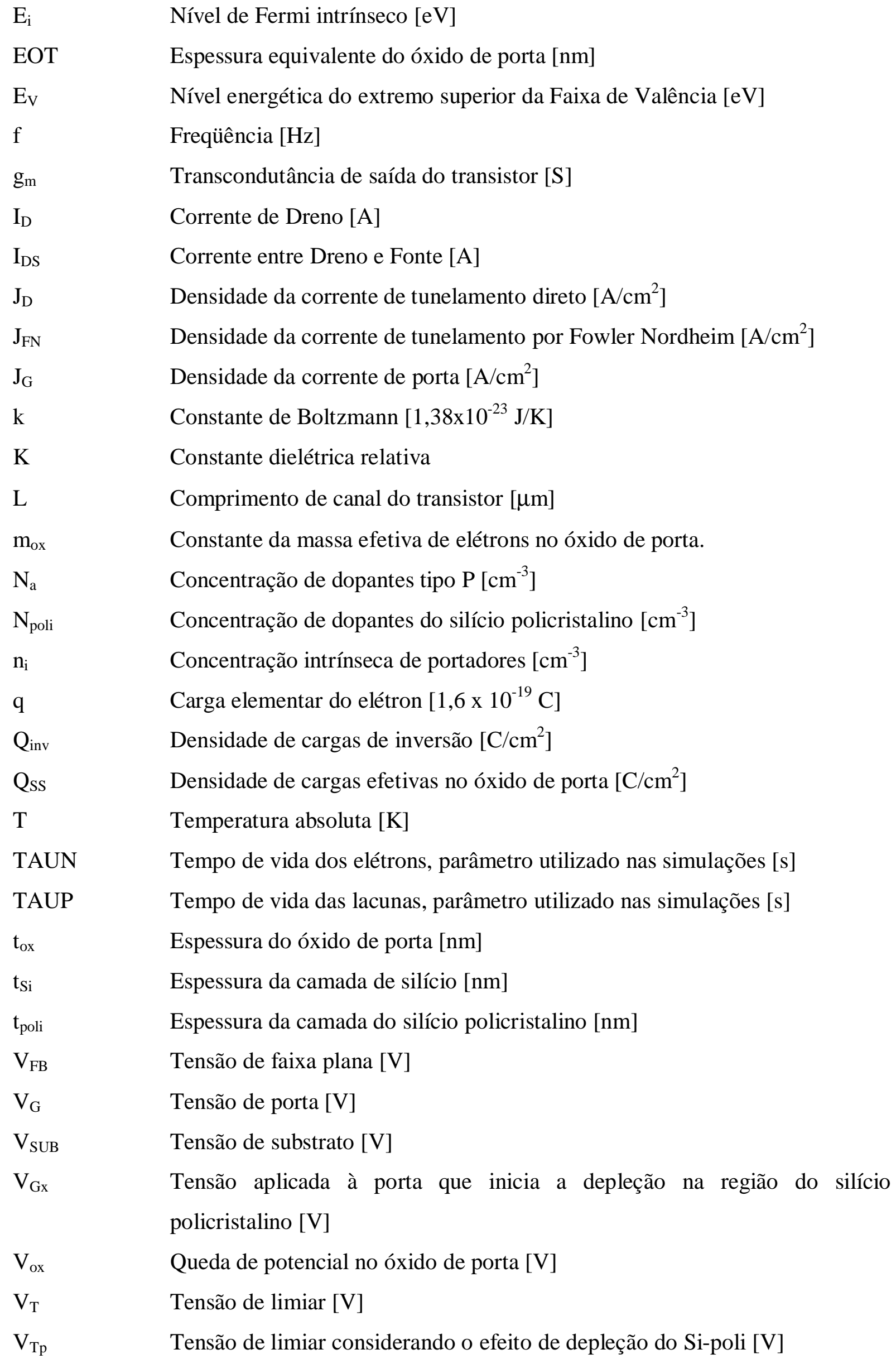




$\begin{array}{ll}\varepsilon_{\mathrm{o}} & \text { Permissividade do vácuo [F/cm] } \\ \varepsilon_{\mathrm{Si}} & \text { Permissividade do silício }\left[11,7 \times 8,85 \times 10^{-14} \mathrm{~F} / \mathrm{cm}\right] \\ \varepsilon_{\mathrm{ox}} & \text { Permissividade do óxido de silício }\left[3,9 \times 8,85 \times 10^{-14} \mathrm{~F} / \mathrm{cm}\right] \\ \phi_{\mathrm{F}} & \text { Potencial de Fermi no silício [V] } \\ \phi_{\mathrm{Fpoli}} & \text { Potencial de Fermi no silício policristalino [V] } \\ \phi_{\mathrm{S}} & \text { Potencial de superfície do silício [V] } \\ \phi_{\mathrm{Sp}} & \text { Potencial de superfície do silício policristalino [V] } \\ \phi_{\mathrm{T}} & \text { Altura da barreira de tunelamento [V] }\end{array}$




\section{SUMÁRIO}

1 INTRODUÇÃO........................................................................................................... 20

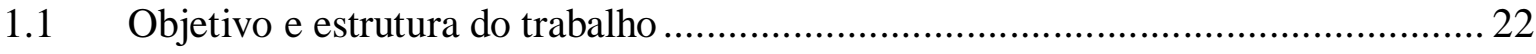

2 CONCEITOS BÁSICOS................................................................................... 23

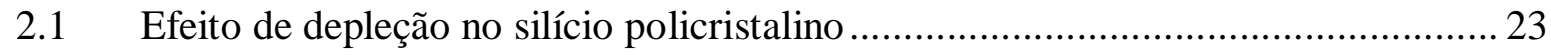

2.1.1 Influência na Capacitância Total ............................................................... 24

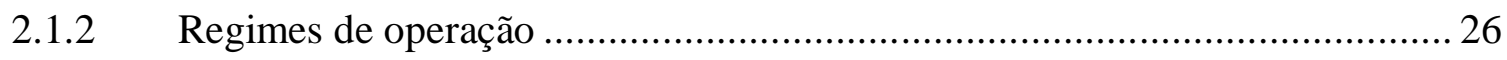

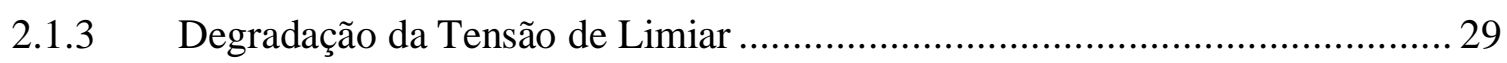

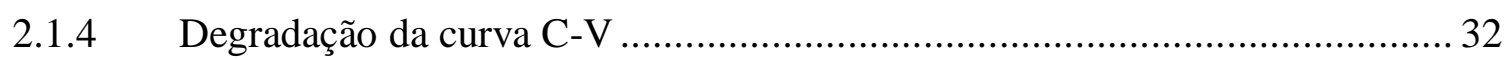

2.1.5 Influência da depleção no Si-poli nas características de um transistor............. 34

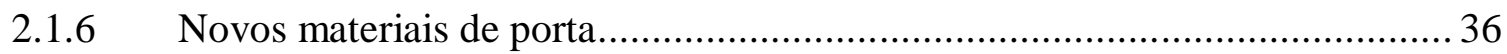

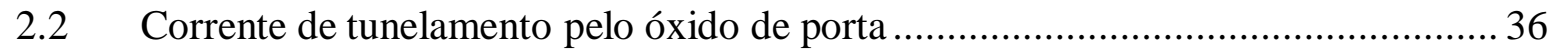

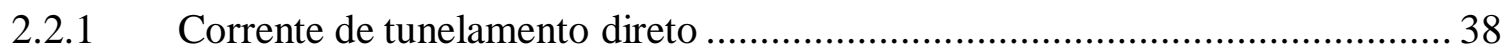

2.2.2 Degradação do Nível de Fermi.................................................................. 39

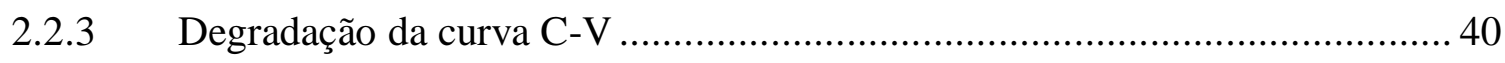

2.2.4 Efeito de depleção no Si-poli e da corrente de tunelamento .......................... 41

2.2.5 Novos dielétricos de porta.................................................................... 43

3 SIMULAÇÃ̃ NUMÉRICA BIDIMENSIONAL ................................................... 47

3.1 Simulador Bidimensional de Dispositivos (MEDICI) ....................................... 47

3.2 Modelos físicos utilizados nas simulações .................................................... 47

3.3 Efeito de depleção no Si-poli ................................................................... 48

3.3.1 Estrutura Si-poli $\mathrm{N}+/ \mathrm{SiO}_{2} /$ Substrato P.................................................. 49

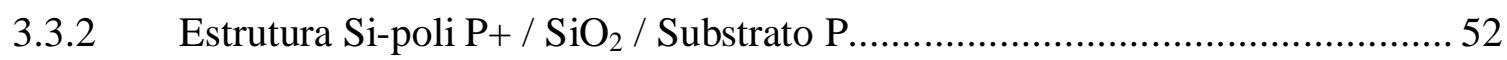

3.4 Corrente de tunelamento pelo óxido de porta ....................................................... 55

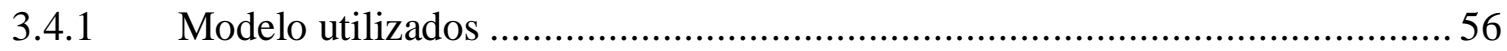

3.4.2 Degradação da largura da região de depleção $\left(\mathrm{d}_{\mathrm{Si}}\right)$.................................... 57

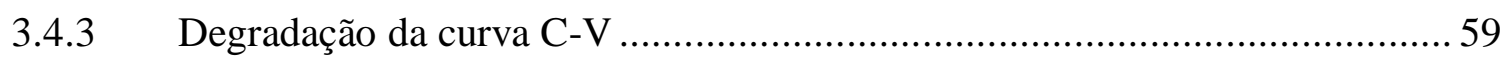

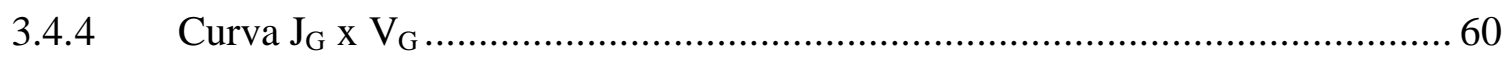

3.4.5 Efeito da depleção no Si-poli e da corrente de tunelamento direto .................. 61 
4 PROPOSTA DE UM MÉTOdO PARA EXTRAÇÃO DA CONCENTRAÇÃo

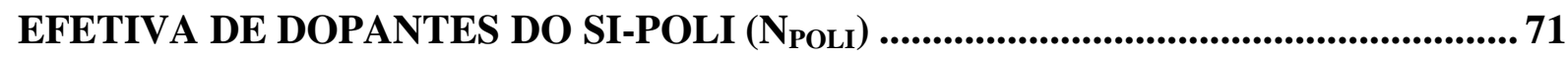

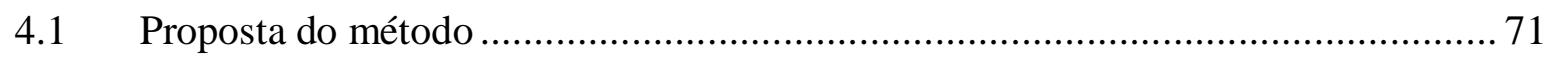

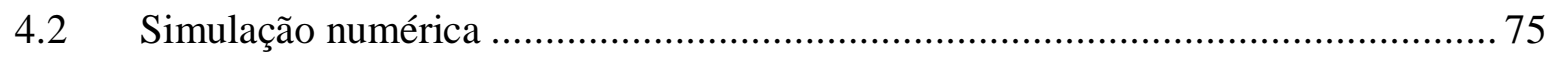

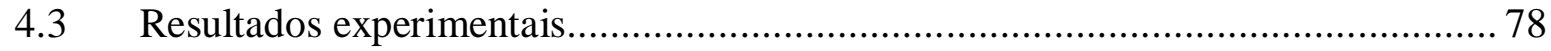

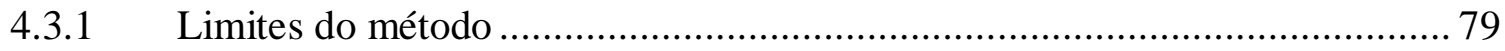

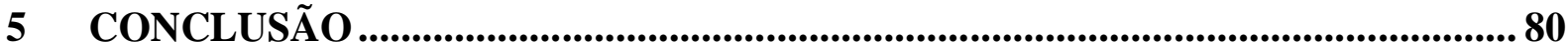

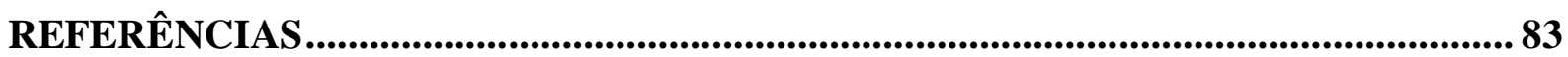

APÊNDICE A - Modelo do arquivo de simulação MEDICI para obtenção da curva C-V de alta freqüência de um capacitor MOS ...............................................................................87 APÊNDICE B - Modelo do arquivo de simulação MEDICI para obtenção da curva C-V de baixa freqüência de uma capacitor MOS .89

APÊNDICE C - Modelo do arquivo de simulação MEDICI para obtenção do diagrama de bandas de energia de um capacitor MOS...................................................................91 APÊNDICE D - Modelo do arquivo de simulação MEDICI para obtenção de curva C-V de alta frequiência e do perfil bidimensional da região de depleção de um capacitor MOS com modelo da corrente de tunelamento direto. .93

APÊNDICE E - Modelo do arquivo de simulação MEDICI para obtenção da curva IG $x$ VG de um capacitor MOS com modelo da corrente de tunelamento direto. .95 


\section{INTRODUÇÃO}

Com o avanço das tecnologias de fabricação de circuitos integrados, o número de transistores contidos em uma pastilha de silício (Chip) tem crescido exponencialmente com o tempo (Figura 1.1), como previsto pela conhecida Lei de Moore ${ }^{1}$. Desta forma a capacidade de processamento tem aumentado continuamente e o custo de fabricação dos transistores por pastilha diminuído, como mostra a Figura $1.2^{2}$.

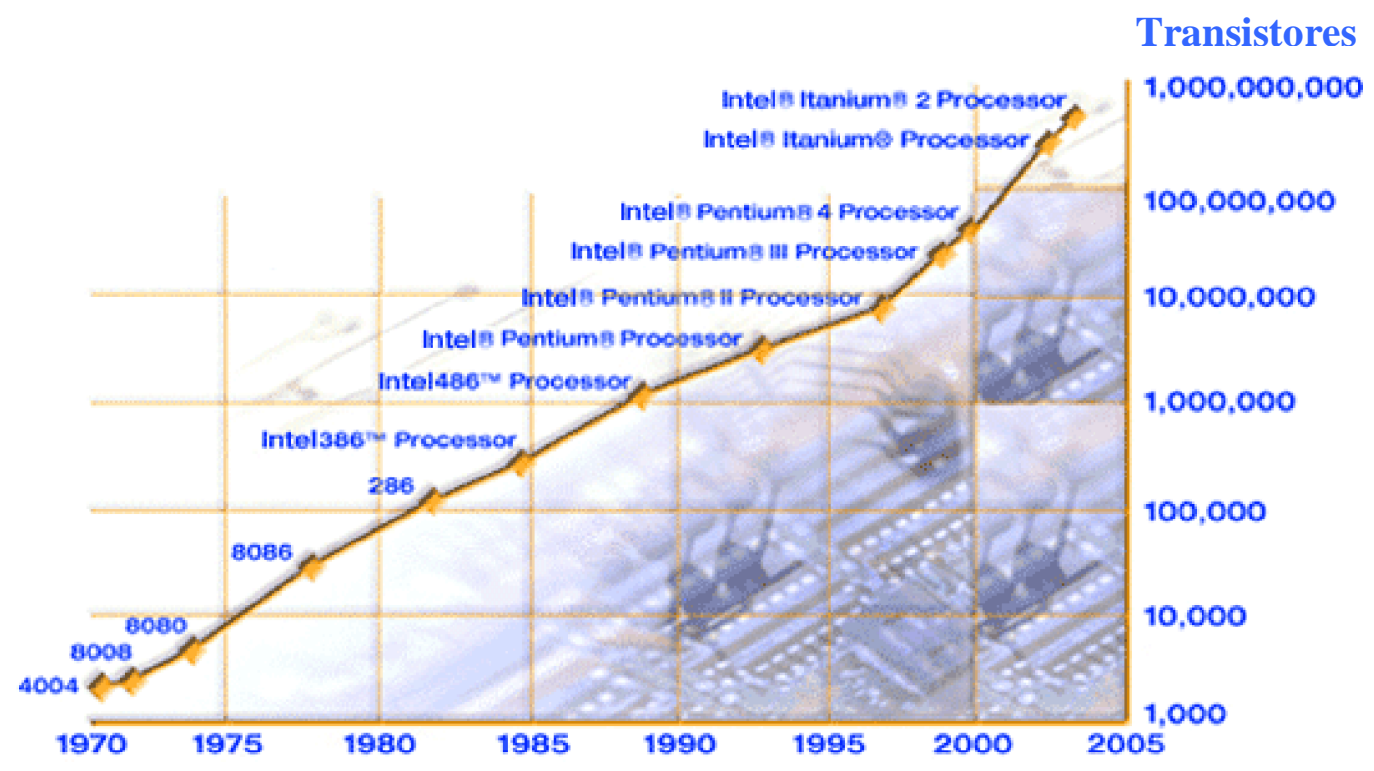

Figura 1.1 - Lei de Moore ${ }^{1}$.

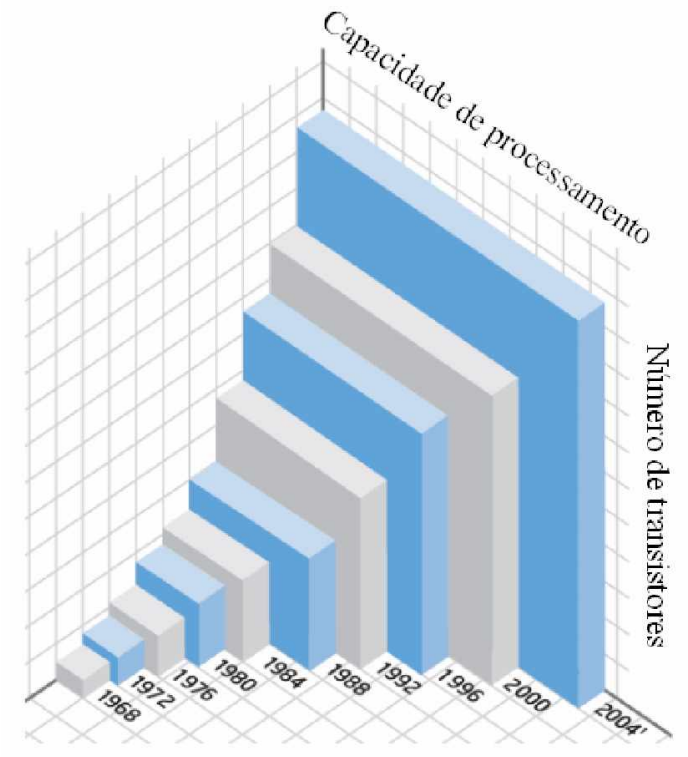

(a)

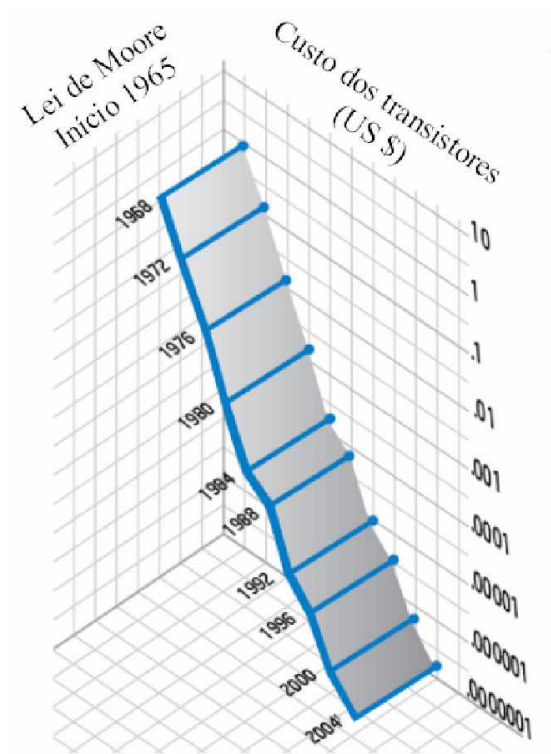

(b)

Figura 1.2 - Impacto da Lei de Moore na (a) capacidade de processamento e no (b) custo dos transistores ${ }^{2}$. 
Para se aumentar o número de transistores de uma pastilha, suas dimensões precisam ser escaladas, diminuindo-se fortemente o comprimento de canal (L) do transistor ${ }^{3}$. A espessura do óxido de porta $\left(\mathrm{t}_{\mathrm{ox}}\right)$ precisa ser escalada linearmente com o comprimento do canal, para manter-se o mesmo controle sobre as cargas do canal e evitar o efeito de canal curto $\left(\mathrm{t}_{\mathrm{ox}}=\mathrm{L} / 40\right)$, conforme mostra a Figura 1.3. Óxidos finos são necessários também para uma operação em baixa potência, onde a tensão de limiar $\left(\mathrm{V}_{\mathrm{T}}\right)$ precisa ser reduzida. Para manter-se uma tensão de limiar coerente com a tecnologia e evitar-se os efeitos de canal curto, as regiões do escalamento exigem que a concentração de dopantes do canal deve ser aumentada ${ }^{4,5}$.

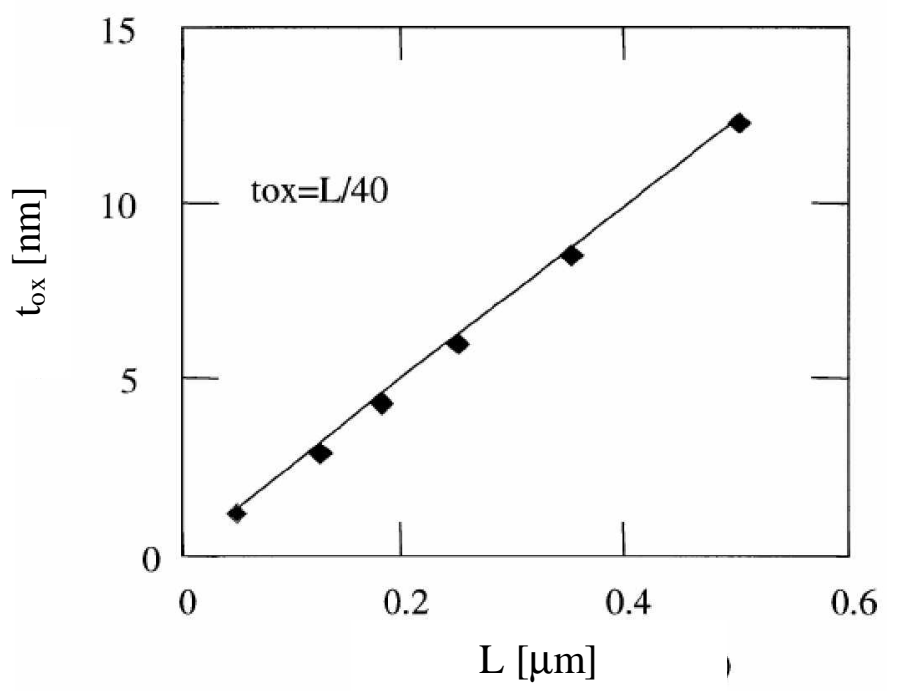

Figura 1.3 - Evolução da espessura do óxido de porta $\left(\mathrm{t}_{\mathrm{ox}}\right)$ com o comprimento de canal $(\mathrm{L})^{5}$.

Esta necessária redução do óxido de porta, traz uma série de problemas que atrapalham o bom desempenho dos dispositivos MOS. Como no caso de dispositivos com porta de silício policristalino (Si-poli), que dependendo da concentração de dopantes próximo da interface Si-poli/óxido pode ficar em depleção em certas condições de polarização. Este efeito conhecido como depleção do Si-poli degrada a curva característica dos capacitores MOS assim como a transcondutância dos transistores. Quando a espessura do óxido de porta é reduzida este efeito torna-se mais significativo.

Este fino óxido de porta propicia também o tunelamento de portadores entre o canal e o Si-poli, gerando uma corrente de porta que dependendo de sua densidade prejudica o comportamento dos dispositivos MOS. 


\subsection{Objetivo e estrutura do trabalho}

Neste trabalho apresentamos um estudo sobre a influência do efeito de depleção no Sipoli e da corrente de tunelamento de porta nas características elétricas de um capacitor MOS. O impacto de ambos os efeitos será observado em curvas da capacitância em função da tensão de porta em baixa e alta frequiência. Um método simples para obtenção da concentração de dopantes do Si-poli e do canal é proposto também neste trabalho.

Este trabalho encontra-se dividido em 5 capítulos, os quais estão abaixo listados:

No Capítulo 2 apresentamos os fundamentos teóricos que dão sustentação ao desenvolvimento do trabalho proposto, os aspectos principais de funcionamento dos capacitores MOS quando influenciados pelo efeito de depleção do Si-poli assim com pelo efeito da corrente de tunelamento. Finalmente, mostramos alguns dos materiais de porta e de isolante que vem sendo estudados com o intuito de suprimir/minimizar a ocorrência destes efeitos.

O Capítulo 3 apresenta um estudo da influência da depleção do Si-poli e da corrente de tunelamento, na curva da capacitância em função da tensão de porta. Os resultados serão apresentados através de simulações numéricas bidimensionais.

O Capítulo 4 descreve o desenvolvimento de um novo método de extração da concentração de dopantes do Si-poli $\left(\mathrm{N}_{\text {poli }}\right)$. Serão apresentadas simulações numéricas bidimensionais e resultados experimentais, com a aplicação do método proposto. As conclusões deste trabalho são enumeradas no Capítulo 5. 


\section{CONCEITOS BÁSICOS}

Neste capítulo é apresentada uma revisão bibliográfica sobre o efeito da depleção no Silício policristalino e sobre a corrente de tunelamento pela porta, os quais sustentam o desenvolvimento do trabalho proposto. São abordadas as degradações das características dos capacitores MOS causadas por estes efeitos.

\subsection{Efeito de depleção no silício policristalino}

O silício policristalino (Si-poli) vem sendo utilizado como material de porta de uma estrutura MOS desde 1966, quando substituiu o conhecido alumínio. Dentre suas qualidades podemos citar ${ }^{6}$ :

- Redução no número de máscaras usadas no processo de fabricação;

- Pode ser levado à altas temperaturas;

- A dopagem das regiões ativas (fonte e dreno) pode ser feita simultaneamente à região de porta $^{7}$;

- Minimização dos problemas de alinhamento, onde as paredes da porta de Si-poli servem para definir as janelas para difusão de fonte e dreno;

- Junções mais rasas devido a menor quantidade de processos térmicos, o que permite uma maior velocidade de operação dos dispositivos;

- O Si-poli pode ser utilizado para interconexão dos dispositivos adjacentes.

Durante o processo de fabricação, a implantação iônica e o recozimento térmico utilizados para a formação das regiões de fonte e dreno, também fornecem uma fonte de dopagem para a porta de Si-poli. Para se evitar penetração de impurezas através do óxido de porta e ainda assim manter a profundidade da junção fonte/dreno requerida, deve-se reduzir a energia da implantação iônica. Esta dopagem insuficiente da porta gera uma região menos dopada junto ao óxido de porta. ${ }^{8}$. Esta camada dependendo da tensão aplicada à porta $\left(\mathrm{V}_{\mathrm{G}}\right)$ pode vir a depletar ${ }^{9}$, conforme mostra a Figura 2.1. Este efeito conhecido como depleção do Si-poli pode causar: distorções nas curvas de capacitância por tensão $(\mathrm{C}-\mathrm{V})$, deslocamento da tensão de faixa plana $\left(\mathrm{V}_{\mathrm{FB}}\right)$ e da tensão de limiar $\left(\mathrm{V}_{\mathrm{T}}\right)$, redução das cargas de inversão ( $\left.\mathrm{Q}_{\text {inv }}\right)$ e por conseqüência da corrente entre dreno e fonte $\left(\mathrm{I}_{\mathrm{DS}}\right)^{10}$. 

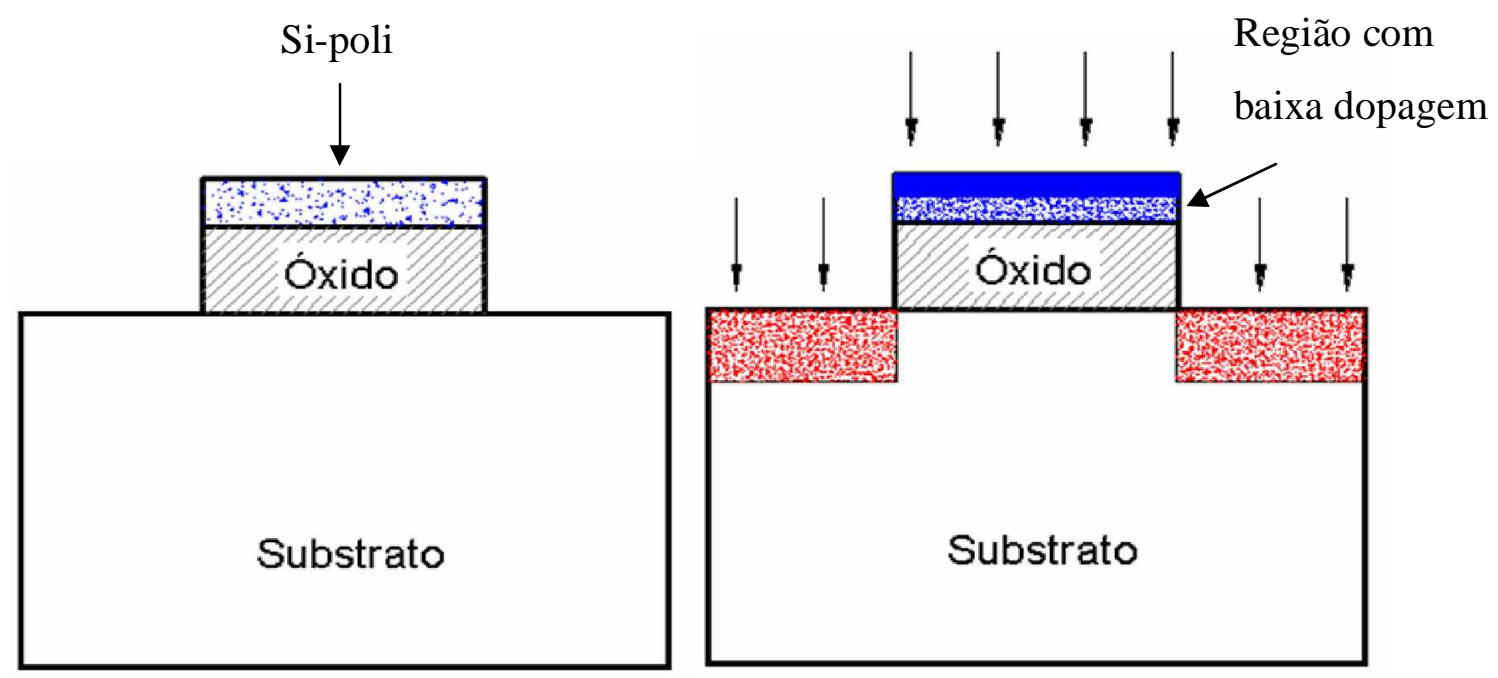

Figura 2.1 Representação esquemática do processo de fabricação de um capacitor MOS com porta de Si-poli indicando a região menos dopada junto ao óxido.

\subsubsection{Influência na Capacitância Total}

A Figura 2.2 ilustra o perfil de um capacitor MOS com eletrodo de porta de metal e o modelo equivalente de capacitâncias associadas a estrutura MOS onde $t_{\mathrm{ox}}$ é a espessura do óxido de porta, $\mathrm{V}_{\mathrm{G}}$ é a tensão aplicada na porta, $\mathrm{C}_{\mathrm{Si}}$ é a capacitância do silício e $\mathrm{C}_{\mathrm{ox}}$ é a capacitância do óxido de porta. A capacitância total $\left(\mathrm{C}_{\mathrm{T}}\right)$ pode ser encontrada pela equação (1).

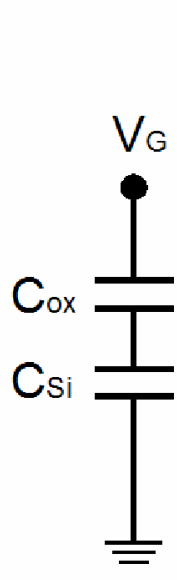

(a)

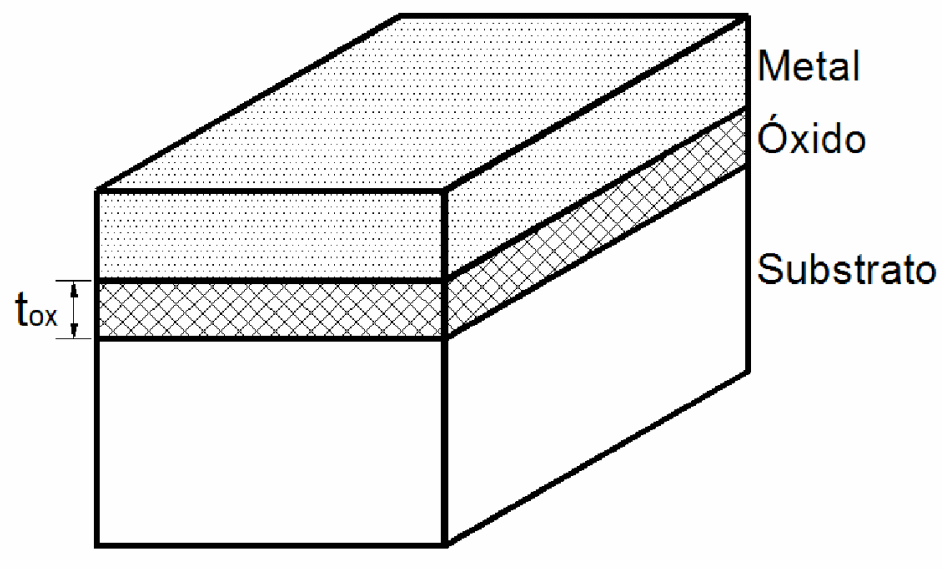

(b)

Figura 2.2 - a) Modelo equivalente de capacitâncias e o b) perfil transversal do capacitor MOS com porta de metal. 


$$
\frac{1}{C_{T}}=\frac{1}{C_{o x}}+\frac{1}{C_{S i}}
$$

onde

$$
\begin{gathered}
C_{o x}=\frac{\varepsilon_{o x}}{t_{o x}} \\
C_{S i}=\frac{\varepsilon_{S i}}{d_{S i}}
\end{gathered}
$$

sendo $\varepsilon_{\mathrm{ox}}$ a permissividade do óxido de silício, $\varepsilon_{\mathrm{Si}}$ a permissividade do silício e $\mathrm{d}_{\mathrm{Si}}$ a largura da região de depleção no silício.

Mas quando utiliza-se porta de Si-poli dopado conforme mostra a Figura 2.3b, deve-se considerar agora sua região de depleção e a capacitância do Si-poli $\left(\mathrm{C}_{\text {poli }}\right)$ deve ser acrescida a capacitância total $^{11}$ (Figura 2.3a), podendo ser calculada pela equação (4).

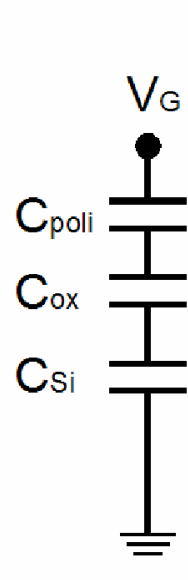

(a)

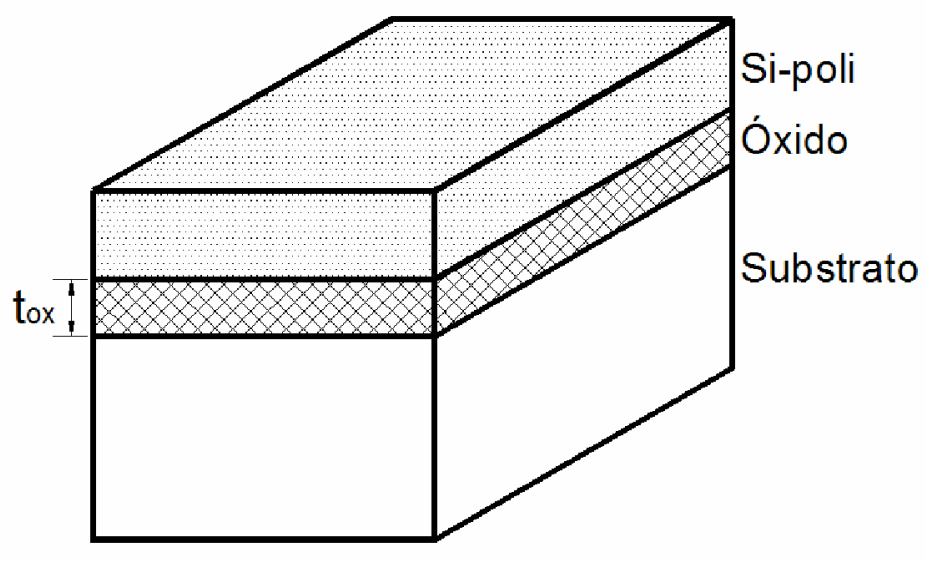

(b)

Figura 2.3 - (a) Modelo equivalente de capacitâncias e o (b) perfil transversal de um capacitor MOS com porta de Si-poli.

$$
\frac{1}{C_{T}}=\frac{1}{C_{o x}}+\frac{1}{C_{S i}}+\frac{1}{C_{p o l i}}
$$




$$
C_{p o l i}=\frac{\varepsilon_{S i}}{d_{p o l i}}
$$

sendo $d_{\text {poli }}$ a largura da região de depleção no Si-poli.

\subsubsection{Regimes de operação}

Segue os diagramas de faixas de energia de um capacitor MOS com substrato tipo P e com porta de Si-poli N+ operando nas quatro condições de funcionamento: acumulação, faixa plana, depleção e inversão.

a) Acumulação nas duas interfaces (Si-poli N+/óxido e óxido/substrato P)

Sabe-se que a tensão de faixa plana $\left(\mathrm{V}_{\mathrm{FB}}\right)$ é a tensão que anula os efeitos de nãoidealidades dos materiais de uma estrutura MOS. Quando se aplica uma tensão na porta menor que a tensão de faixa plana $\left(\mathrm{V}_{\mathrm{G}}<\mathrm{V}_{\mathrm{FB}}\right)$, as lacunas que são os portadores majoritários (substrato tipo P), são atraídas à interface óxido/substrato até formar uma região de acumulação. O diagrama de faixas de energia da Figura 2.4 apresenta está situação.

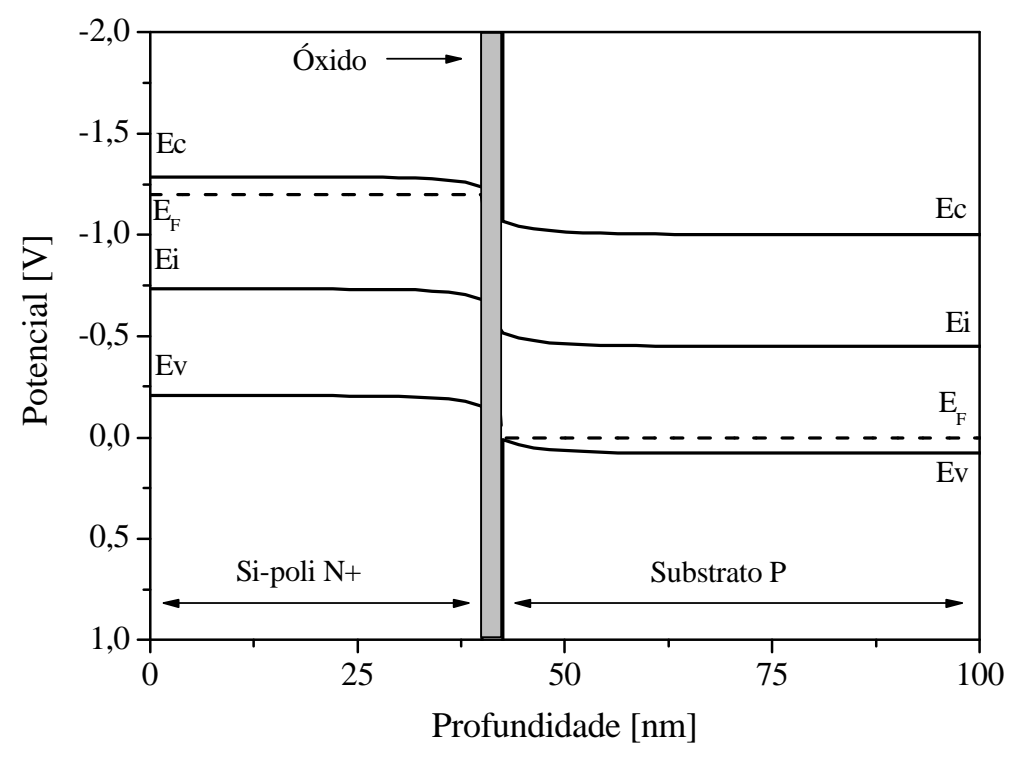

Figura 2.4 - Diagrama de faixas de energia para um capacitor MOS na condição de acumulação. 
onde:

$E_{C}$ - Energia de condução - Nível mínimo de energia para um elétron entrar na camada de condução.

$\mathrm{E}_{\mathrm{F}}$ - Nível de Fermi - Nível de energia médio dos elétrons no material

$\mathrm{E}_{\mathrm{i}}$ - Energia intrínseca - Nível médio energético dos elétrons em um semicondutor intrínseco.

$E_{v}$ - Energia de valência - Nível máximo de energia para um elétron permanecer na camada de valência.

Tem-se que o nível intrínseco $\left(\mathrm{E}_{\mathrm{i}}\right)$ se afasta do nível de Fermi $\left(\mathrm{E}_{\mathrm{F}}\right)$ gerando um encurvamento das faixas de energia para cima. Já na interface Si-poli N+/óxido os elétrons que são portadores majoritários são atraídos até formar uma região de acumulação nesta interface.

b) Faixa plana nas duas interfaces (Si-poli N+/óxido e óxido/substrato P)

Conforme a tensão aplicada na porta $\left(\mathrm{V}_{\mathrm{G}}\right)$ aumenta, tanto a camada de acumulação da interface Si-poli N+/óxido, quanto a da interface óxido/substrato são reduzidas (devido ao menor campo elétrico) chegando a serem eliminadas quando $\mathrm{V}_{\mathrm{G}}=\mathrm{V}_{\mathrm{FB}}$ (desprezando-se a carga no óxido $\mathrm{Q}_{\mathrm{SS}}$ ). Neste momento não há encurvamento das faixas de energia, como mostra a Figura 2.5 .

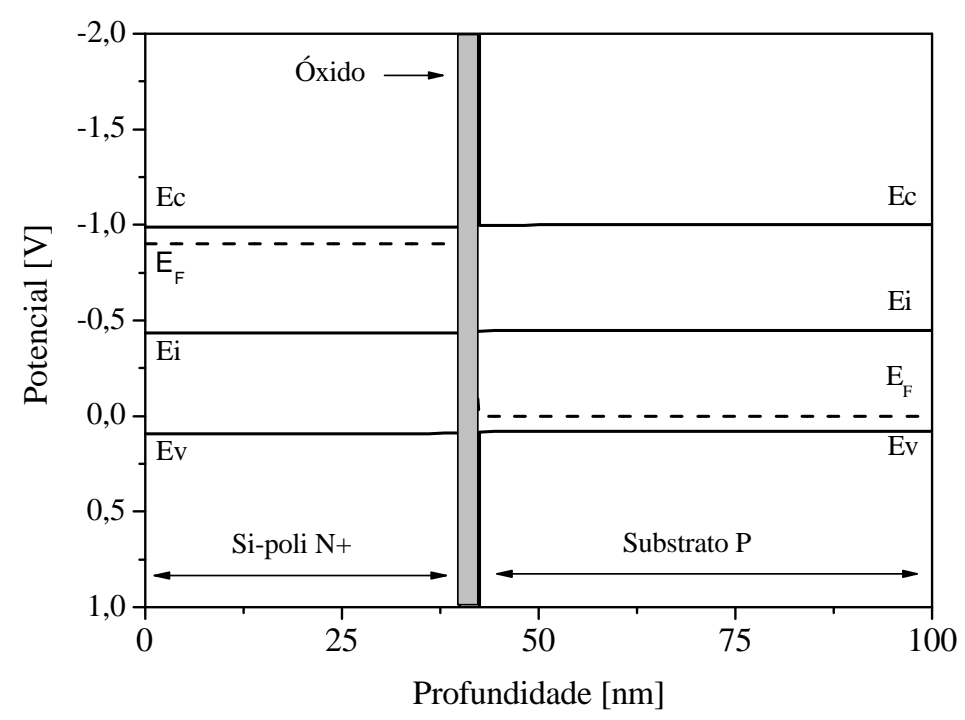

Figura 2.5 - Diagrama de faixas de energia para um capacitor MOS na condição de faixa plana. 
c) Depleção nas duas interfaces (Si-poli N+/óxido e óxido/substrato P)

Aumentando-se a tensão aplicada à porta $\mathrm{V}_{\mathrm{G}}$ acima de $\mathrm{V}_{\mathrm{FB}}$, mas abaixo da tensão de limiar $\left(\mathrm{V}_{\mathrm{T}}\right)$, tem-se, na interface óxido/substrato uma região de depleção de portadores resultando em uma região de cargas negativas (ions). Nesta condição o nível intrínseco $\left(\mathrm{E}_{\mathrm{i}}\right)$ tende a se aproximar do nível de Fermi $\left(\mathrm{E}_{\mathrm{F}}\right)$. Na interface Si-poli N+/óxido uma região de depleção também é formada. Pode-se observar na Figura 2.6 que as duas interfaces (Si-poli N+/óxido e óxido/substrato) estão em depleção.

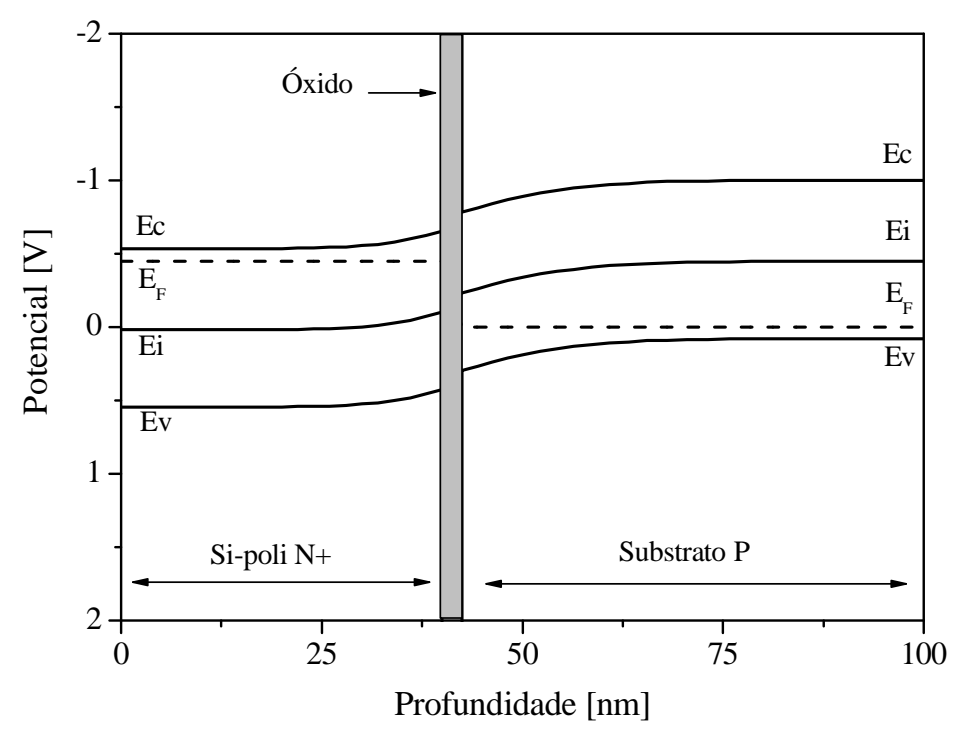

Figura 2.6 - Diagrama de faixas de energia para um capacitor MOS na condição de depleção.

d) Inversão nas duas interfaces (Si-poli N+/óxido e óxido/substrato P)

Para uma tensão de porta $\left(\mathrm{V}_{\mathrm{G}}\right)$ superior a $\mathrm{V}_{\mathrm{T}}$, pode-se observar uma atração de portadores minoritários (elétrons), formando uma região de inversão na interface óxido/substrato. Na interface Si-poli $\mathrm{N}+/$ óxido as lacunas (portadores minoritários) são atraídos formando também uma região de inversão. Conforme a tensão aumenta, diz-se que o capacitor está em inversão forte onde o potencial de superfície no silício e no Si-poli e a largura da região de depleção tanto do $\mathrm{Si}$-poli $\mathrm{N}+\left(\mathrm{d}_{\text {poli }}\right)$ quanto do silício $\left(\mathrm{d}_{\mathrm{Si}}\right)$ alcançam seu valor máximo. No diagrama de faixas de energia o nível intrínseco $\left(\mathrm{E}_{\mathrm{i}}\right)$ ultrapassa o nível de Fermi $\left(\mathrm{E}_{\mathrm{F}}\right)$, como mostra a Figura 2.7. 


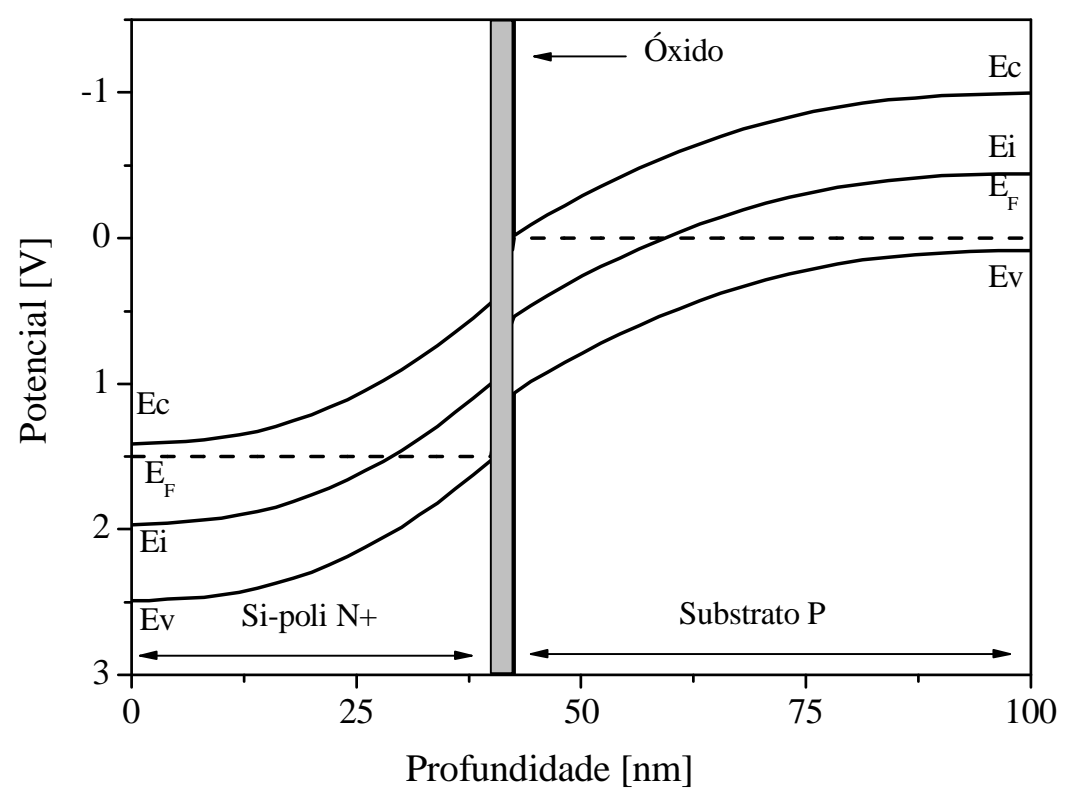

Figura 2.7 - Diagramas de faixas de energia para uma capacitor MOS na condição de inversão forte.

\subsubsection{Degradação da Tensão de Limiar}

Se a porta de Si-poli apresenta uma concentração de dopantes $N_{\text {poli }}<5 \times 10^{19} \mathrm{~cm}^{-3}$, ela não pode mais ser tratada como uma superfície equipotencial e a tensão aplicada na porta $\mathrm{V}_{\mathrm{G}}$ será reduzida também pelo potencial de superfície no Si-poli $\left(\phi_{\mathrm{Sp}}\right)^{12,13}$, como mostra a Figura 2.8 .

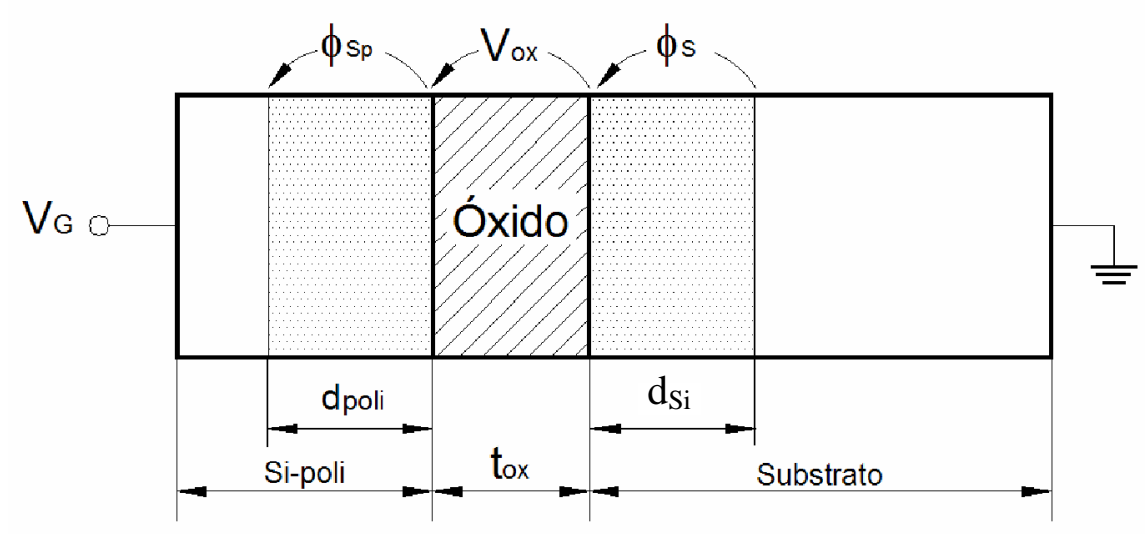

Figura 2.8 - Estrutura Si-poli / óxido / substrato com a representação das quedas de potenciais. 
Este fenômeno pode ser facilmente explicado como um divisor de tensão em série através do diagrama de faixas de energia conforme mostra a Figura 2.9. Pode-se observar que a interface Si-poli N+/óxido está depletada, enquanto a interface do canal (óxido/substrato P) já está invertida. Como resultado a tensão aplicada à porta $\left(\mathrm{V}_{\mathrm{G}}\right)$ será expressa pela equação (6).

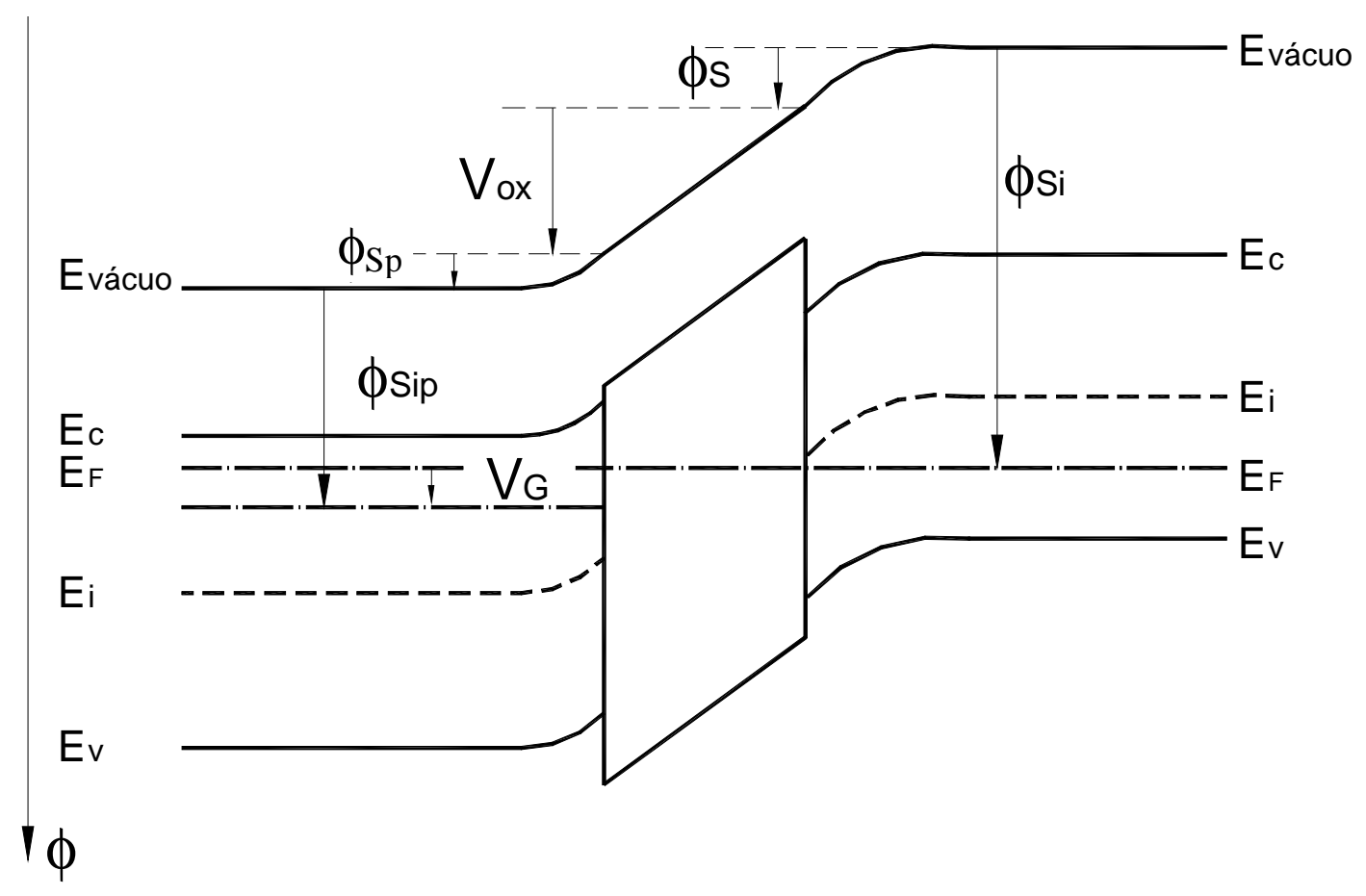

Figura 2.9 - Diagrama de faixas de energia de uma estrutura Si-poli N+/ óxido / substrato P.

$$
V_{G}=\phi_{S p}+V_{o x}+\phi_{S}+\left(\phi_{S i p}-\phi_{S i}\right)
$$

onde

$$
V_{o x}=-\frac{Q_{S i}}{C_{o x}}-\frac{Q_{S S}}{C_{o x}}
$$

sendo $\mathrm{Q}_{\mathrm{Si}}$ a densidade de cargas no silício e $\mathrm{Q}_{\mathrm{Ss}}$ a densidade efetiva de cargas no óxido de porta.

O potencial de superfície no Si-poli $\left(\phi_{\mathrm{Sp}}\right)$ pode ser encontrado resolvendo-se a equação de Poisson na região do Si-poli, acoplada com a equação de Laplace na região do óxido de porta. As leis de Gauss na interface Si-poli/óxido providenciam as condições de acoplamento $^{12}$, resultando na equação (8). 


$$
\phi_{S p}=V_{G}-V_{F B}-\phi_{S}-a_{v}\left[\sqrt{1+\frac{2}{a_{v}}\left(V_{G}-V_{F B}-\phi_{S}-1\right)}\right]
$$

onde:

$$
a_{v}=\frac{q \varepsilon_{S i} N_{p o l i}}{C_{o x}{ }^{2}}
$$

sendo

q a carga elementar do elétron

Resolvendo as equações (6) e (8) tem-se a tensão de limiar que considera o efeito de depleção do Si-poli $\left(\mathrm{V}_{\mathrm{Tp}}\right)$, podendo ser calculada através da equação (10). Para uma concentração de dopantes no Si-poli alta $\left(\mathrm{N}_{\text {poli }}>5 \times 10^{19} \mathrm{~cm}^{-3}\right)$, este termo $\mathrm{a}_{\mathrm{v}}$ se torna muito grande (>50), e passa a ser desprezado na equação (10), fazendo com que a tensão de limiar desconsidere o efeito de depleção do $\operatorname{Si-poli~}\left(\mathrm{V}_{\mathrm{T}}\right)^{14}$.

$$
V_{T p}=\underbrace{V_{F B}+2 \phi_{F}-\frac{Q_{S i}}{C_{o x}}}_{\mathrm{V}_{\mathrm{T}}}+\frac{1}{2 a_{v}}\left(\frac{Q_{S i}}{C_{o x}}\right)^{2}
$$

sendo

$\phi_{\mathrm{F}} \mathrm{O}$ potencial de Fermi da camada de silício.

Como este termo $\mathrm{a}_{\mathrm{v}}$ é proporcional a concentração de dopantes do Si-poli, quanto menor esta concentração, maior será a tensão de limiar $\left(\mathrm{V}_{\mathrm{Tp}}\right)$, conforme mostra a Figura 2.10. 


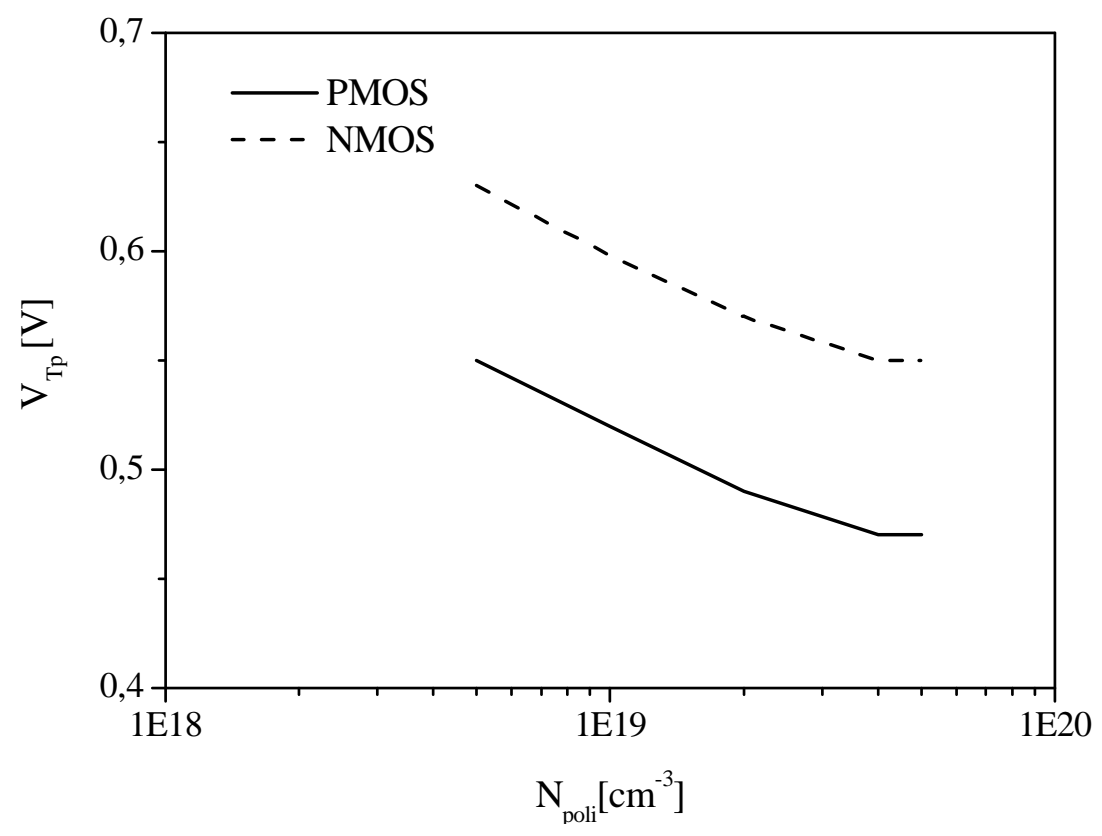

Figura 2.10 - Curvas $\mathrm{V}_{\mathrm{Tp}}$ em função de $\mathrm{N}_{\text {poli }}$, indicando o aumento da tensão de limiar com a redução de $\mathrm{N}_{\text {poli }}{ }^{12}$.

\subsubsection{Degradação da curva $\mathrm{C}-\mathrm{V}$}

A curva da capacitância em função da tensão $(\mathrm{C}-\mathrm{V})$ é um dos métodos mais conhecidos para caracterização de estruturas MOS, pois possibilita a extração de alguns parâmetros como a tensão de faixa plana $\left(\mathrm{V}_{\mathrm{FB}}\right)$, a tensão de limiar $\left(\mathrm{V}_{\mathrm{T}}\right)$, a concentração de dopantes no silício $\left(\mathrm{N}_{\mathrm{a}}\right)$, espessura do óxido de porta $\left(\mathrm{t}_{\mathrm{ox}}\right)$, densidade de cargas no óxido $\left(\mathrm{Q}_{\mathrm{ss}}\right)$, entre outros. Mas para uma estrutura que sofre do efeito de depleção no Si-poli, a curva C-V apresenta algumas anomalias que impedem sua utilização ${ }^{15}$.

A Figura 2.11 mostra curvas $\mathrm{C}-\mathrm{V}$ em alta freqüência (AF) de um capacitor MOS com substrato P e porta de Si-poli N+ com alta e baixa dopagem. Sabe-se que sem o efeito de depleção do Si-poli a capacitância mínima $\left(\mathrm{C}_{\mathrm{min}}\right)$ na região de inversão $\left(\mathrm{V}_{\mathrm{G}}>\mathrm{V}_{\mathrm{T}}\right)$ é dada pela associação série de $\mathrm{C}_{\mathrm{ox}}$ e $\mathrm{C}_{\text {Simin }}$, mas quando há depleção na região da porta, $\mathrm{C}_{\text {poli }}$ deve ser acrescida e uma diminuição no valor da capacitância mínima $\left(C_{\min }\right)$ é observada ${ }^{16,17}$. 


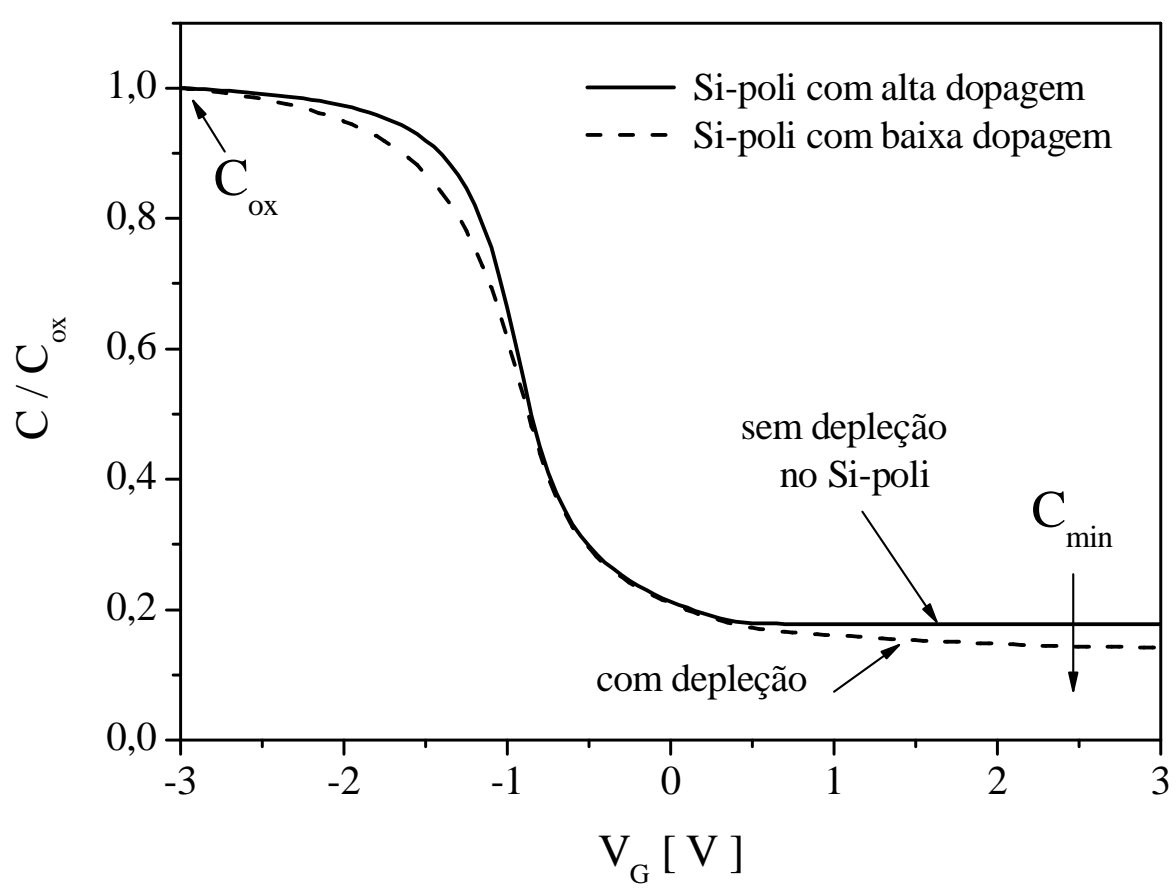

Figura 2.11 - Curva $\mathrm{C} x \mathrm{~V}_{\mathrm{G}}$ normalizada em função de $\mathrm{C}_{\mathrm{ox}}$ operando em alta freqüência para um capacitor MOS, indicando a influência do efeito de depleção no Si-poli.

Na condição de baixa freqüência (BF), um capacitor MOS com porta de Si-poli N+ com alta dopagem quando operado na região de inversão $\left(\mathrm{V}_{\mathrm{G}}>\mathrm{V}_{\mathrm{T}}\right)$ permite aos portadores responder a variação de $\mathrm{V}_{\mathrm{G}}$ e o resultado é a formação de uma camada de inversão forte na interface óxido/substrato. Por sua espessura pequena, a capacitância do silício $\left(\mathrm{C}_{\mathrm{Si}}=\mathrm{C}_{\mathrm{d}}+\mathrm{C}_{\mathrm{inv}}\right)$ que é expressa pela associação paralela da capacitância de depleção no silício $\left(\mathrm{C}_{\mathrm{d}}\right)$ com a capacitância de inversão $\left(\mathrm{C}_{\mathrm{inv}}\right)$, se torna muito alta tendendo ao infinito. Como resultado a associação série de capacitâncias $\left(1 / \mathrm{C}_{\mathrm{T}}=1 / \mathrm{C}_{\mathrm{ox}}+1 / \mathrm{C}_{\mathrm{Si}}\right)$ na região de inversão, é expressa apenas por $\mathrm{C}_{\mathrm{ox}}$, como pode ser visto no ponto A da Figura 2.12. Quando utilizada porta de Si-poli com baixa dopagem (que sofre do efeito de depleção do Si-poli), deve-se levar em consideração a capacitância do Si-poli $\left(\mathrm{C}_{\text {poli }}\right)$, que deve ser acrescida a associação série da capacitância $\left(1 / \mathrm{C}_{\mathrm{T}}=1 / \mathrm{C}_{\text {poli }}+1 / \mathrm{C}_{\mathrm{ox}}\right.$ desprezando-se $\left.\mathrm{C}_{\mathrm{Si}}\right)$. O resultado é uma diminuição na capacitância total, como mostra o ponto B na Figura 2.12. A capacitância total continua diminuindo até o ponto $\mathrm{C}$ enquanto o Si-poli estiver depletando. Conforme $\mathrm{V}_{\mathrm{G}}$ aumenta a região do Si-poli começa a inverter na interface com o óxido de porta. Neste caso a capacitância de inversão do Si-poli $\left(\mathrm{C}_{\text {invpoli }}\right)$ tende a infinito e a capacitância do Si-poli $\mathrm{C}_{\text {poli }}=\mathrm{C}_{\mathrm{dpoli}}+\mathrm{C}_{\text {invpoli }}$ passa a ser desprezada. Como resultado a capacitância total retorna para a condição ideal que é $\mathrm{C}_{\mathrm{ox}}$ (ponto $\left.\mathrm{D}\right)^{18,19}$. 


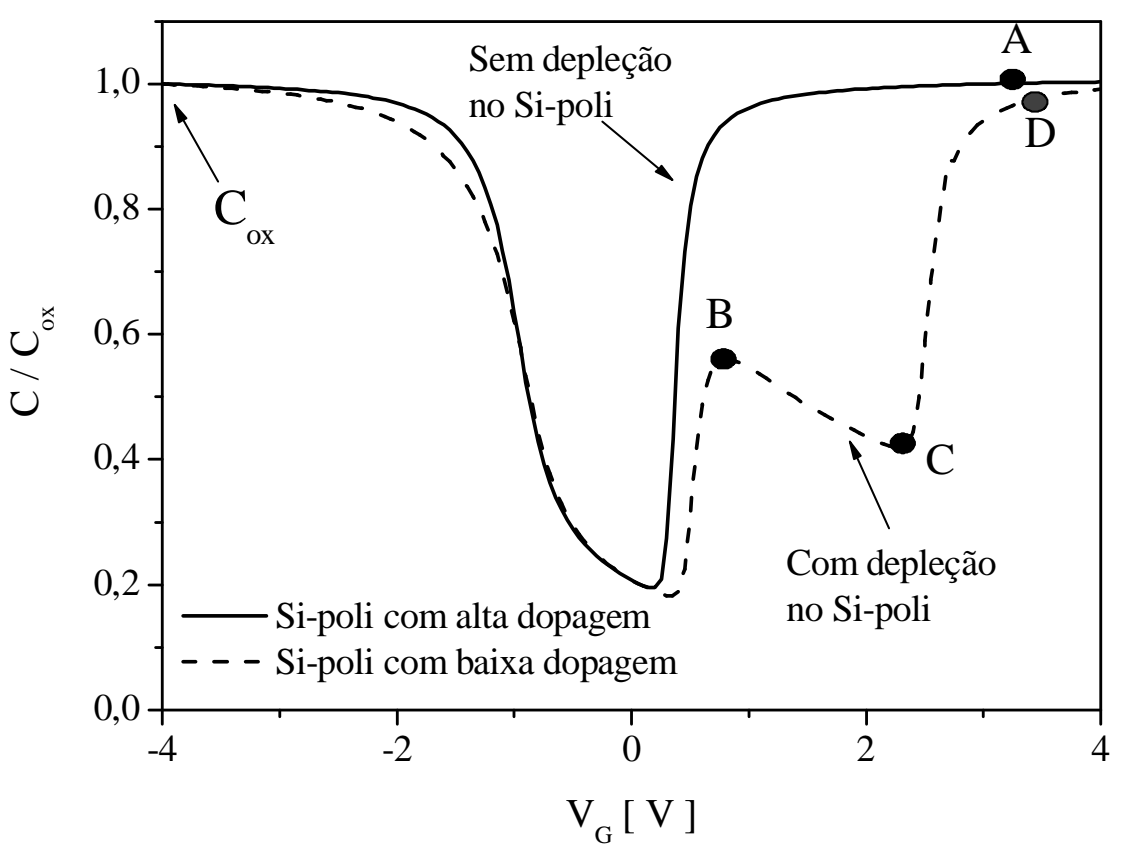

Figura 2.12 - Curva $C x V_{G}$ normalizada em função de $C_{o x}$ em baixa frequiência de um capacitor MOS, indicando a influência do efeito de depleção do Si-poli.

\subsubsection{Influência da depleção no Si-poli nas características de um transistor}

Essa região de depleção que se forma na interface Si-poli/óxido sendo altamente resistiva pode ser considerada como uma extensão do óxido de porta, onde seu aumento $\left(t_{\mathrm{ox}}\right.$ efetivo) causa uma diminuição na geração de cargas de inversão no substrato $\left(Q_{\text {inv }}\right)$ e, por conseqüência, uma diminuição na capacitância de inversão no silício $\left(C_{\text {inv }}\right)$, sendo $C=d Q / d V_{G}$. Logo, quanto menor a concentração de dopantes do Si-poli na interface com o óxido, maior será sua região de depleção, maior será a espessura do óxido de porta efetivo e menor será a carga de inversão no silício $\mathrm{Q}_{\text {inv }}{ }^{9}$.

Sabe-se que a transcondutância $\left(\mathrm{g}_{\mathrm{m}}\right)$ de um transistor MOS é a medida de eficácia do controle da corrente de dreno $\left(\mathrm{I}_{\mathrm{D}}\right)$ pela tensão de porta $\left(\mathrm{V}_{\mathrm{G}}\right)$, mas esta redução na capacitância de inversão $\left(\mathrm{C}_{\text {inv }}\right)$, gerada pela região de depleção no Si-poli, pode degradar a transcondutância causando um redução que impede sua utilização, conforme Figura $2.13^{9}$. 


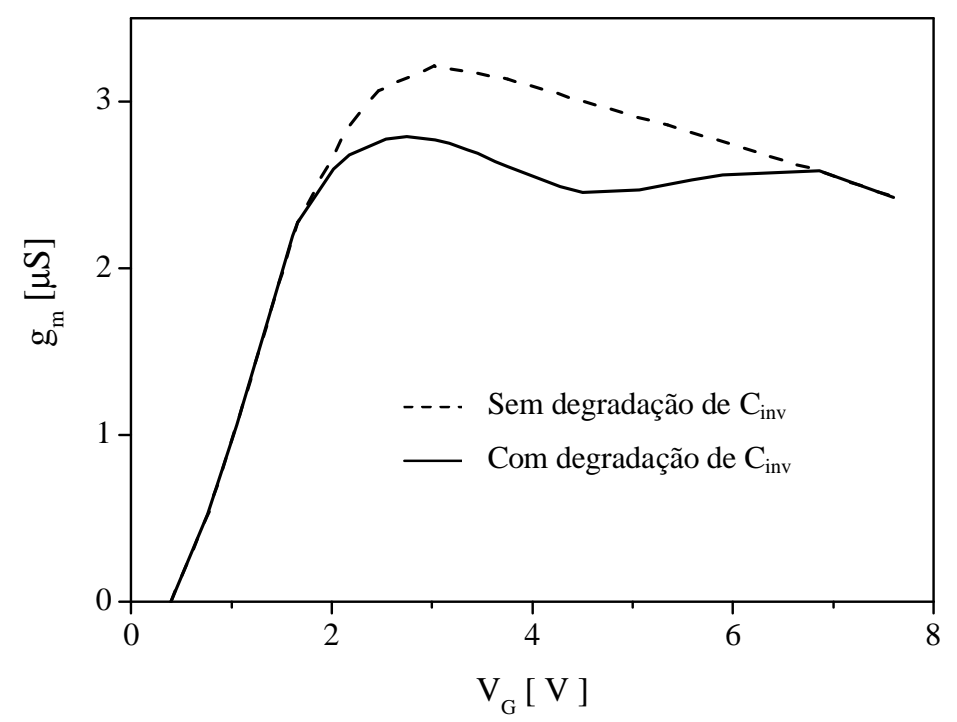

Figura 2.13 - Curvas da transcondutância $\left(g_{m}\right)$ em função de $V_{G}{ }^{9}$.

Um dos principais parâmetros que influencia as características da curva de corrente pela tensão (I-V) de um transistor é a tensão de limiar $\mathrm{V}_{\mathrm{T}}$, sendo esta dependente da espessura do óxido de porta $\left(\mathrm{t}_{\mathrm{ox}}\right)$, da concentração de dopantes no substrato $\left(\mathrm{N}_{\mathrm{a}}\right)$, da concentração de dopantes no Si-poli $\left(\mathrm{N}_{\text {poli }}\right)$ e das cargas presentes no óxido $\left(\mathrm{Q}_{\mathrm{ss}}\right)$. Conforme já visto, a redução de $\mathrm{N}_{\text {poli }}$ faz com que a tensão de limiar $\left(\mathrm{V}_{\mathrm{T}}\right)$ aumente gerando uma redução na corrente de dreno $\left(I_{D}\right)$, degradando seu valor como pode ser visto na Figura $2.14^{20}$. Esta degradação em $I_{D}$ é tanto pior quanto menor for $\mathrm{t}_{\mathrm{ox}}$.

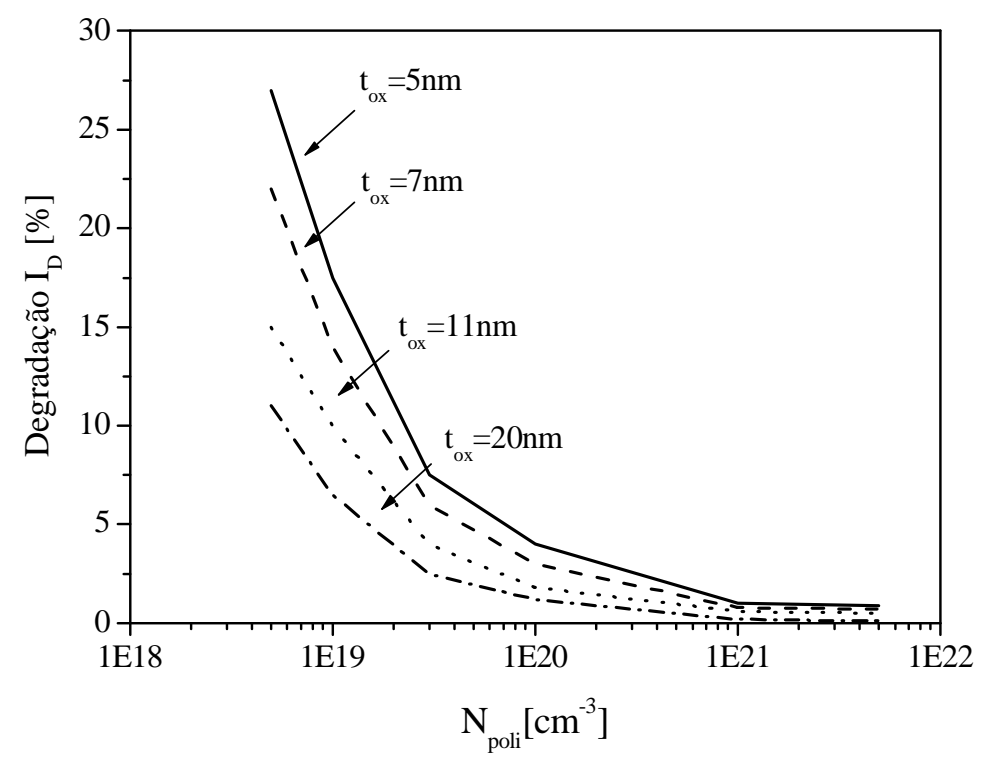

Figura 2.14 - Curva da degradação da corrente de dreno $\left(I_{D}\right)$ em função de $\mathrm{N}_{\text {poli }}{ }^{20}$. 


\subsubsection{Novos materiais de porta}

Conforme as dimensões dos dispositivo são escaladas, o efeito de depleção no Si-poli torna-se mais importante. Para se evitar a depleção do Si-poli, alguns novos materiais de porta de metal vem sendo estudados como por exemplo:

- Siliceto de níquel (NiSi) e siliceto de titânio $\left(\mathrm{TiSi}_{2}\right)$ - Possuem as mesmas características de um metal puro e uma alta condutividade ${ }^{21}$.

- Tântalo (Ta) - Seu processo de fabricação exige baixa temperatura afim de se evitar uma reação do mesmo com o isolante ${ }^{22}$.

- Molibdênio (Mo) - Sua diferença de função trabalho depende das condições de deposição, recozimento e do dielétrico de porta ${ }^{23}$.

- Nitreto de Titânio (TiN)

Em qualquer dos casos citados, a depleção do material de porta não existe mais.

\subsection{Corrente de tunelamento pelo óxido de porta}

Esta corrente de tunelamento que atravessa óxidos de porta finos, foi inicialmente abordada por Lothar Wolfgang Nordeheim (1926), que considerava que alguns elétrons no metal poderiam atravessar a barreira de potencial, representada pela superfície do metal, mesmo se tivesse energia menor que a altura da barreira ${ }^{24}$. Com esta hipótese e juntamente com Ralph Howard Fowler criaram um modelo que diz que a emissão de portadores se dá por dois efeitos: efeito térmico (devido ao aumento da temperatura) e efeito de campo (devido a ação do campo elétrico na superfície do metal, onde este campo diminui a barreira de potencial e o potencial de superfície). Posteriormente estes efeitos ficaram conhecidos como “efeito túnel” e foram melhores estudados por Leo Esaki $(1949)^{25}$.

De maneira geral, pode-se dizer que o tunelamento, através de uma barreira de potencial, pode ser caracterizado pelo coeficiente de transmissão que representa a probabilidade de um elétron atravessar a barreira. O valor deste coeficiente de transmissão depende do formato da barreira (triangular, retangular, etc), da altura e da largura. Quanto mais fino o óxido de porta, mais alto será o coeficiente de transmissão.

Analisando-se o formato da barreira em que o portador precisa atravessar, a corrente de tunelamento pela porta pode ser estudada em três regimes de operação, conforme mostra a Figura 2.15. 


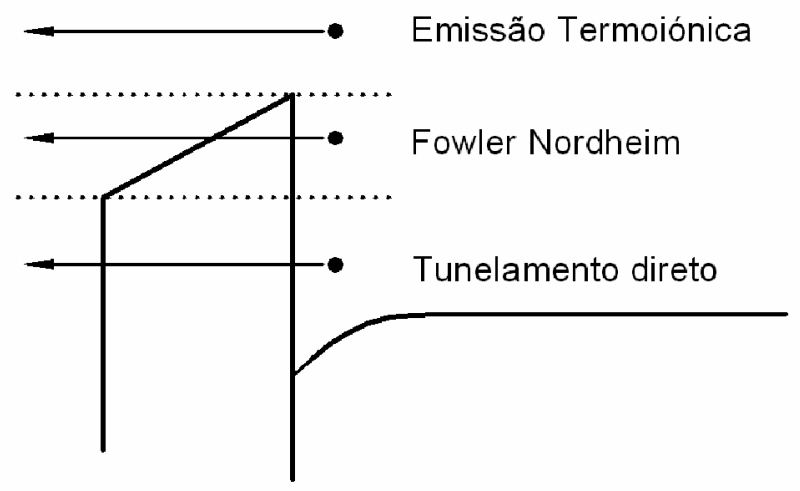

Figura 2.15 - Diagrama de faixas exemplificando os três principais tipos de injeção de portadores através do isolante.

A teoria da emissão termoiónica assume que os elétrons que tem energia maior do que a barreira, irão atravessá-la independente de seu formato. Os elétrons ganham energia através da temperatura ou agitação.

Para óxidos com espessuras de até $\mathrm{t}_{\mathrm{ox}}>6 \mathrm{~nm}$, a corrente de fuga é explicada pelo tunelamento de elétrons por Fowler Nordheim, onde sua barreira é dita como triangular. Óxidos menores sofrem tunelamento direto de corrente, pois possuem energia suficiente para atravessar a fina barreira trapezoidal, passando direto pela banda proibida do óxido ${ }^{26}$.

A Figura 2.16 (a) mostra que para uma densidade de corrente de tunelamento por Fowler Nordheim $\left(\mathrm{J}_{\mathrm{FN}}\right)$, o formato da barreira é triangular e a diferença de potencial sobre o óxido $\left(\mathrm{qV}_{\mathrm{ox}}\right)$ é maior do que a altura da barreira de tunelamento $\left(\phi_{\mathrm{T}}\right)$. Já na Figura 2.16 (b), onde tem-se uma densidade de corrente de tunelamento direto $\left(\mathrm{J}_{\mathrm{D}}\right)$, pode-se observar que o formato da barreira é trapezoidal onde $\mathrm{qV}_{\mathrm{ox}}$ é menor que $\phi_{\mathrm{T}}{ }^{27}$.

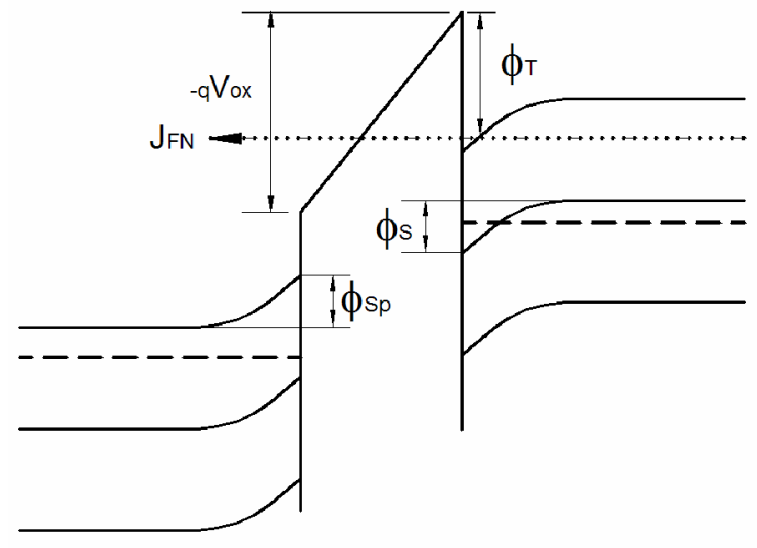

(a)

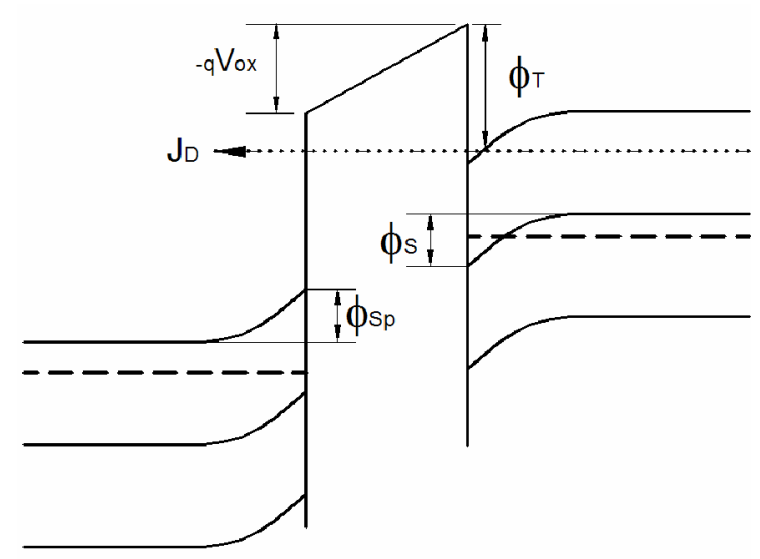

(b)

Figura 2.16 - Diagramas de faixas de energia de uma estrutura Si-poli N+ / óxido / substrato P no caso da corrente de (a) tunelamento por Fowler-Nordheim e de (b) tunelamento direto. 
A Figura 2.17 mostra a curva da densidade da corrente de tunelamento $\left(\mathrm{J}_{\mathrm{G}}\right)$ em função da tensão aplicada à porta $\left(\mathrm{V}_{\mathrm{G}}\right)$, para uma estrutura Si-poli $\mathrm{N}+/ \mathrm{SiO}_{2} /$ Substrato N. Pode-se observar que a tensão aplicada na porta $\left(\mathrm{V}_{\mathrm{G}}\right)$ também influência na escolha do modelo de tunelamento, pois quanto menor a espessura do óxido $\left(\mathrm{t}_{\mathrm{ox}}\right)$ e $\mathrm{V}_{\mathrm{G}}$, mais a curva experimental deixa de ser comparada com as curvas simuladas com o modelo de corrente de tunelamento por Fowler Nordheim, e tente a se igualar as curvas com o modelo da corrente de tunelamento direto. Neste ponto há uma transição do formato da barreira de triangular para trapezoidal ${ }^{5,27}$.

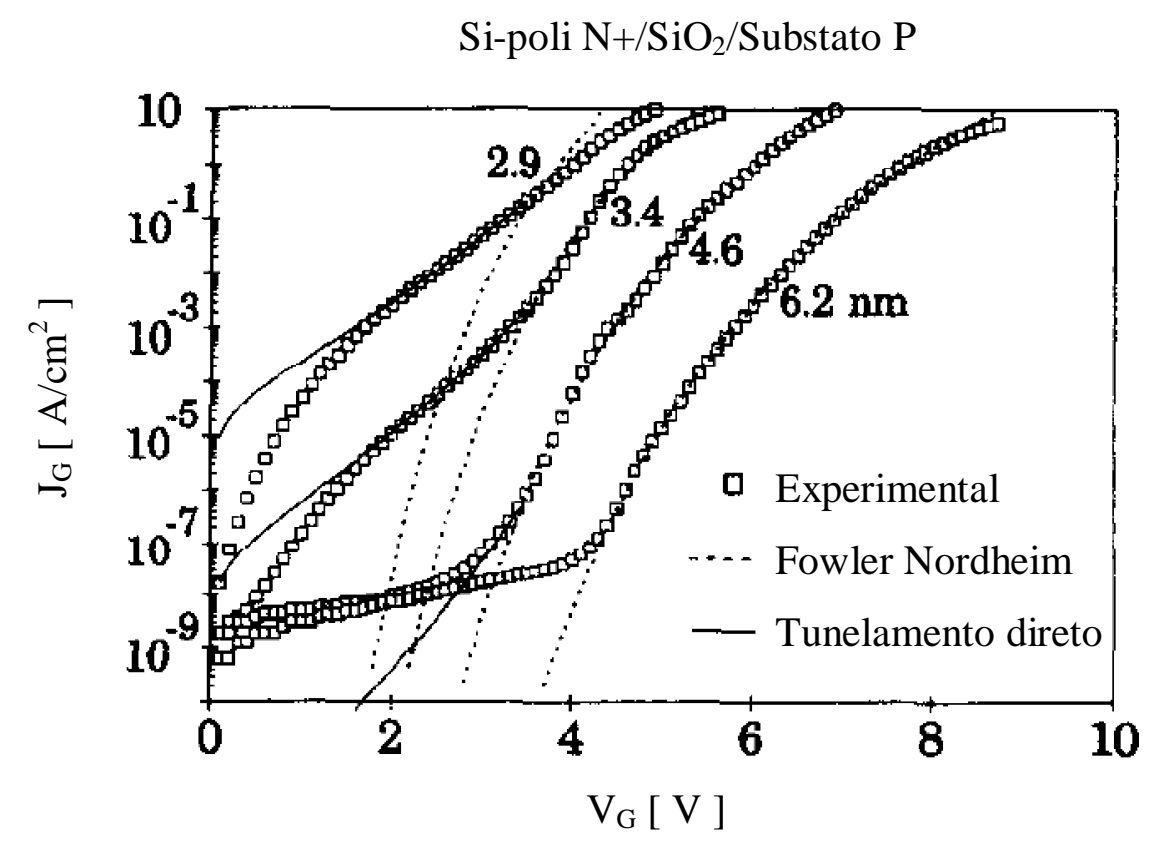

Figura 2.17 - Curvas da densidade da corrente de tunelamento $\left(\mathrm{J}_{\mathrm{G}}\right)$ em função da tensão aplicada à porta $\left(\mathrm{V}_{\mathrm{G}}\right)$ para $\mathrm{t}_{\mathrm{ox}}$ variando de 2,9 a $6,2 \mathrm{~nm}^{27}$.

\subsubsection{Corrente de tunelamento direto}

A Figura 2.18 mostra as componentes da corrente de tunelamento direto (TD), para um transistor nMOSFET com porta de Si-poli N+, operando com uma polarização positiva na porta. Onde:

(a) CBET - são os elétrons que estão na banda de condução do substrato $\mathrm{P}$, e que podem tunelar na direção do Si-poli N+.

(b) VBET - são os elétrons que estão na banda de valência do substrato $\mathrm{P}$, e que podem tunelar na direção do Si-poli N+. 
(c) VBHT - são as lacunas que estão na banda de valência do Si-poli N+, e que podem tunelar na direção do substrato P.

Para uma porta de Si-poli $\mathrm{N}+$ e um substrato $\mathrm{P}$, as alturas das barreiras são: CBET $(3,1 \mathrm{eV})$; VBET $(4,2 \mathrm{eV})$ e VBHT $(4,5 \mathrm{eV})$. Como CBET é a menor barreira, o tunelamento de elétrons da banda de condução é o mecanismo predominante ${ }^{28}$.

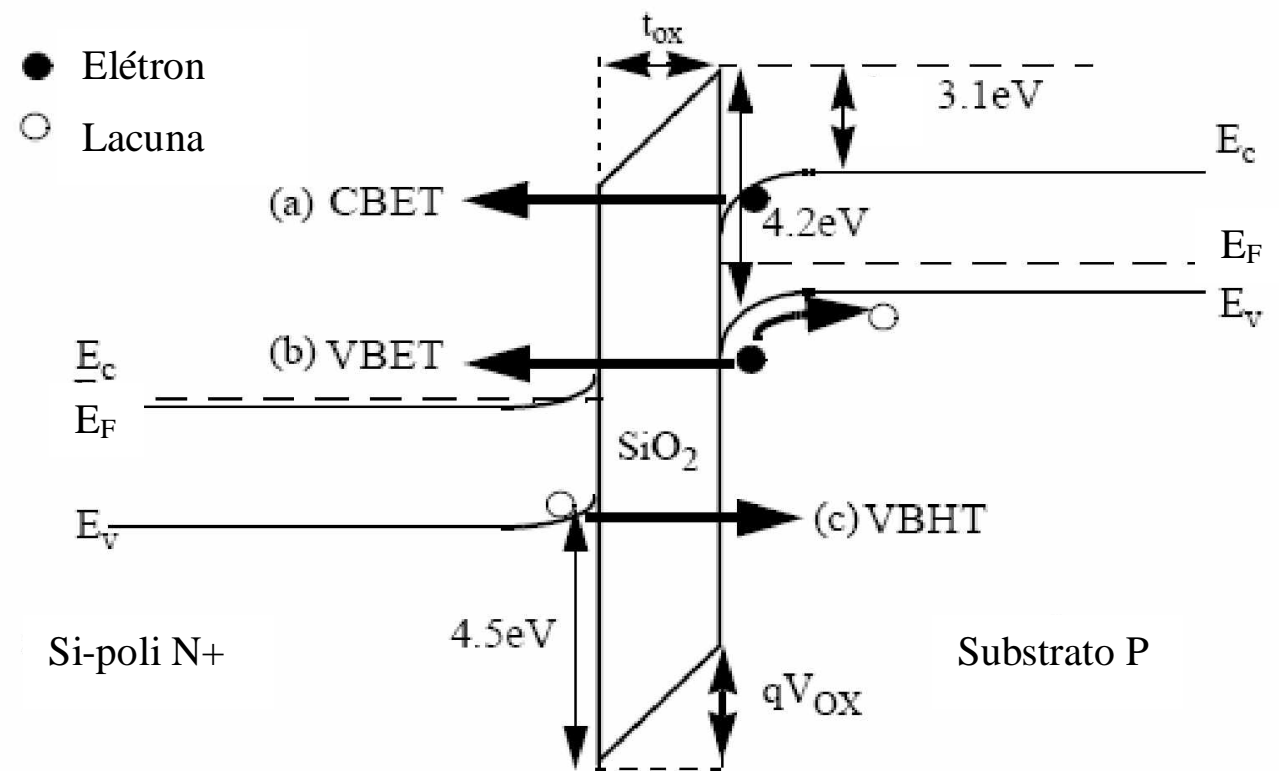

Figura 2.18 - Diagrama de faixas de energia de uma estrutura nMOSFET com substrato P e porta de Si-poli $\mathrm{N}+$, e os mecanismos da corrente de tunelamento direto ${ }^{28}$

\subsubsection{Degradação do Nível de Fermi}

Sabe-se que o Nível de Fermi $\left(\mathrm{E}_{\mathrm{F}}\right)$ é o nível de energia médio dos elétrons no material. Uma estrutura que sofre o efeito da corrente de tunelamento direto (TD) pela porta, tem seu Nível de Fermi alterado, pois os elétrons que tunelam do substrato para porta, fazem esse valor aumentar, devido ao excesso de portadores que se acumulam na porta. Este aumento no posicionamento do Nível de Fermi $\left(\mathrm{E}_{\mathrm{F}}\right)$, a uma mesma tensão de porta, gera um aumento no potencial, pois para se assegurar que a região de depleção continue invertida, o potencial deve ultrapassar o Nível de Fermi, que por sua vez foi deslocado devido ao tunelamento de portadores. 
Sabe-se que a largura da região de depleção no silício $\left(\mathrm{d}_{\mathrm{Si}}\right)$ é proporcional ao potencial de superfície $\left(\phi_{S}\right)$, conforme mostra a equação (11). Logo este aumento em $\phi_{S}$ gerado pelo tunelamento, faz com que a largura da região de depleção aumente.

$$
d_{S i}=\sqrt{\frac{2 \varepsilon_{S i} \phi_{S}}{q N_{a}}}
$$

\subsubsection{Degradação da curva $C-V$}

Como mostra a equação (12), este aumento na largura da região de depleção $\left(\mathrm{d}_{\mathrm{Si}}\right)$ causado pela corrente de tunelamento faz com que a capacitância do silício $\left(\mathrm{C}_{\mathrm{Si}}\right)$ diminua. A Figura 2.19 mostra uma curva $\mathrm{C}-\mathrm{V}$ normalizada em $\mathrm{C}_{\mathrm{ox}}$ de alta freqüência, para uma estrutura alumínio / $\mathrm{SiO}_{2}$ / Substrato $\mathrm{P}$, onde pode-se observar que a curva com tunelamento (sólida) apresenta uma redução em $\mathrm{C}_{\min }$ na região de inversão, resultado da diminuição de $\mathrm{C}_{\mathrm{Si}}$.

$$
C_{S i}=\frac{\varepsilon_{S i}}{d_{S i}}
$$

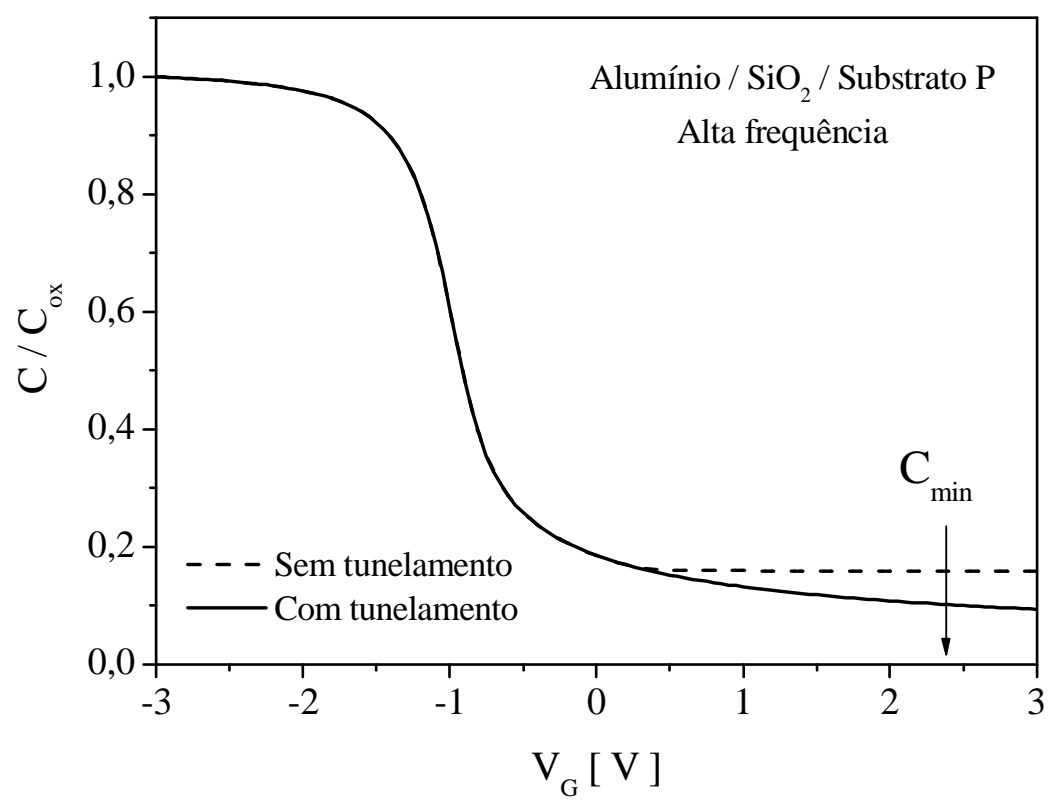

Figura 2.19 - Curva $\mathrm{C}$ x $\mathrm{V}_{\mathrm{G}}$ normalizada em função de $\mathrm{C}_{\mathrm{ox}}$ de alta frequiência, demonstrando a influência da corrente de tunelamento. 
Na Figura 2.20 está apresentada uma curva $\mathrm{C}-\mathrm{V}$ de baixa freqüência para uma estrutura Alumínio / $\mathrm{SiO}_{2}$ / Substrato $\mathrm{P}$, onde neste caso os causadores da redução na capacitância total $\left(\mathrm{C}_{\mathrm{T}}\right)$, que deveria tender a $\mathrm{C}_{\mathrm{ox}}$ na região de inversão, são as cargas de inversão na interface óxido/silício. A corrente de tunelamento gera uma condição de não equilíbrio de portadores, fazendo a densidade de cargas de inversão diminuir. Por consequiência a capacitância de inversão $\left(\mathrm{C}_{\text {inv }}\right)$ também reduz, deixando de ser desprezada na associação série de capacitâncias na região de inversão ${ }^{29,30,31}$.

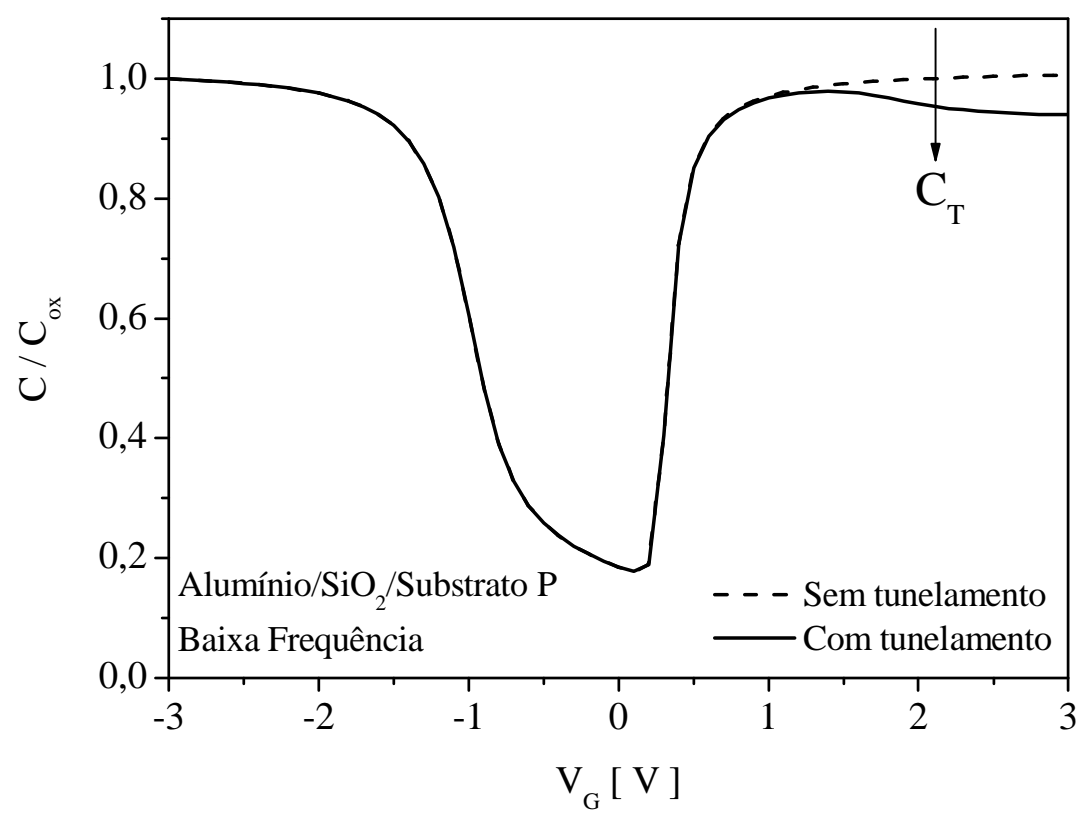

Figura 2.20 - Curva $\mathrm{C}$ x V $\mathrm{V}_{\mathrm{G}}$ normalizada em função de $\mathrm{C}_{\mathrm{ox}}$ de baixa freqüência, demonstrando a influência da corrente de tunelamento.

\subsubsection{Efeito de depleção no Si-poli e da corrente de tunelamento}

Sabe-se que a densidade da corrente de tunelamento $\left(\mathrm{J}_{\mathrm{G}}\right)$, é função da queda de potencial no óxido $\left(\mathrm{V}_{\mathrm{ox}}\right)$. Para uma estrutura com alta dopagem no Si-poli $\mathrm{V}_{\text {ox }}$ aumenta pois como a região de depleção no Si-poli é muito pequena, a tensão aplicada na porta $\left(\mathrm{V}_{\mathrm{G}}\right)$ cai quase que inteiramente no óxido ${ }^{32}$. A Figura 2.21 mostra este aumento em $\mathrm{V}_{\text {ox }}$ para altas dopagens no Si-poli ( $\left.\mathrm{N}_{\text {poli }}\right)$ em função de $\mathrm{V}_{\mathrm{G}}$. 


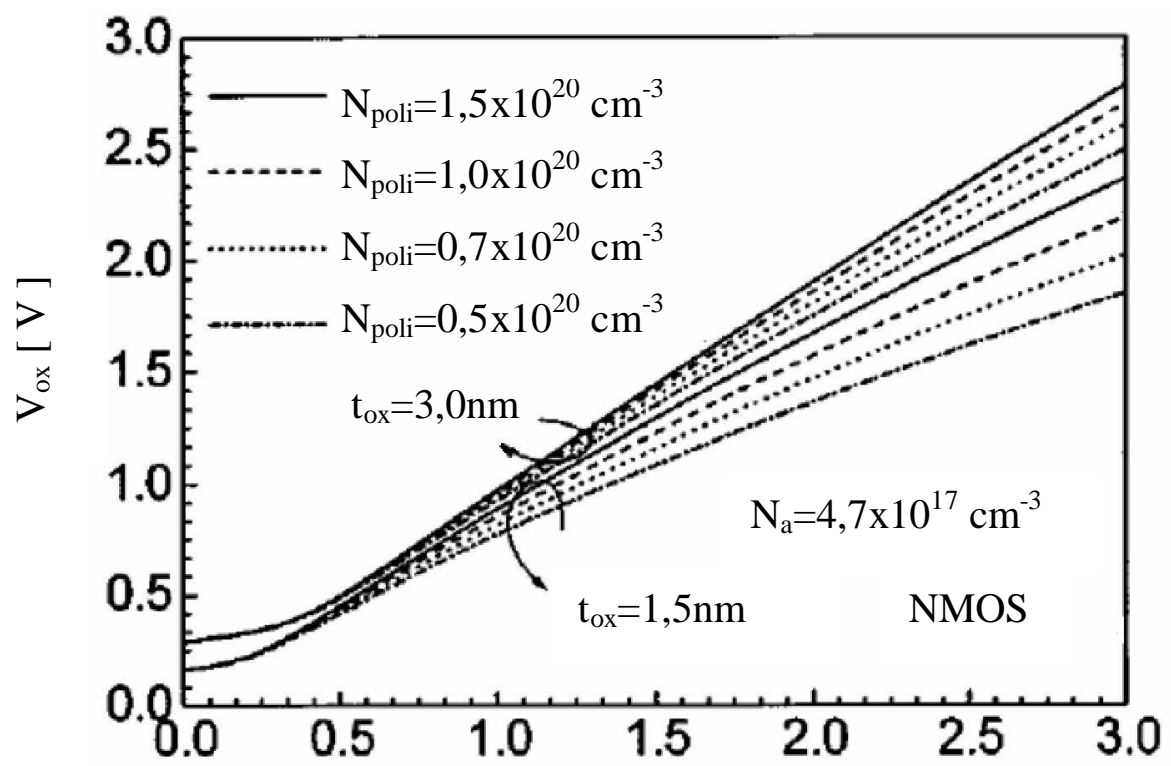

Figura 2.21 - Curvas de $V_{o x}$ em função de $V_{G}$, para diferentes $N_{\text {poli }}$ e $t_{o x}{ }^{32}$.

Na Figura 2.22 pode-se observar o aumento na densidade da corrente de tunelamento $\left(\mathrm{J}_{\mathrm{G}}\right)$ para altas dopagens no Si-poli, proveniente do aumento de $\mathrm{V}_{\mathrm{ox}}$. Pode-se analisar também a influência do óxido de porta, onde a redução na espessura do óxido de porta eleva a corrente de porta mais ainda.

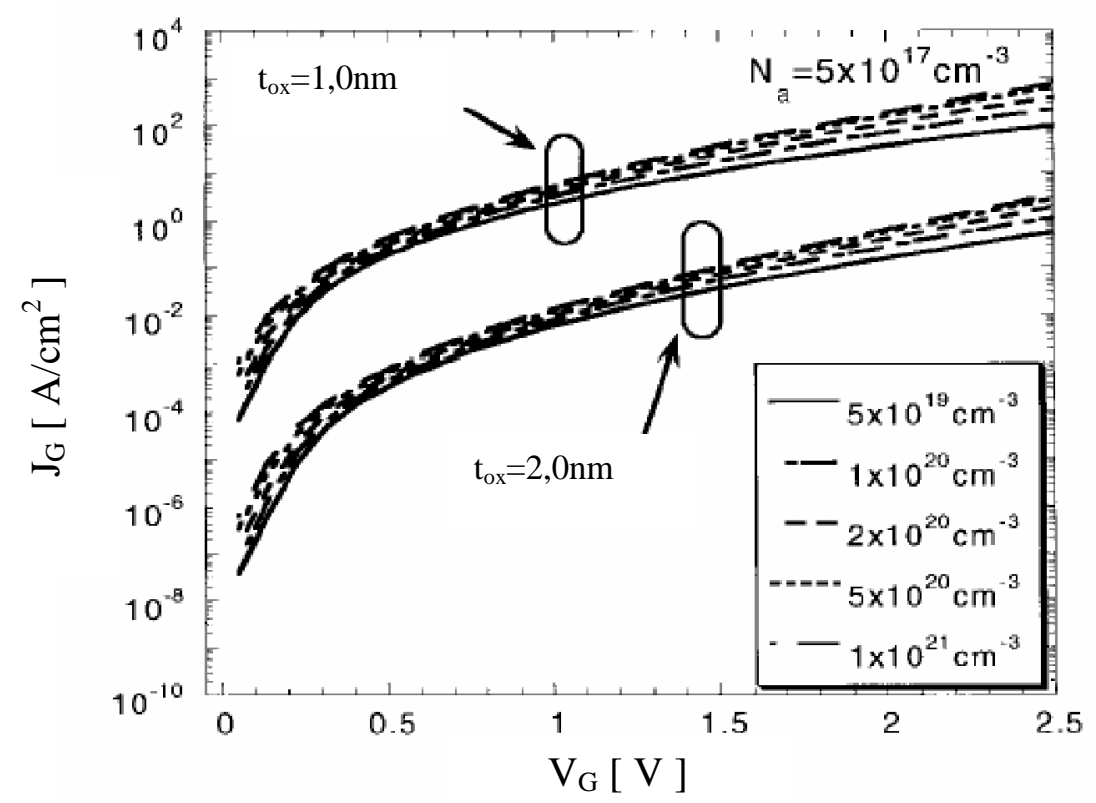

Figura 2.22 - Curva da densidade da corrente de tunelamento $\left(\mathrm{J}_{\mathrm{G}}\right)$ em função de $\mathrm{V}_{\mathrm{G}}$, para diferentes espessuras no óxido de porta e concentrações no Si-poli ${ }^{33}$. 
As curvas C-V de uma estrutura Si-poli N+ / óxido / Substrato estão apresentadas na Figura 2.23. Operando em alta freqüência (Figura 2.23a), a capacitância mínima sofre uma redução, tanto pela capacitância do Si-poli $\left(\mathrm{C}_{\text {poli }}\right)$ como pela capacitância do silício $\left(\mathrm{C}_{\mathrm{Si}}\right)$ que são modificadas pela corrente de tunelamento. Para uma curva C-V em baixa frequiência (Figura 2.23b), como os portadores tem tempo de resposta à $\mathrm{V}_{\mathrm{G}}$, a capacitância de inversão no silício $\left(\mathrm{C}_{\mathrm{inv}}\right)$ deve ser considerada pois a corrente de tunelamento altera suas características. Com $\mathrm{C}_{\mathrm{inv}}$ deixando de ser infinito, o que se observa é uma diminuição na capacitância total na região de inversão.

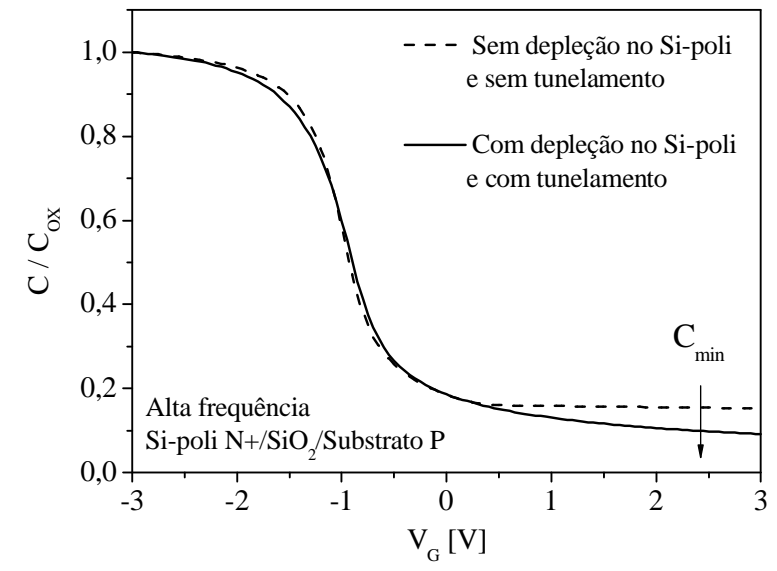

(a)

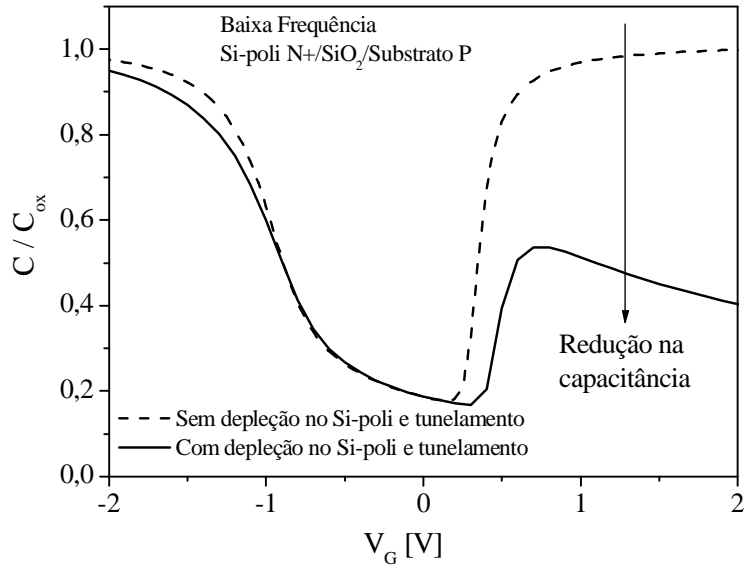

(b)

Figura 2.23 - Curvas C-V de uma estrutura Si-poli N+/ $\mathrm{SiO}_{2} /$ Substrato P em (a) alta e (b) baixa frequiência.

Uma maior análise sobre a influência da corrente de tunelamento nas curvas $\mathrm{C}-\mathrm{V}$, está apresentada no Capítulo 3 através de simulações numéricas bidimensionais.

\subsubsection{Novos dielétricos de porta}

O óxido de silício $\left(\mathrm{SiO}_{2}\right)$ vem sendo utilizado como dielétrico de porta pelas industrias de semicondutores pelos últimos 30 anos. Mas seu escalamento começou a ser limitado pela corrente de tunelamento do canal para a porta (levando à perda de controle do dispositivo) e pelo efeito de depleção do Si-poli (que aumenta para óxidos finos). A Figura 2.24 mostra que ultimamente não basta reduzir o óxido de silício, mas sim substituí-lo por novos materiais, a fim de reduzir estes novos efeitos ${ }^{4,5}$. 


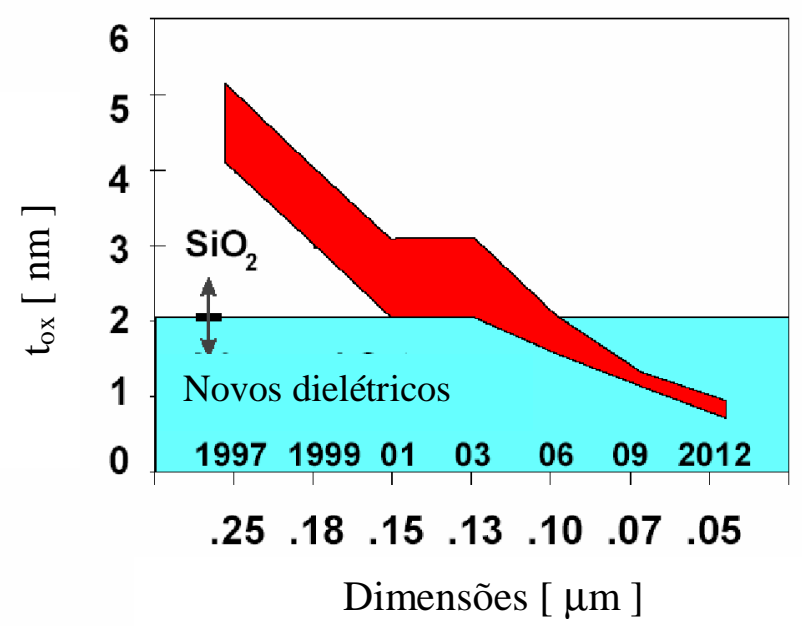

Figura 2.24 - Relação de $\mathrm{t}_{\mathrm{ox}}$ em função das dimensões dos dispositivos, fazendo uma análise da necessidade de novos matérias de porta para substituição do $\mathrm{SiO}_{2}{ }^{4}$.

Sabe-se que a capacitância do óxido de porta $\left(\mathrm{C}_{\mathrm{o}}\right)$ é dada pela equação (13), onde $\mathrm{K}$ é a constante dielétrica do óxido e expressa quanta carga um material consegue segurar, $\varepsilon_{\mathrm{o}}$ é a permissividade do vácuo e $\mathrm{A}$ é a área do capacitor. No caso do óxido de silício $\left(\mathrm{SiO}_{2}\right)$ a constante dielétrica é $\mathrm{K}=3,9^{34}$.

$$
C_{o}=\frac{K \varepsilon_{o} A}{t_{o x}}
$$

A Figura 2.25 mostra que uma estrutura convencional com óxido de porta $\mathrm{SiO}_{2}$ com uma espessura de 1,2 nm, pode ser substituída por uma estrutura com óxido que tenha uma alta constante dielétrica (High- $k$ ) e uma espessura de $3 \mathrm{~nm}$ aproximadamente, e ainda assim possuir as mesmas características de uma estrutura com óxido fino, mas com a vantagem de possuir uma corrente de tunelamento muito menor ${ }^{35}$. 


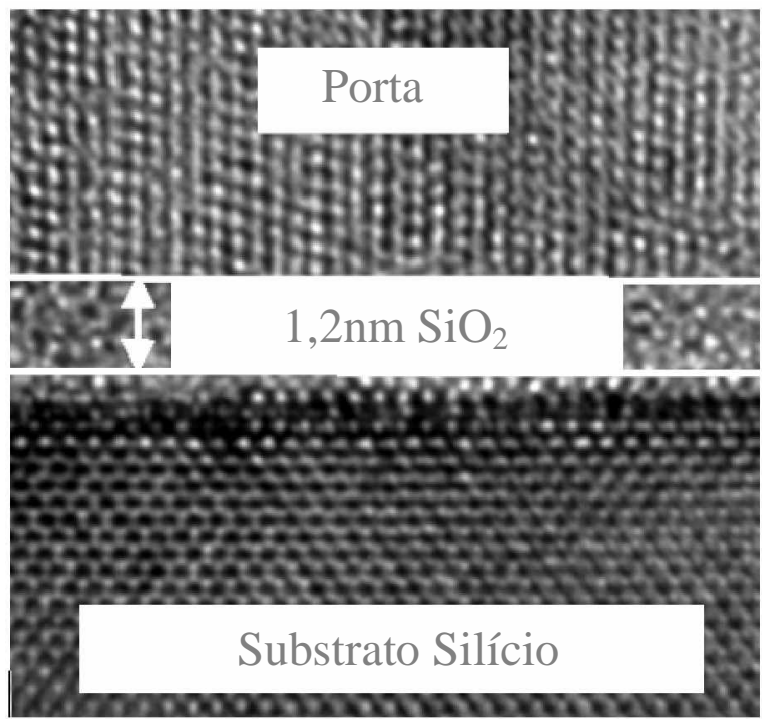

(a)
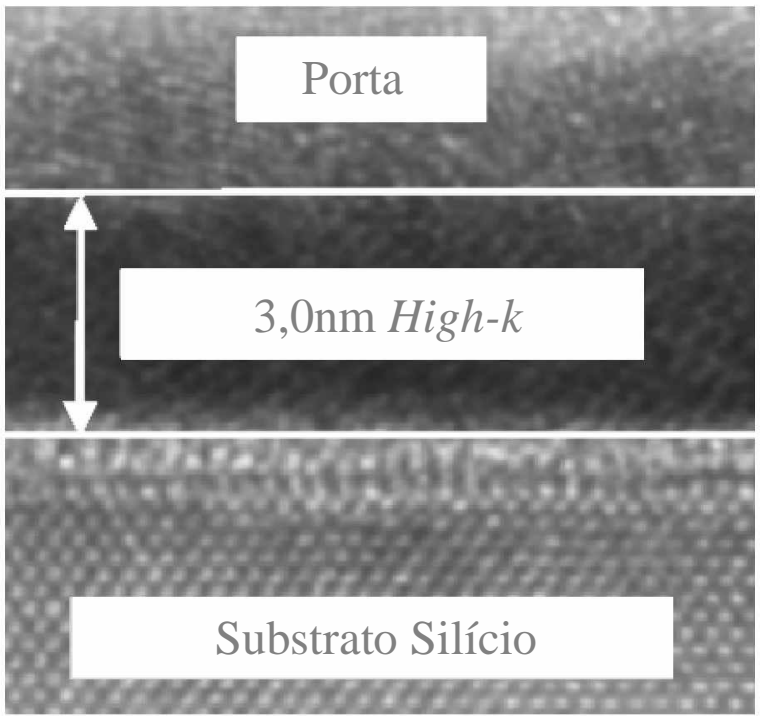

(b)

Figura 2.25 - Comparação entre uma (a) estrutura convencional com dielétrico de porta óxido de silício $\left(\mathrm{SiO}_{2}\right)$ e (b) uma estrutura com dielétrico de porta High-k36.

A Tabela 2.1 mostra alguns dielétricos de porta que podem ser escalados, mantendo-se as mesmas características do $\mathrm{SiO}_{2}$ mas que possuem uma menor corrente de tunelamento devido a sua maior constante dielétrica ${ }^{5}$.

Tabela 2.1 - Constante dielétrica (K) de novos dielétricos de porta ${ }^{5,37}$.

\begin{tabular}{cc}
\hline Material & $\mathbf{K}$ \\
\hline Oxido / Nitreto & $5-8$ \\
$\mathrm{Al}_{2} \mathrm{O}_{3}$ & $9-11$ \\
$\mathrm{Ta}_{2} \mathrm{O}_{5}$ & $25-60$ \\
$\mathrm{CoTiO}_{3}$ & $40-100$ \\
$\left(\mathrm{Ba}, \mathrm{Sr} \mathrm{TiO}_{3}\right.$ & $>200$ \\
$\mathrm{Y}_{2} \mathrm{O}_{3}$ & $10-30$ \\
$\mathrm{HfO}_{2}$ & $10-25$ \\
\hline
\end{tabular}


A Figura 2.26 mostra uma curva de densidade de corrente de porta $\left(\mathrm{J}_{\mathrm{G}}\right)$ em função da espessura equivalente do óxido de porta (EOT). Pode-se observar que óxidos com alta constante dielétrica (High k) possuem uma menor corrente de tunelamento em relação ao óxido de silício $\left(\mathrm{SiO}_{2}\right)^{3}$.

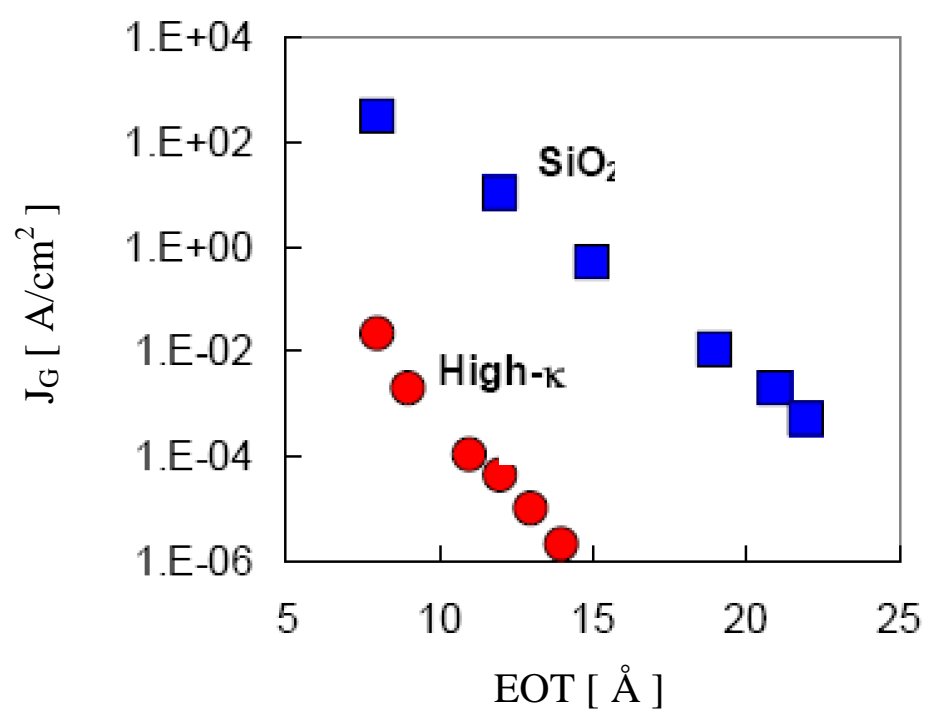

Figura 2.26 - Curva da corrente de porta $\left(\mathrm{J}_{\mathrm{G}}\right)$ em função da espessura equivalente do óxido de porta $(\mathrm{EOT})^{3}$. 


\section{SIMULAÇÃO NUMÉRICA BIDIMENSIONAL}

Apresentaremos neste capítulo as simulações numéricas bidimensionais, realizadas com o auxílio do simulador MEDICI $^{38}$, a fim de se analisar a influência do efeito de depleção no Si-poli e da corrente de tunelamento direto nas características dos capacitores MOS. Segue também uma breve apresentação do programa MEDICI, com a descrição dos tipos de dispositivos que é capaz de simular, modelos, estatísticas e métodos de analise.

\subsection{Simulador Bidimensional de Dispositivos (MEDICI)}

O simulador MEDICI ${ }^{38}$ é um programa de simulação numérica de dispositivos que pode ser utilizado para simular o comportamento de capacitores, transistores MOS e bipolares, e outros dispositivos semicondutores. Possui modelo bidimensional para a distribuição do potencial e concentração de portadores. O programa pode ser usado para prever as características elétricas para condições arbitrárias de polarização.

As simulações obedecem uma grade não linear triangular que nos permite modelar a geometria do dispositivo com superfície planar ou não planar. Elementos adicionais podem ser inseridos conforme a quantidade especificada pelo usuário, assim como o potencial ou a concentração de impurezas pode ser variada. Eletrodos podem ser colocados em qualquer lugar da estrutura do dispositivo.

Modelos físicos são incorporados ao programa para uma simulação precisa, incluindo modelos para recombinação, foto geração, ionização por impacto, estreitamento da banda de energia, tunelamento, mobilidade e tempo de vida de portador.

O MEDICI tem a capacidade de resolver as equações de Poisson, equações de continuidade para elétrons e lacunas, e analisar dispositivos cuja corrente é denominada por um único tipo de portador, como por exemplo em MOSFETs, JFETs e MESFETs.

\subsection{Modelos físicos utilizados nas simulações}

Vários modelos físicos podem ser incorporados ao programa, onde os mais utilizados e estudados para a realização das simulações foram listados na Tabela 3.1. 
Tabela 3.1 - Modelos físicos utilizados nos arquivos de simulação.

Modelo

Descrição

AUGER

ANALYTIC

BOLTZMAN

CONSRH

FLDMOB

PRINT

PRPMOB

TEMPERAT
Especifica a recombinação Auger.

Prevê a dependência da mobilidade com a concentração e com a temperatura.

Especifica o estreitamento da faixa proibida de energia devido a alta dopagem incluindo a variação espacial da concentração intrínseca e o deslocamento das margens das faixas de energia.

Especifica as estatísticas de Boltzman

Especifica a recombinação por Shockley-Read-Hall usando a concentração dependente dos tempos de vida de portadores.

Considera a dependência da mobilidade com o campo elétrico horizontal considerando a velocidade de saturação do portador.

Especifica que a situação atual a todos os modelos, algumas constantes e alguns parâmetros dependentes da temperatura serão reportados no arquivo de saída.

Prevê a redução da mobilidade com o campo elétrico transversal.

Especifica a temperatura de operação da estrutura.

\subsection{Efeito de depleção no Si-poli}

Com o intuito de se analisar os efeitos da depleção no Si-poli nas características dos capacitores MOS tipo P, foram utilizadas duas estruturas diferentes: uma com porta de 
Si-poli N+, onde a depleção no Si-poli ocorre no mesmo instante da depleção no substrato; e outra estrutura com porta de Si-poli P+. Curvas da capacitância em função da tensão de porta tanto em baixa como em alta frequiência foram simuladas para ambas as estruturas, a fim de se verificar as degradações observadas no Capítulo 2. E para verificar se a região do Si-poli realmente depletava, curvas do potencial em função da profundidade foram simuladas.

\subsubsection{Estrutura Si-poli $\mathrm{N}+/ \mathrm{SiO}_{2} /$ Substrato $\mathrm{P}$}

Na Figura 3.1 estão apresentadas as curvas simuladas da capacitância (C) em função da tensão de porta $\left(\mathrm{V}_{\mathrm{G}}\right)$, resultantes para um capacitor MOS tipo P com porta de Si-poli N+ operando em alta freqüência $(\mathrm{f}=1 \mathrm{MHz})$, com as seguintes características: espessura do óxido de porta $\left(t_{o x}\right)$ de $2,5 \mathrm{~nm}$, espessura do Si-poli $\left(t_{\text {poli }}\right)$ de $40 \mathrm{~nm}$, concentração de dopantes no substrato $\left(\mathrm{N}_{\mathrm{a}}\right)$ de $1 \times 10^{18} \mathrm{~cm}^{-3}$ e diferentes concentrações de dopantes do Si-poli $\left(\mathrm{N}_{\text {poli }}=1 \times 10^{20}, 5 \times 10^{19}, 1 \times 10^{19}, 5 \times 10^{18}\right.$ e $\left.1 \times 10^{18} \mathrm{~cm}^{-3}\right)$. Foi simulado também um dispositivo com contato de Si-poli N+ altamente dopado, onde o efeito de depleção no Si-poli é desconsiderado. Um exemplo de arquivo MEDICI utilizado para a realização destas simulações pode ser visto no Apêndice A.

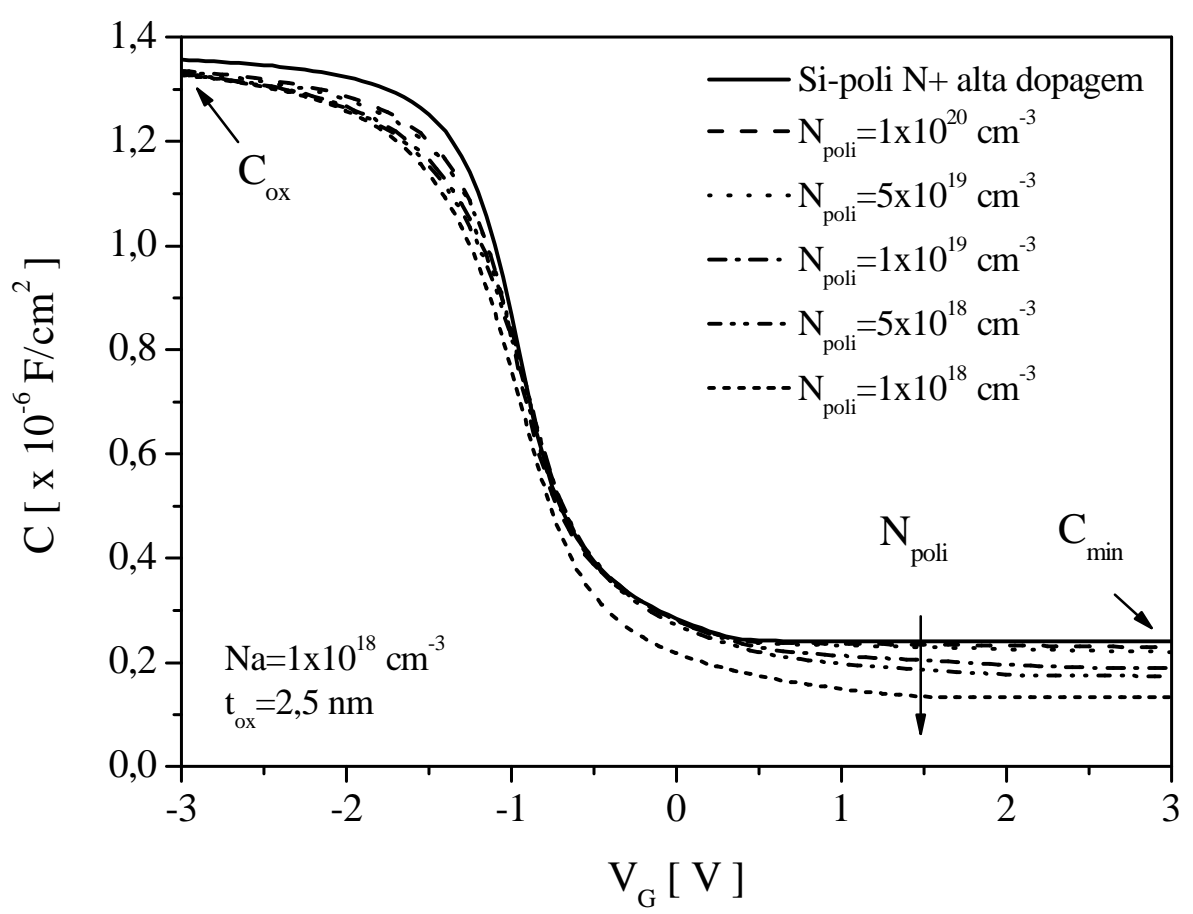

Figura 3.1 . Curvas $\mathrm{C} x \mathrm{~V}_{\mathrm{G}}$ simuladas para um capacitor com porta de Si-poli $\mathrm{N}+$, operando em alta freqüência. 
Pode-se observar na Figura 3.1 que a capacitância mínima $\left(\mathrm{C}_{\min }\right)$ na região de inversão $\left(\mathrm{V}_{\mathrm{G}}>0\right)$ apresenta uma queda conforme a concentração de dopantes do Si-poli diminui, resultado da depleção do Si-poli.

Foram simuladas curvas $\mathrm{C}-\mathrm{V}$ em baixa freqüência, para isso foi necessária uma alteração no tempo de vida de portadores no arquivo de simulação MEDICI. Para o tempo de vida das lacunas utilizou-se TAUP $=2 \times 10^{-12} \mathrm{~s}$ e para o tempo de vida dos elétrons TAUN $=3 \times 10^{-12} \mathrm{~s}$, para um melhor ajuste da curva $\mathrm{C}-\mathrm{V}$. Os mesmos dispositivos estudados na Figura 3.1 foram utilizados, onde as curvas da capacitância em função da tensão de porta $\left(\mathrm{V}_{\mathrm{G}}\right)$ estão apresentadas na Figura 3.2. Um exemplo de arquivo MEDICI utilizado para a realização destas simulações pode ser visto no Apêndice B.

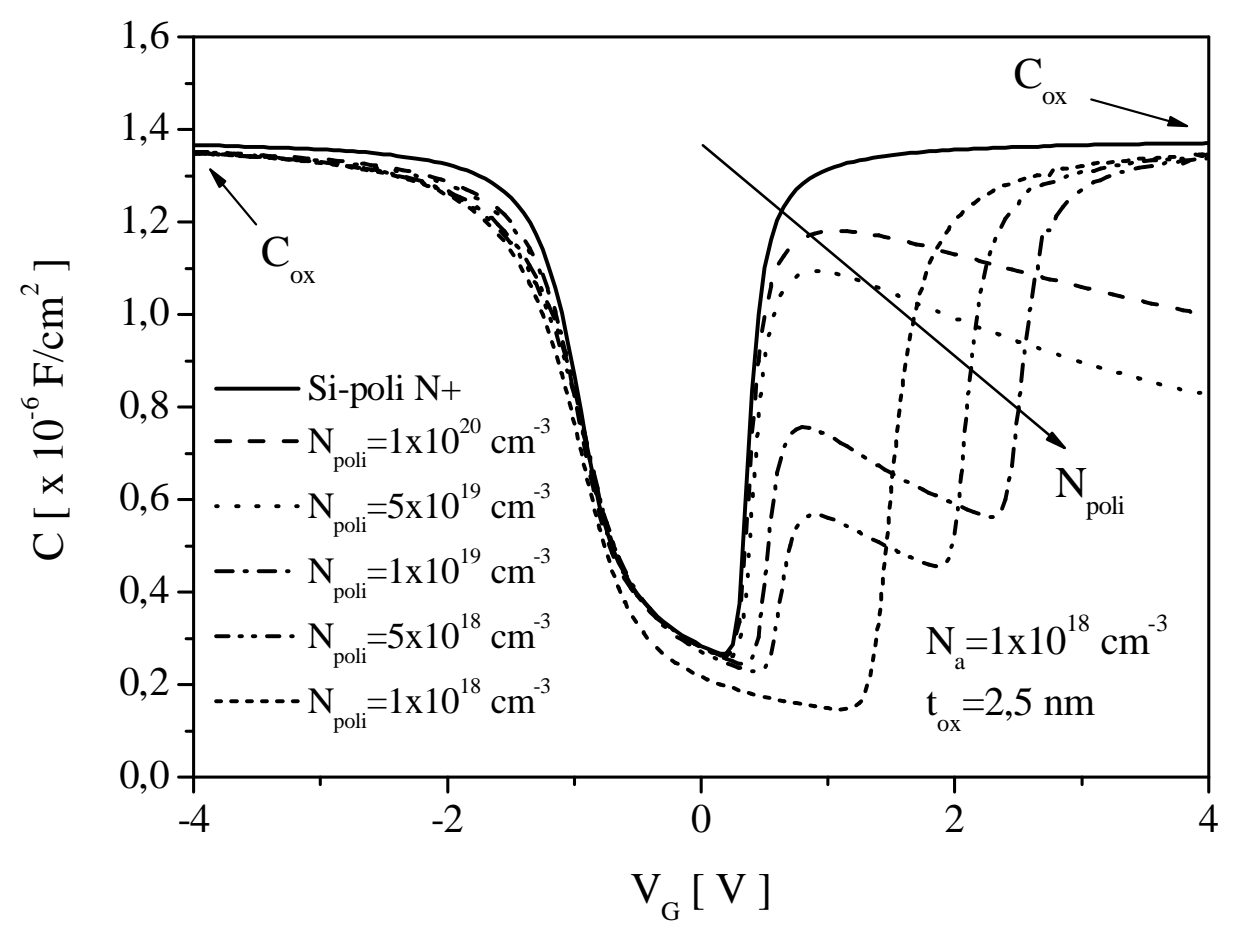

Figura 3.2 - Curvas $\mathrm{C}$ x $\mathrm{V}_{\mathrm{G}}$ simuladas para um capacitor com porta de Si-poli $\mathrm{N}+$, operando em baixa freqüência.

Operando em baixa freqüência, na região de inversão $\left(\mathrm{V}_{\mathrm{G}}>0\right)$ a capacitância total deixa de ser expressa apenas por $\mathrm{C}_{\mathrm{ox}}$, e passa a ser a associação série de $\mathrm{C}_{\mathrm{ox}}$ com a capacitância do Si-poli $\left(\mathrm{C}_{\text {poli }}\right)$, resultando em uma diminuição na capacitância, como pode ser visto na Figura 3.2. $\mathrm{O}$ retorno da capacitância para a condição ideal $\left(\mathrm{C}_{\mathrm{ox}}\right)$ para um alto $\mathrm{V}_{\mathrm{G}}$, deve-se à inversão da região da interface do $\mathrm{Si}$-poli $\mathrm{N}+$ com o óxido, que leva $\mathrm{C}_{\text {poli }}$ tender ao infinito. 
Após a verificação das curvas $\mathrm{C}-\mathrm{V}$, procedeu-se a análise dos gráficos do Potencial e da concentração dos portadores ambos em função da profundidade, para uma estrutura Si-poli $\mathrm{N}+/ \mathrm{SiO}_{2} /$ Substrato $\mathrm{P}$, com $\mathrm{t}_{\mathrm{ox}}=2,5 \mathrm{~nm}, \mathrm{~N}_{\mathrm{a}}=1 \times 10^{18} \mathrm{~cm}^{-3}$ e $\mathrm{N}_{\text {poli }}=1 \times 10^{19} \mathrm{~cm}^{-3}$ e estão apresentadas na Figura 3.3, onde:

(a) para $\mathrm{V}_{\mathrm{G}}=0,5 \mathrm{~V}$, onde a curva do potencial mostra que o substrato já está invertido e $\mathrm{d}_{\mathrm{Si}}$ é máximo, entretanto o Si-poli inicia a depleção. A curva da concentração de elétrons no substrato ultrapassou a curva da concentração de lacunas, indicando a inversão. Neste caso ainda não há degradação da curva $\mathrm{C}-\mathrm{V}$;

(b) para $\mathrm{V}_{\mathrm{G}}=1,5 \mathrm{~V}$, o Si-poli encontra-se depletado, como pode ser visto na curva do potencial. A concentração de lacunas aproxima-se da concentração de elétrons. Na curva $\mathrm{C}-\mathrm{V}$ de alta freqüência $\mathrm{C}_{\min }$ começa a decair (Figura 3.1) e na $\mathrm{C}-\mathrm{V}$ de baixa freqüência a capacitância total deixa de tender a $\mathrm{C}_{\mathrm{ox}}$ e diminui(Figura 3.2);

(c) para $\mathrm{V}_{\mathrm{G}}=4 \mathrm{~V}$, a curva da concentração de lacunas no Si-poli ultrapassou a curva da concentração de elétrons, indicando a inversão da região. Na curva do potencial, $d_{\text {poli já }}$ alcançou seu máximo. A curva $\mathrm{C}-\mathrm{V}$ de alta freqüência não é afetada pelas cargas de inversão, mas a $\mathrm{C}-\mathrm{V}$ de baixa freqüência retorna a normalidade $\left(\mathrm{C}_{\mathrm{ox}}\right)$. Esta tensão de porta foi apenas simulada com o intuito de se mostrar a tendência da curva, pois sabe-se que para dispositivos com óxido de porta muito fino é necessário uma baixa tensão de polarização, para se evitar a ruptura do óxido.
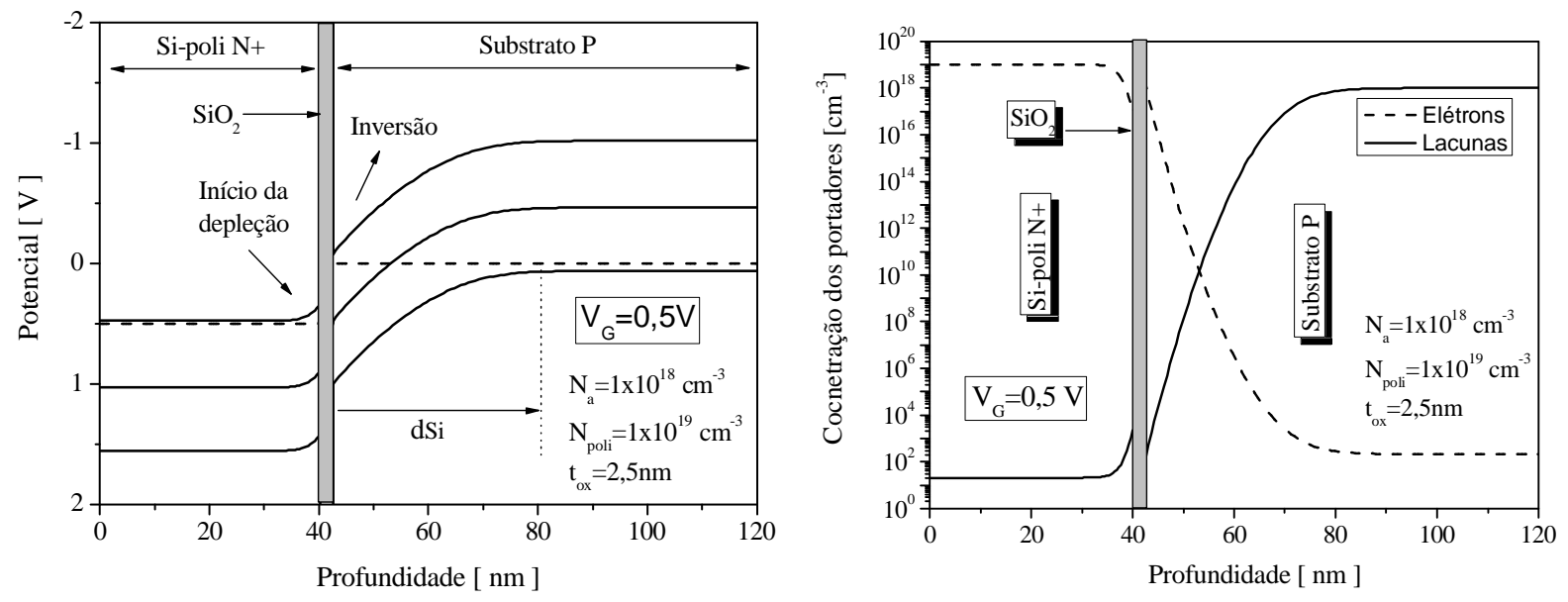

(a) 

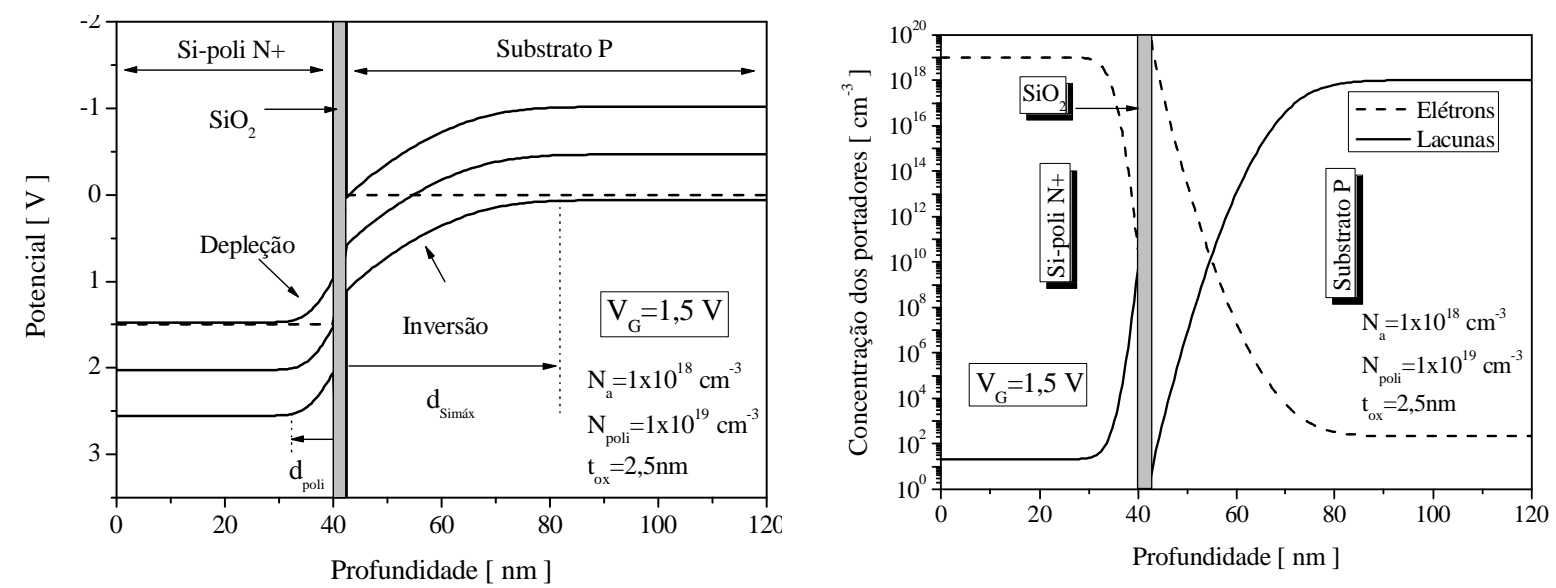

(b)
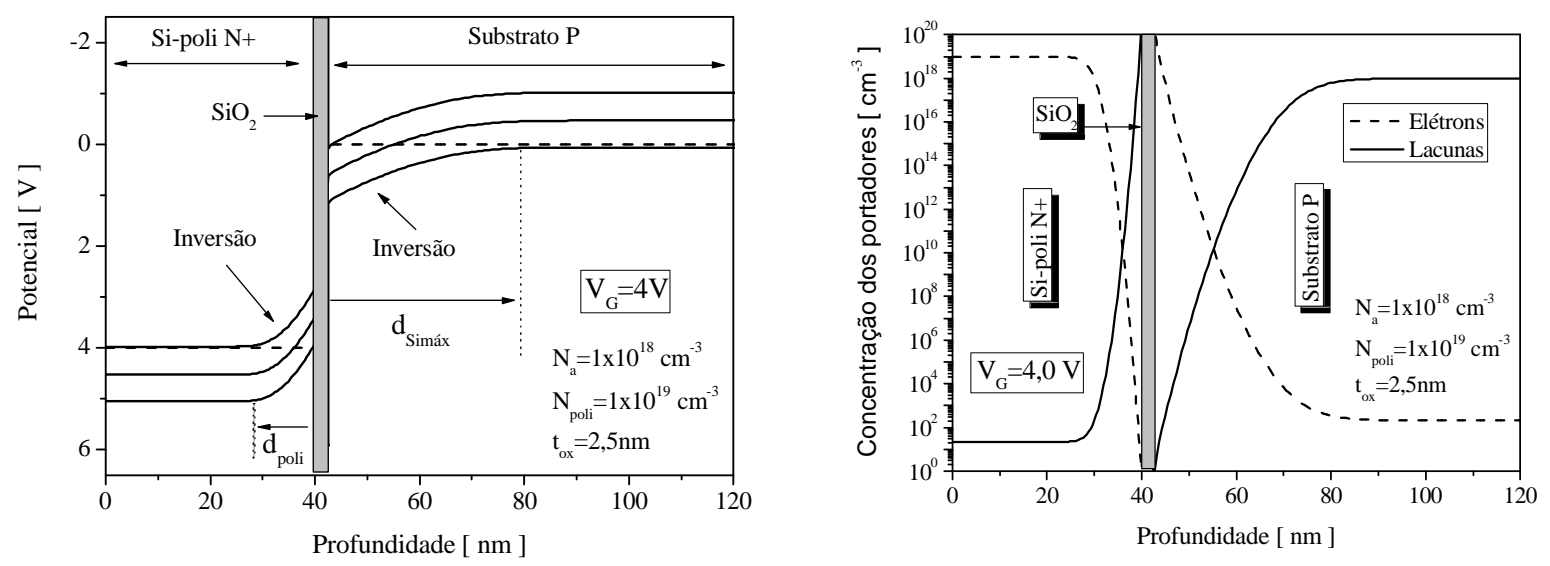

(c)

Figura 3.3 - Curvas do Potencial e da concentração dos portadores, ambas em função da profundidade, para uma estrutura $\mathrm{Si}$-poli $\mathrm{N}+/ \mathrm{SiO}_{2} / \mathrm{Substrato} \mathrm{P}$ e com diferentes tensões de porta (a) $\mathrm{V}_{\mathrm{G}}=0,5 \mathrm{~V}$, (b) $\mathrm{V}_{\mathrm{G}}=1,5 \mathrm{~V}$ e (c) $\mathrm{V}_{\mathrm{G}}=4 \mathrm{~V}$.

Um exemplo de arquivo MEDICI utilizado para a realização destas simulações pode ser visto no Apêndice C.

\subsubsection{Estrutura Si-poli $\mathrm{P}+/ \mathrm{SiO}_{2} /$ Substrato $\mathrm{P}$}

Para o estudo foram utilizados capacitores MOS tipo $\mathrm{P}$ e porta de Si-poli $\mathrm{P}+$, onde as regiões de depleção das interfaces Si-poli P+/óxido e óxido/substrato $\mathrm{P}$, acontecem para tensões de porta diferentes. As características dos dispositivos são: espessura do óxido de porta $\left(\mathrm{t}_{\mathrm{ox}}\right)$ de $2,5 \mathrm{~nm}$, espessura do Si-poli $\left(\mathrm{t}_{\text {poli }}\right)$ de $40 \mathrm{~nm}$, concentração de dopantes no substrato $\left(\mathrm{N}_{\mathrm{a}}\right)$ de $1 \times 10^{18} \mathrm{~cm}^{-3}$ e diferentes concentrações do Si-poli $\left(\mathrm{N}_{\text {poli }}=1 \times 10^{20}, 5 \times 10^{19}\right.$, 
$1 \times 10^{19}, 5 \times 10^{18}$ e $\left.1 \times 10^{18} \mathrm{~cm}^{-3}\right)$. Também foi simulado um capacitor com contato Si-poli P+ com alta dopagem, para servir de base na comparação da curvas.

Foram simuladas curvas da capacitância em função da tensão de porta $\left(\mathrm{V}_{\mathrm{G}}\right)$ em alta freqüência $(\mathrm{f}=1 \mathrm{MHz})$, conforme mostra a Figura 3.4. Pode-se observar a influência da depleção do Si-poli P+ para tensões negativas na porta, onde a associação série de capacitância é dada apenas por $\mathrm{C}_{\mathrm{ox}}$ e pela capacitância do Si-poli $\left(\mathrm{C}_{\text {poli }}\right)$, estando a região do substrato acumulada. Logo a queda observada na capacitância para $\mathrm{V}_{\mathrm{G}}<0$ é resultado apenas de $\mathrm{C}_{\text {poli. }}$

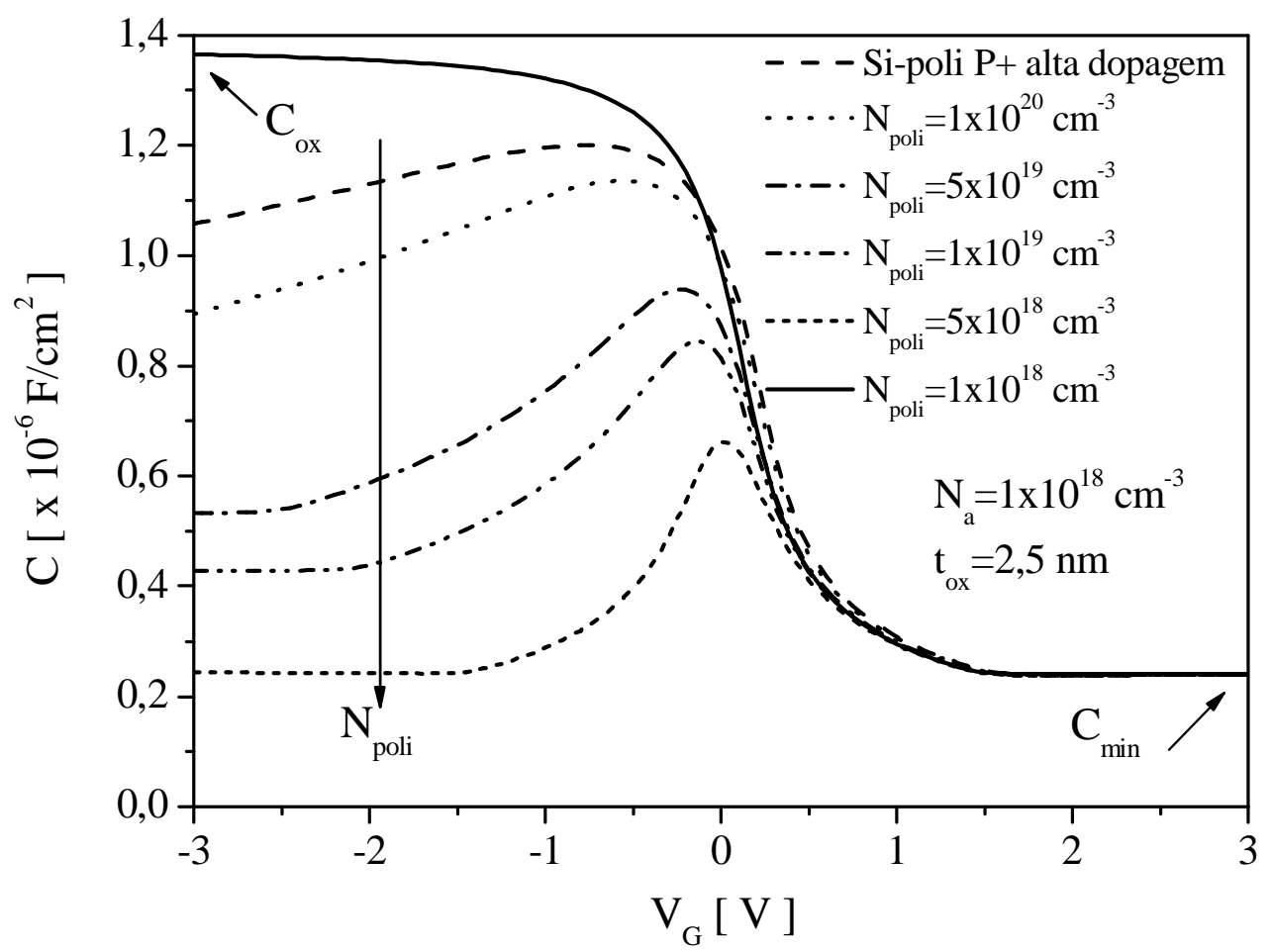

Figura 3.4 - Curvas $\mathrm{C}$ x $\mathrm{V}_{\mathrm{G}}$ simuladas para um capacitor com porta de $\mathrm{Si}$-poli $\mathrm{P}+$, operando em alta frequiência.

Na Figura 3.5 são apresentadas as curvas C-V simuladas para os mesmos dispositivos da Figura 3.4, mas agora operando em baixa frequiência. Observa-se que a inversão do Si-poli P+ leva a curva a sua característica ideal, pois como os portadores tem tempo de resposta à variação de $\mathrm{V}_{\mathrm{G}}, \mathrm{C}_{\text {poli }}$ tende ao infinito e não influencia na associação série com $\mathrm{C}_{\mathrm{ox}}$. 


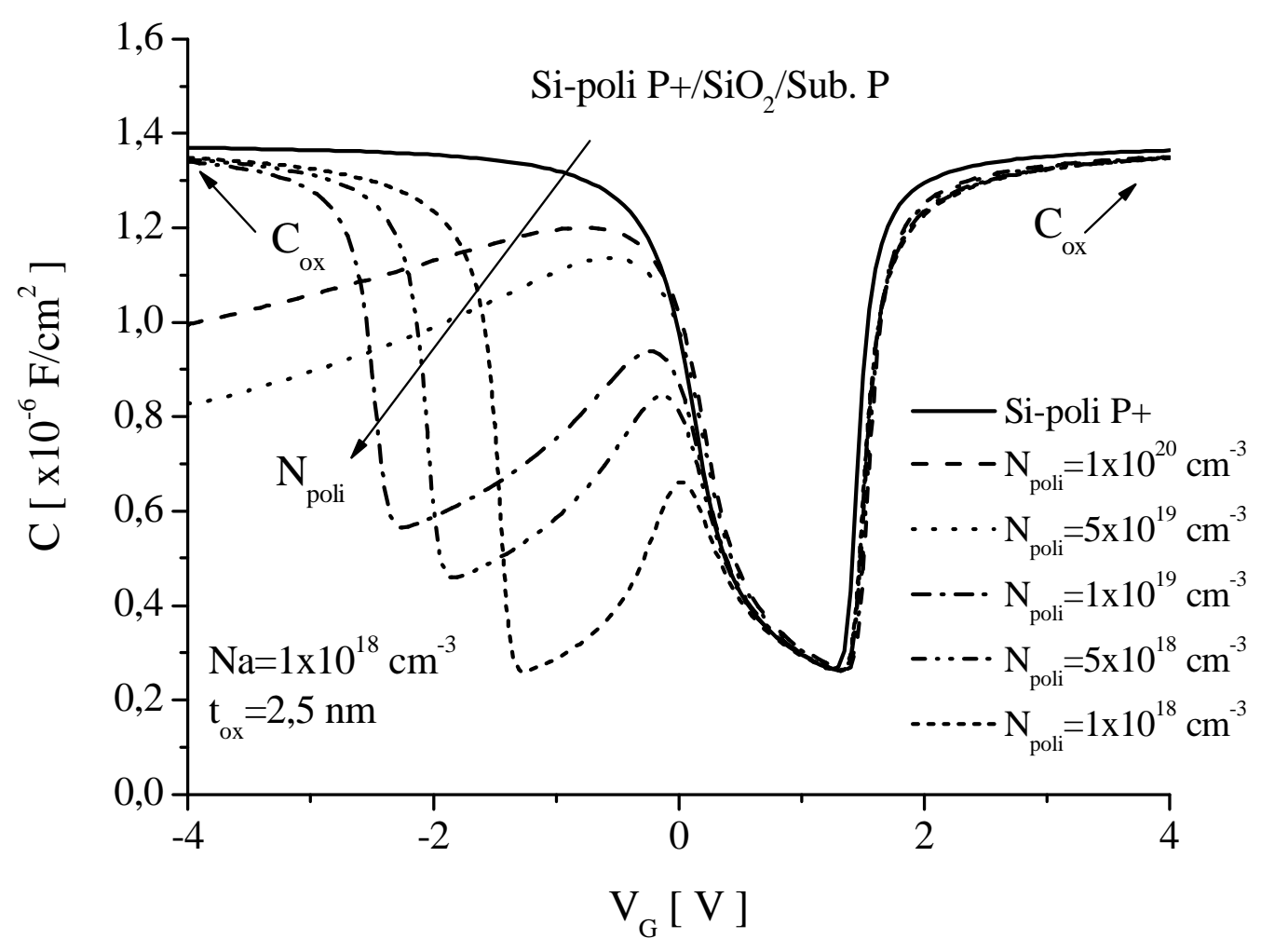

Figura 3.5 - Curvas $\mathrm{C}$ x $\mathrm{V}_{\mathrm{G}}$ simuladas para um capacitor com porta de Si-poli $\mathrm{P}+$, operando em baixa freqüência.

A Figura 3.6 mostra as curvas simuladas do Potencial em função da profundidade, para um capacitor MOS com porta de Si-poli $\mathrm{P}+, \mathrm{t}_{\mathrm{ox}}=2,5 \mathrm{~nm}, \mathrm{~N}_{\mathrm{a}}=1 \times 10^{18} \mathrm{~cm}^{-3} \mathrm{e}$ $\mathrm{N}_{\text {poli }}=1 \times 10^{19} \mathrm{~cm}^{-3}$. Foram utilizadas diferentes tensões de porta onde:

(a) para $\mathrm{V}_{\mathrm{G}}=0 \mathrm{~V}$, o resultado é o início da acumulação na interface $\mathrm{SiO}_{2} /$ Substrato P. Mas por outro lado na interface $\mathrm{Si}$-poli $\mathrm{P}+/ \mathrm{SiO}_{2}$ a região encontra-se iniciando a depleção e nenhuma alteração é vista na curva $\mathrm{C}-\mathrm{V}$.

(b) para $\mathrm{V}_{\mathrm{G}}=-1,5 \mathrm{~V}$, a região do Si-poli está depletada e a capacitância total sofre uma queda devido associação série de $\mathrm{C}_{\mathrm{ox}}$ e $\mathrm{C}_{\text {poli. }}$.

(c) para $\mathrm{V}_{\mathrm{G}}=-4 \mathrm{~V}$, tem-se a inversão da interface $\mathrm{Si}$-poli/ $/ \mathrm{SiO}_{2}$. Neste caso, a capacitância retorna para o ideal $\left(\mathrm{C}_{\mathrm{ox}}\right)$ para uma curva $\mathrm{C}-\mathrm{V}$ de baixa freqüência. 


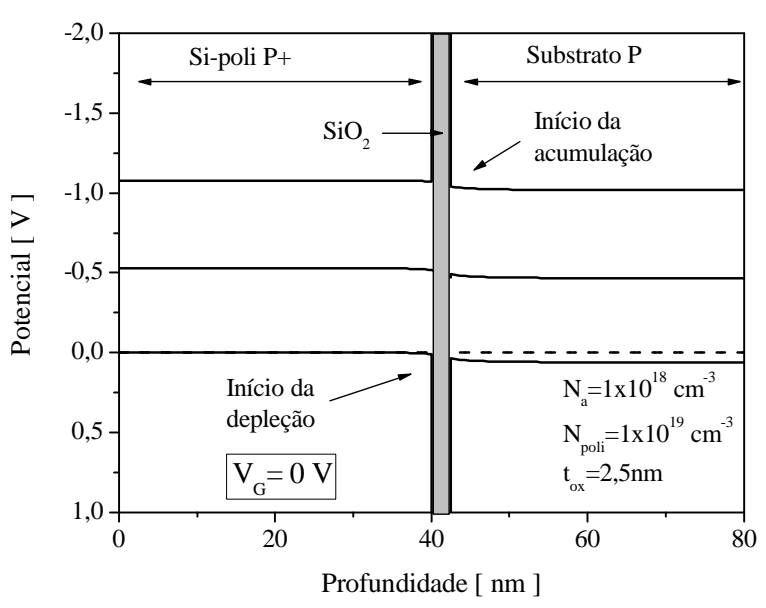

(a)

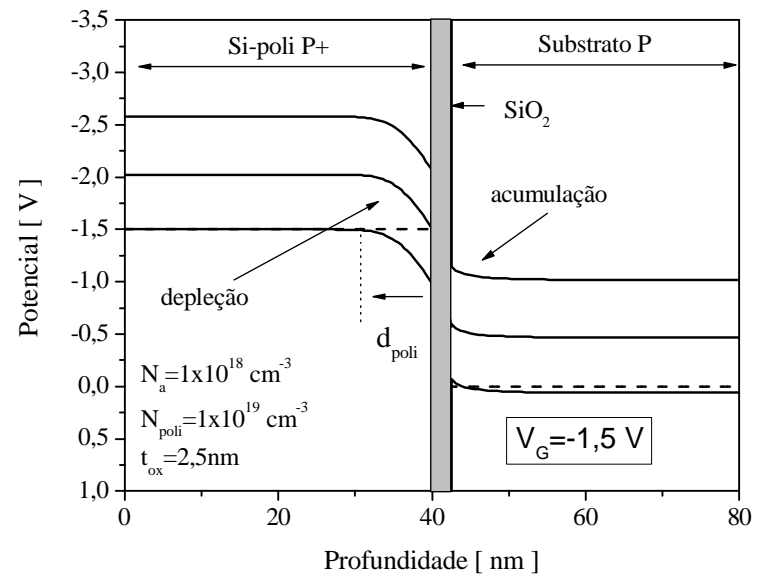

(b)

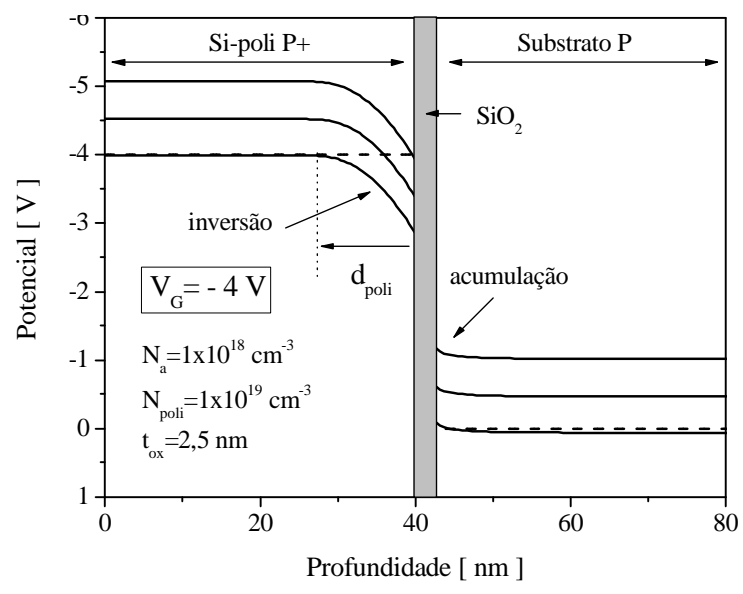

(c)

Figura 3.6 - Curvas do Potencial em função da Profundidade, para uma estrutura Si-poli $\mathrm{P}+/ \mathrm{SiO}_{2} / \mathrm{Sub}$. $\mathrm{P}$, com tensões de porta de (a) $\mathrm{V}_{\mathrm{G}}=0 \mathrm{~V}$, (b) $\mathrm{V}_{\mathrm{G}}=-1,5 \mathrm{~V}$ e (c) $\mathrm{V}_{\mathrm{G}}=-4 \mathrm{~V}$.

\subsection{Corrente de tunelamento pelo óxido de porta}

Os resultados apresentados nos itens anteriores foram obtidos desconsiderando-se a corrente de tunelamento pela porta. Entretanto, conforme visto no Capítulo 2, uma vez que as espessuras dos óxidos são reduzidas, o modelo da corrente de tunelamento deve-se ser inserido nas simulações, a fim de se analisar as degradações causadas nas características dos capacitores MOS. Pelo fato de terem sido simulados dispositivos com óxidos inferiores que $\mathrm{t}_{\mathrm{ox}}<3 \mathrm{~nm}$, o modelo da corrente de tunelamento direto foi utilizado nos arquivos de simulação. 


\subsubsection{Modelo utilizados}

Para selecionar o modelo da corrente de tunelamento direto no simulador MEDICI deve-se especificar o parâmetro "DT.CUR". O modelo analisa a corrente de dois modos diferentes: modo de pós-processamento, calculando a corrente coletada em cada eletrodo solicitado (para acionar este modo o parâmetro "DT.CUR" deve ser indicado no comando de solução "SOLVE") e no modo auto-consistente, sendo esta uma condição limite para os elétrons e lacunas ao longo da interface óxido-silício (este modo é acionado indicando-se o parâmetro DT.CUR no modelo "MODELS" do arquivo de simulação).

O MEDICI pode calcular o tunelamento através das três fontes listadas abaixo, onde as mesmas devem ser indicadas no "SOLVE" e no "MODELS" do arquivo de simulação.

- Tunelamento de elétrons da banda de condução (DT.CBET)

- Tunelamento de elétrons da banda de valência (DT.VBET)

- Tunelamento de lacunas da banda de valência (DT.VBHT)

Três métodos de evolução da corrente podem ser utilizados e devem ser indicados através de numeração pelo parâmetro "DT.METH". Para especificar o parâmetro "DT.METH" deve-se analisar se será modo pós-processamento ou auto-consistente.

- Evolução analítica (1)

- Integração numérica do coeficiente de tunelamento WKB (2)

- Integração numérica do coeficiente de tunelamento Gundlach (3)

- Integração numérica do coeficiente de tunelamento AiryTMT (4)

Os aproximações de WKB (Wentzel-Kramer-Brillouin) foram utilizadas nas simulações, pois quando há corrente de tunelamento as soluções de Schrodinger não podem mais ser consideradas e conforme a literatura é o método que melhor descreve a corrente de tunelamento direto. Contudo, conforme a tensão de porta se torna muito pequena $\left(\mathrm{V}_{\mathrm{G}}<1 \mathrm{~V}\right)$ as aproximações WKB também deixam de ser válidas ${ }^{39,40}$. 


\subsubsection{Degradação da largura da região de depleção $\left(d_{\mathrm{Si}}\right)$}

Conforme visto no Capítulo 2, durante o tunelamento de corrente pela porta, os elétrons ou lacunas tunelam da banda do semicondutor ou do eletrodo, através do isolante, para a banda do outro semicondutor ou eletrodo. Este tunelamento causa uma ausência de portadores no substrato, resultando em um aumento no potencial de superfície $\left(\phi_{\mathrm{s}}\right)$ e na largura da região de depleção $\left(\mathrm{d}_{\mathrm{Si}}\right)$. Para obtenção da largura da região de depleção no silício $\left(\mathrm{d}_{\mathrm{Si}}\right)$ foi necessária a especificação do parâmetro "DEPLETIO" no arquivo de simulação MEDICI, onde o resultado é uma estrutura gráfica bidimensional e o arquivo das simulações pode ser visto no Apêndice D.

A Figura 3.7 apresenta a simulação do perfil bidimensional para capacitores MOS tipo P com porta de alumínio (para se evitar o efeito de depleção do Si-poli), com $\mathrm{N}_{\mathrm{a}}=1 \times 10^{18} \mathrm{~cm}^{-3}, \mathrm{t}_{\mathrm{ox}}=2,2 \mathrm{~nm}$ e para uma tensão de porta $\mathrm{V}_{\mathrm{G}}=3 \mathrm{~V}$, onde a região de depleção já atingiu seu valor máximo $\left(\mathrm{d}_{\text {Simáx }}\right)$. Observa-se que $\mathrm{d}_{\text {Simáx }}$ aumenta quando inserido modelo da corrente de tunelamento direto.

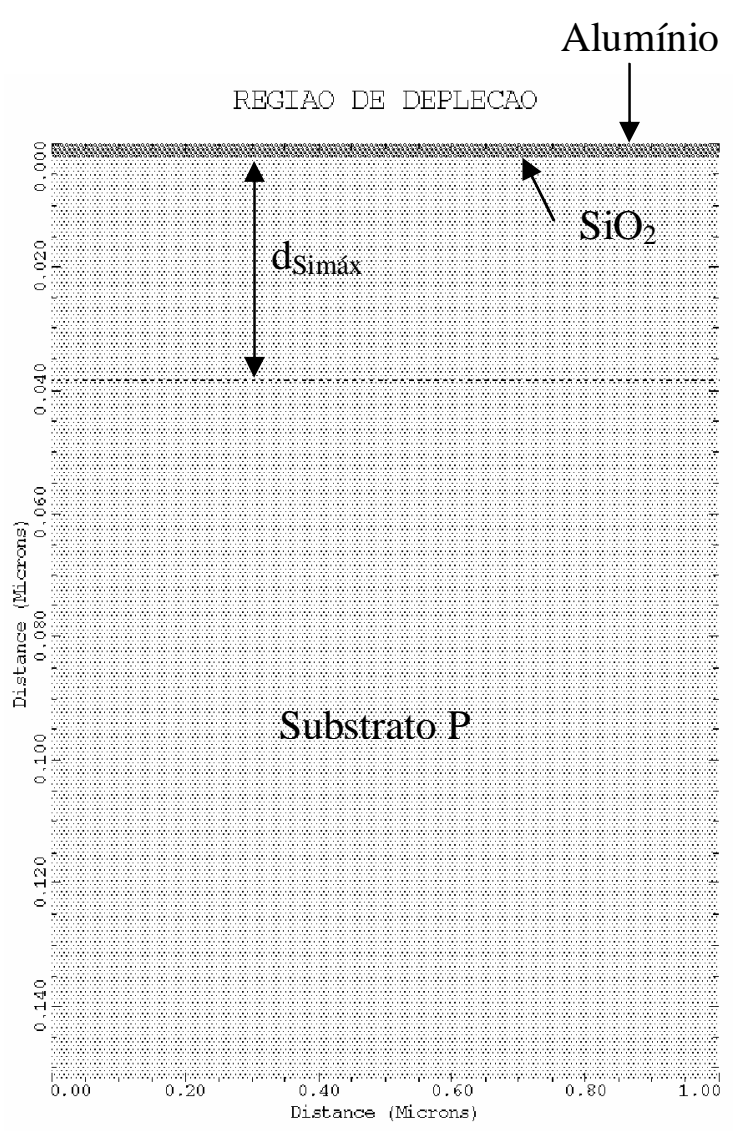

(a)

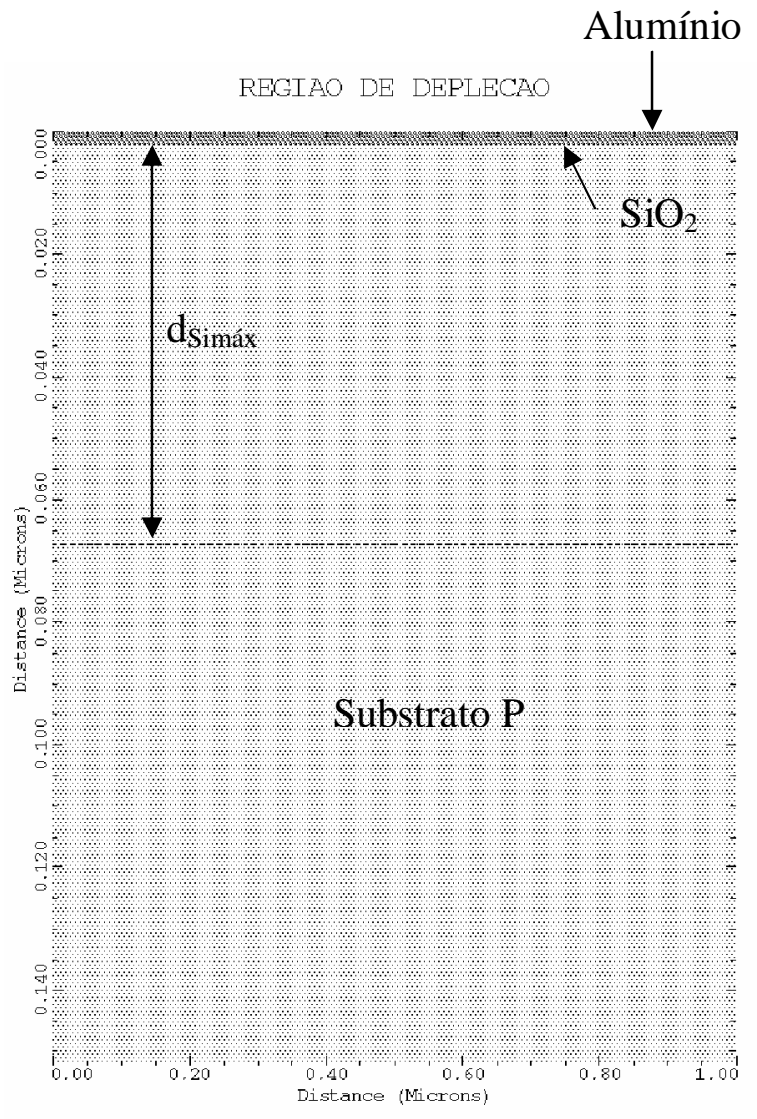

(b)

Figura 3.7 - Simulação do perfil bidimensional de uma estrutura Alumínio/ $\mathrm{SiO}_{2} / \mathrm{Substrato} \mathrm{P}$, onde (a) é sem corrente de tunelamento direto e (b) é com tunelamento, para $\mathrm{V}_{\mathrm{G}}=3 \mathrm{~V}$. 
Com a largura máxima da região de depleção extraída do perfil bidimensional, foi calculada a capacitância do silício $\left(\mathrm{C}_{\mathrm{Si}}=\varepsilon_{\mathrm{Si}} / \mathrm{d}_{\mathrm{Si}}\right)$ para diferentes tensões de porta. Pode-se observar na Figura 3.8 uma diminuição em $\mathrm{C}_{\mathrm{Si}}$, e que se mostra dependente da tensão de porta $\left(\mathrm{V}_{\mathrm{G}}\right)$, pois a corrente de tunelamento direto aumenta conforme $\mathrm{V}_{\mathrm{G}}$ aumenta.

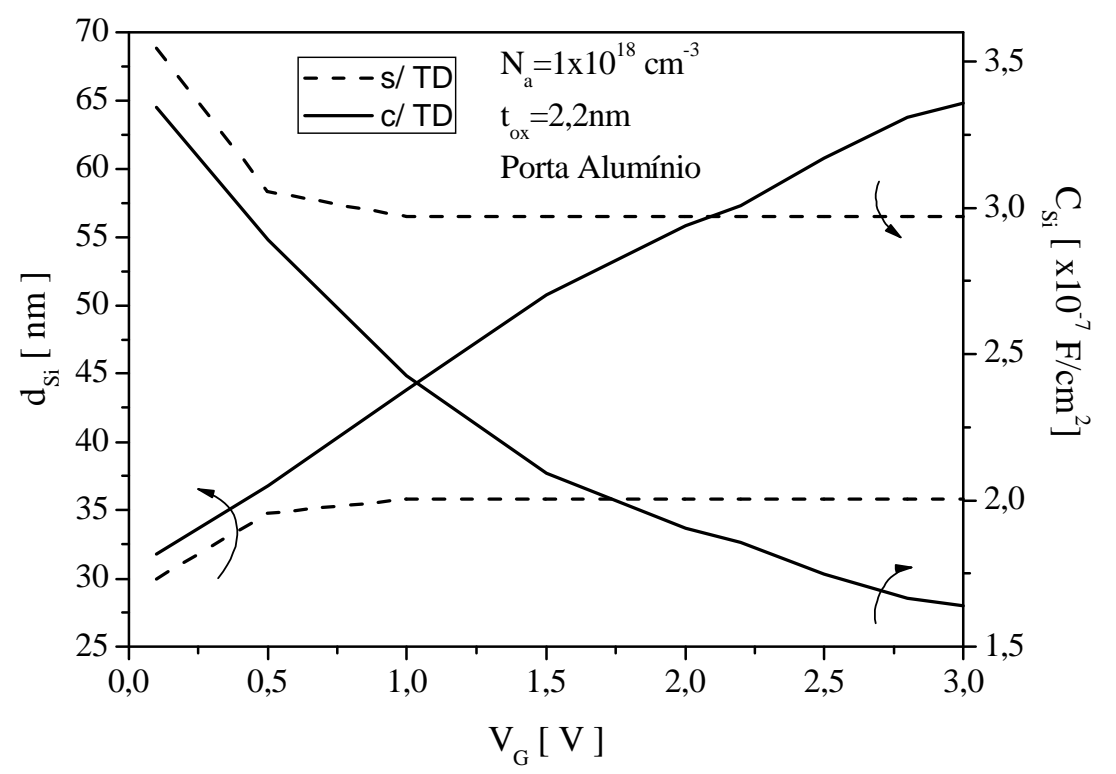

Figura 3.8 - Curvas da largura da região de depleção $\left(\mathrm{d}_{\mathrm{Si}}\right)$ e da capacitância do silício $\left(\mathrm{C}_{\mathrm{Si}}\right)$, ambas em função de $V_{G}$, para $t_{o x}=2,2 \mathrm{~nm}$.

O perfil bidimensional foi simulado para diferentes espessuras do óxido de porta $\left(\mathrm{t}_{\mathrm{ox}}\right)$, e com as demais características iguais as da Figura 3.7 e $\mathrm{V}_{\mathrm{G}}=3 \mathrm{~V}$. Foram extraídas as larguras máximas das regiões depleção no silício $\left(\mathrm{d}_{\text {Simáx }}\right)$ e os resultados estão apresentados na Tabela 3.2. A diminuição em $\mathrm{t}_{\mathrm{ox}}$ gera uma maior aumento em $\left(\mathrm{d}_{\text {Simáx }}\right)$, devido a maior corrente de tunelamento direto.

Tabela 3.2 - Valores da largura máxima da região de depleção $\left(\mathrm{d}_{\text {Simáx }}\right)$ para diferentes $\mathrm{t}_{\mathrm{ox}}$ sob influência do tunelamento de corrente.

\begin{tabular}{ccc}
\hline \multirow{2}{*}{$\mathrm{t}_{\mathrm{ox}}(\mathrm{nm})$} & \multicolumn{2}{c}{$\mathrm{d}_{\text {Simáx }}(\mathrm{nm})$} \\
\cline { 2 - 3 } & Sem TD & Com TD \\
\hline 1,5 & 36,5 & 66,5 \\
2,0 & 36,5 & 65,0 \\
2,2 & 36,5 & 64,8 \\
2,5 & 36,5 & 63,5 \\
\hline
\end{tabular}




\subsubsection{Degradação da curva C-V}

As curvas C-V simuladas da Figura 3.9 foram obtidas em capacitores MOS tipo P com porta de alumínio, $\mathrm{t}_{\mathrm{ox}}=2,2 \mathrm{~nm} \mathrm{e} \mathrm{N}_{\mathrm{a}}=1 \times 10^{18} \mathrm{~cm}^{-3}$, operando em alta freqüência. Um exemplo de arquivo MEDICI utilizado para a realização destas simulações pode ser visto no Apêndice D. Na curva sólida não foi utilizado modelo da corrente de tunelamento direto e nenhuma degradação foi observada. Mas quando inserido o modelo DT.CUR (curva tracejada) a capacitância mínima $\left(\mathrm{C}_{\min }\right)$ à partir de uma certa tensão de porta $\left(\mathrm{V}_{\mathrm{G}} \cong 0,5\right)$, começa a reduzir. Esta tensão, onde as curvas começam a se separar, representa a tensão de porta que faz a corrente de tunelamento ter valores significativos, a ponto de alterar as características dos dispositivos (ponto A). Deve-se este efeito ao aumento na largura da região de depleção do substrato pela corrente de tunelamento, que faz $\mathrm{C}_{\mathrm{Si}}$ diminuir. Como a associação série de capacitâncias na região de inversão tende ao menor valor a capacitância mínima $\left(\mathrm{C}_{\min }\right)$ sofre uma queda.

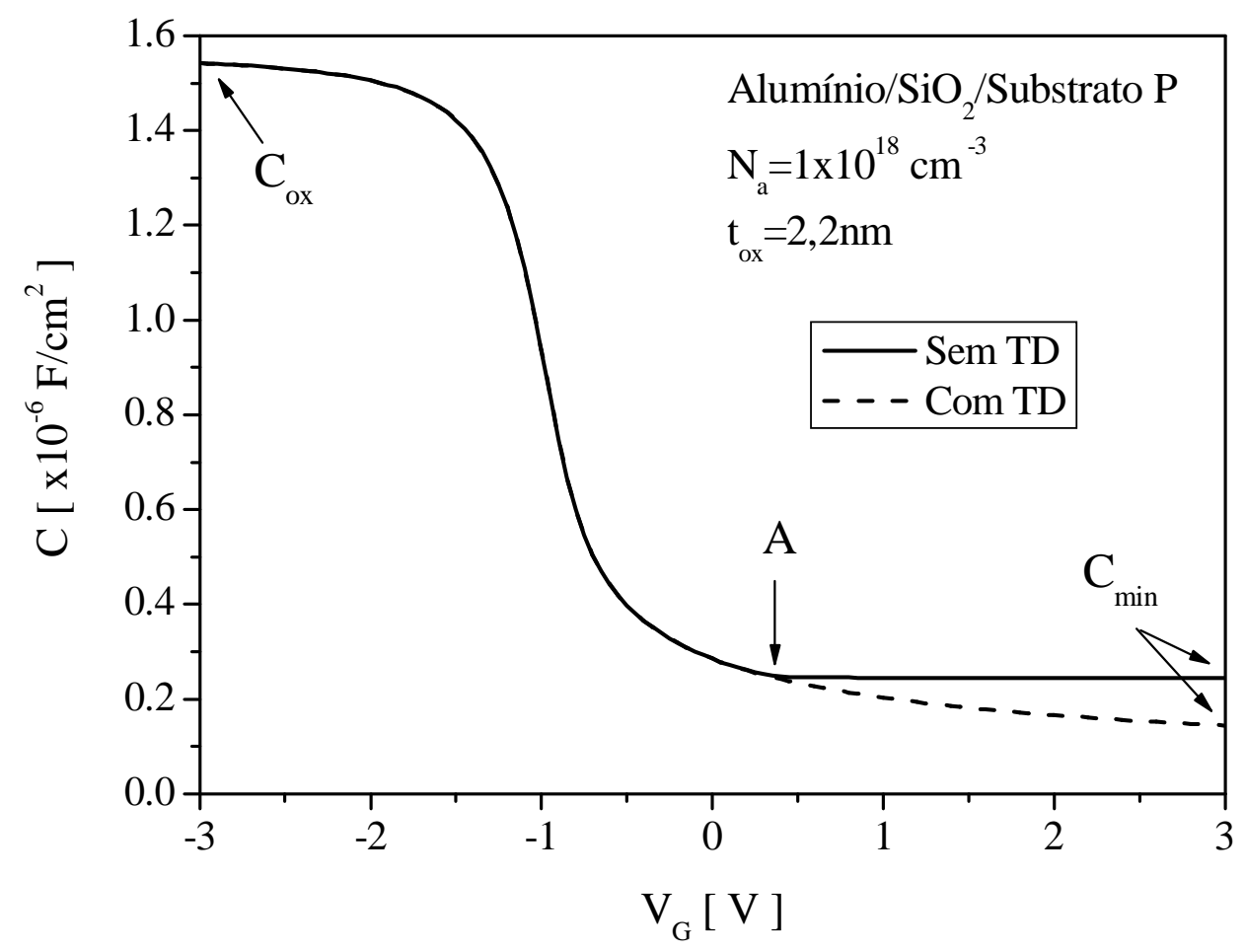

Figura 3.9 - Curvas C-V em alta freqüência, demonstrando a influência da corrente de tunelamento direto (TD), para um capacitor MOS tipo $\mathrm{P}$ com porta de alumínio, $\mathrm{t}_{\mathrm{ox}}=2,2 \mathrm{~nm}$ e $\mathrm{N}_{\mathrm{a}}=1 \times 10^{18} \mathrm{~cm}^{-3}$. 
Mas quando simulada uma curva C-V em baixa freqüência, a análise deve ser um pouco mais detalhada, como apresentado na Figura 3.10 onde foram repetidas as mesmas características da Figura 3.9. Neste caso a redução na capacitância total deve-se à diminuição da densidade de cargas de inversão, pois em baixa frequiência os portadores tem tempo de resposta a variação de tensão. Como resultado a capacitância de inversão $\left(\mathrm{C}_{\text {inv }}\right)$ deixa de ser infinita na associação série de capacitâncias na região de inversão, e a capacitância total $\left(\mathrm{C}_{\mathrm{T}}\right)$ sofre uma queda ${ }^{30}$.

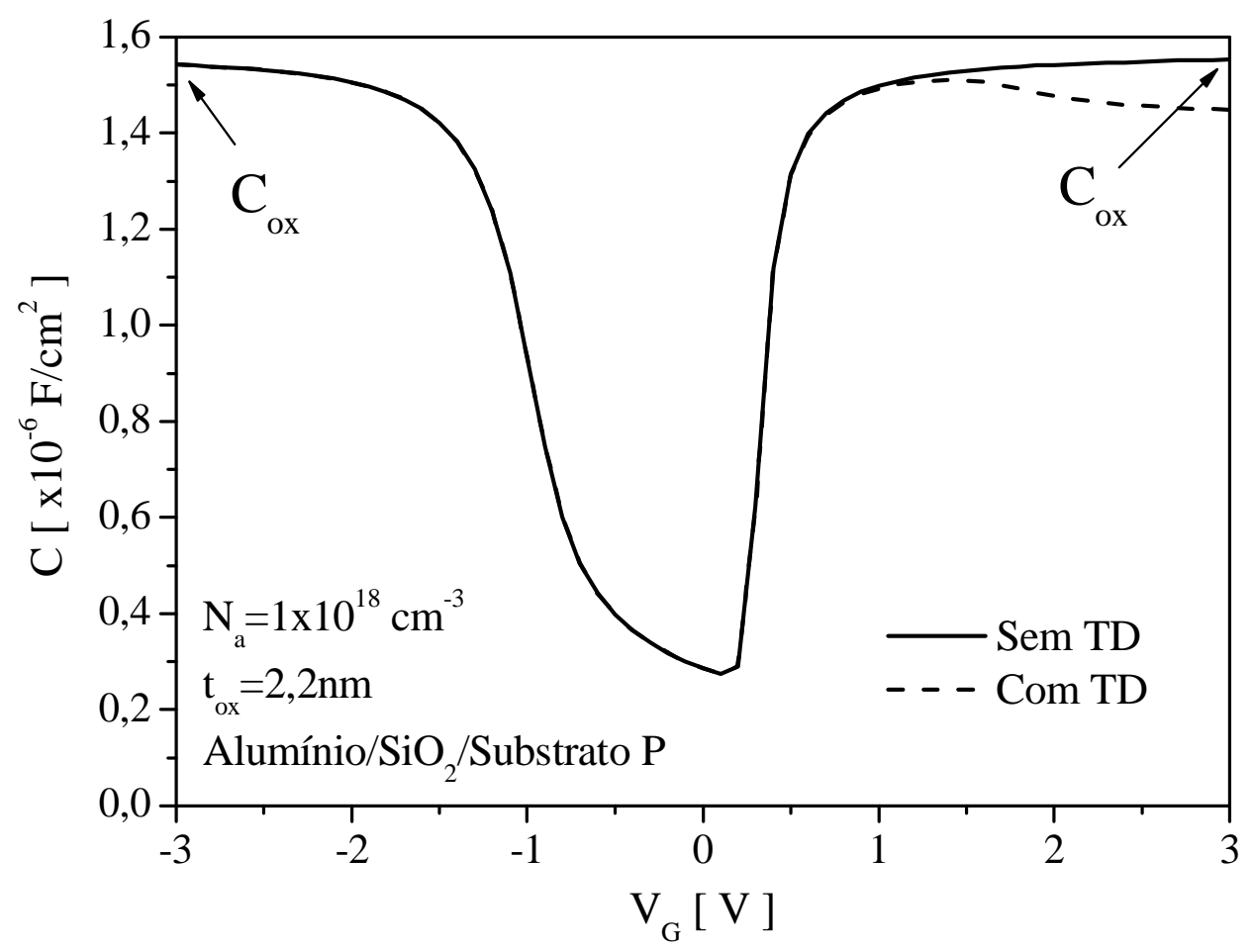

Figura 3.10 - Curvas C-V em baixa freqüência, demonstrando a influência da corrente de tunelamento direto (TD), para um capacitor MOS tipo $P$ com porta de alumínio, $\mathrm{t}_{\mathrm{ox}}=2,2 \mathrm{~nm}$ e $\mathrm{N}_{\mathrm{a}}=1 \times 10^{18} \mathrm{~cm}^{-3}$.

\subsubsection{Curva $\mathbf{J}_{\mathbf{G}} \times \mathrm{V}_{\mathbf{G}}$}

A curva da densidade de corrente de porta $\left(\mathrm{J}_{\mathrm{G}}\right)$ em função da tensão de porta $\mathrm{V}_{\mathrm{G}}$ é utilizada para representar a alteração na corrente de tunelamento conforme a tensão aumenta. Na Figura 3.11 foram simuladas curvas $\mathrm{J}_{\mathrm{G}} \mathrm{x} \mathrm{V}_{\mathrm{G}}$, para capacitores MOS tipo P com porta de alumínio, $\mathrm{N}_{\mathrm{a}}=1 \times 10^{18} \mathrm{~cm}^{-3}, \mathrm{t}_{\mathrm{ox}}$ variando entre 2 e 2,4nm. Um exemplo de arquivo MEDICI utilizado para a realização destas simulações pode ser visto no Apêndice E. Pode-se observar 
que quanto mais fina a espessura do óxido de porta maior será a corrente, pois a barreira que os portadores tem de atravessar é menor.

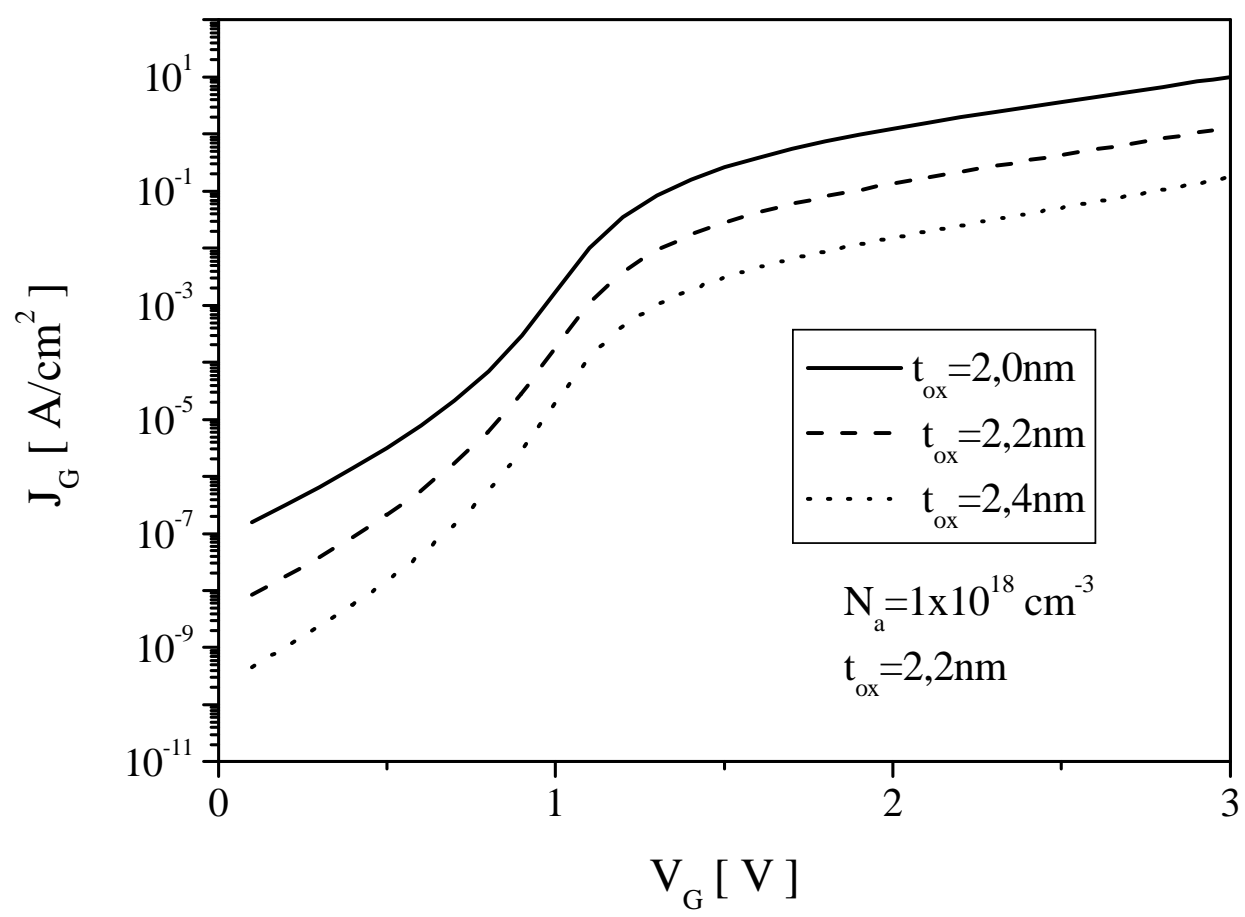

Figura 3.11 - Curvas da densidade de corrente $\left(\mathrm{J}_{\mathrm{G}}\right)$ em função de $\mathrm{V}_{\mathrm{G}}$, para diferentes $\mathrm{t}_{\mathrm{ox}}$.

\subsubsection{Efeito da depleção no Si-poli e da corrente de tunelamento direto}

Como apresentado, o efeito da depleção do Si-poli juntamente com a corrente de tunelamento degradam a curva $\mathrm{C}-\mathrm{V}$, impossibilitando seu uso na extração de alguns parâmetros. Para se estudar melhor a soma dos dois efeitos, inicialmente foram simuladas curvas da densidade de corrente $\left(\mathrm{J}_{\mathrm{G}}\right)$ em função da tensão de porta $\left(\mathrm{V}_{\mathrm{G}}\right)$, para capacitores MOS tipo $P$ com $t_{o x}=2,2 \mathrm{~nm}, \mathrm{~N}_{\mathrm{a}}=1 \times 10^{18} \mathrm{~cm}^{-3} \mathrm{e}$ diferentes concentrações de dopantes no Si-poli $\mathrm{N}+\left(\mathrm{N}_{\text {poli }}=1 \times 10^{21}, 1 \times 10^{20}, 1 \times 10^{19}\right.$ e $\left.1 \times 10^{18} \mathrm{~cm}^{-3}\right)$, como pode ser visto na Figura 3.12. As curvas mostram que altas concentrações de dopantes do Si-poli $\left(\mathrm{N}_{\text {poli }}\right)$, possuem maior densidade de corrente conforme a tensão de porta aumenta. Neste caso, a região de depleção do Si-poli é muito fina e a tensão de polarização cai quase que por inteiro no óxido, gerando uma maior corrente de tunelamento. 


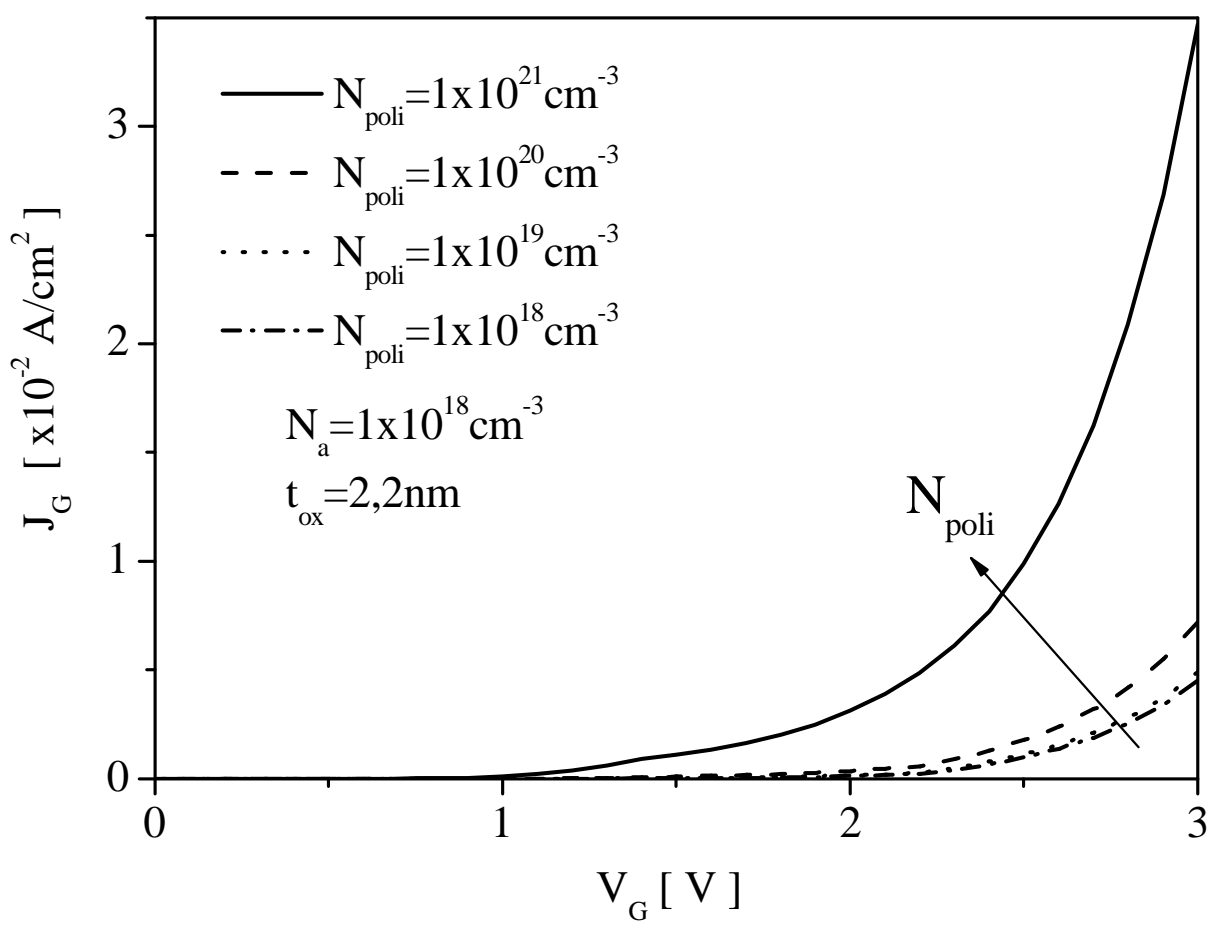

Figura 3.12 - Curva da densidade de corrente de tunelamento $\left(J_{G}\right)$ em função de $V_{G}$, para diferentes concentrações de dopantes no Si-poli.

À medida que os portadores tunelam do substrato para o eletrodo da porta (causando um aumento em $\left.\mathrm{d}_{\mathrm{Si}}\right)$, ocorre uma redução na largura da região de depleção no Si-poli $\left(\mathrm{d}_{\text {poli }}\right)$, devido ao aumento do número de portadores. A fim de observar estas alterações nas larguras das regiões de depleção do Si-poli e do substrato, foram simulados os perfis bidimensionais para capacitores MOS tipo $\mathrm{P}$ com porta de Si-poli $\mathrm{N}+, \mathrm{N}_{\text {poli }}=1 \times 10^{19}, \mathrm{~N}_{\mathrm{a}}=1 \times 10^{18} \mathrm{~cm}^{-3}, \mathrm{t}_{\mathrm{ox}}=2,2$ nm e para uma tensão de porta $\mathrm{V}_{\mathrm{G}}=3 \mathrm{~V}$. O resultado é observado na Figura 3.13 onde na (a) apenas o efeito de depleção do Si-poli foi considerado e na (b) o modelo da corrente de tunelamento foi inserido e o que se observa é uma diminuição em $\mathrm{d}_{\text {polimáx }} \mathrm{e}$ um aumento em $\mathrm{d}_{\text {Simáx. }}$ 


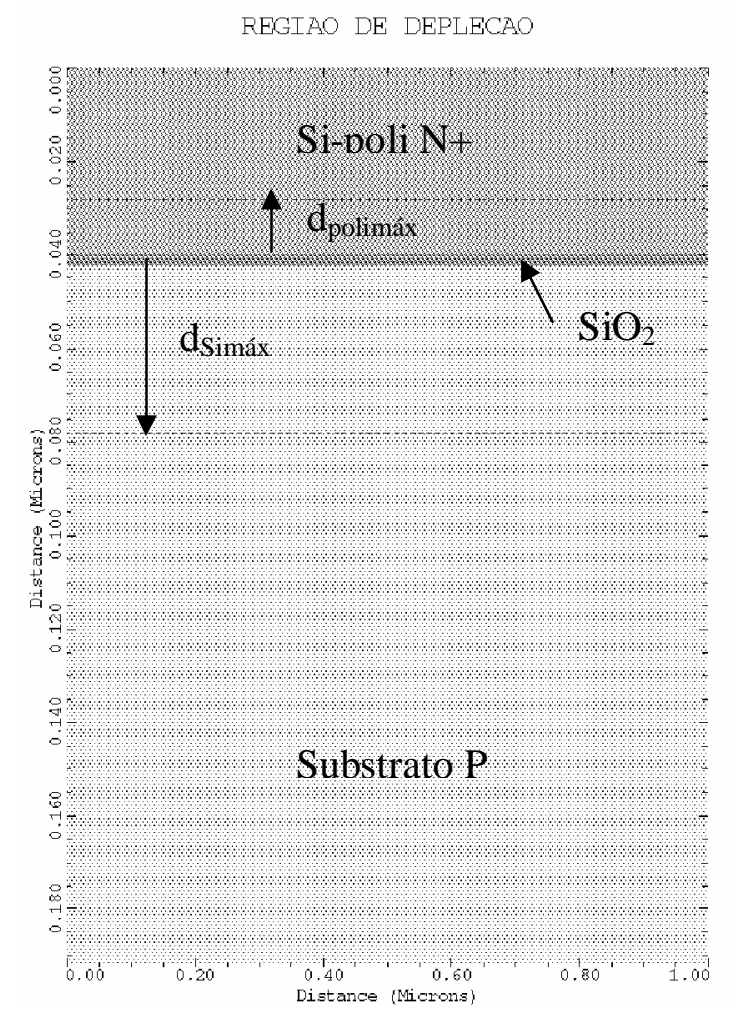

(a)

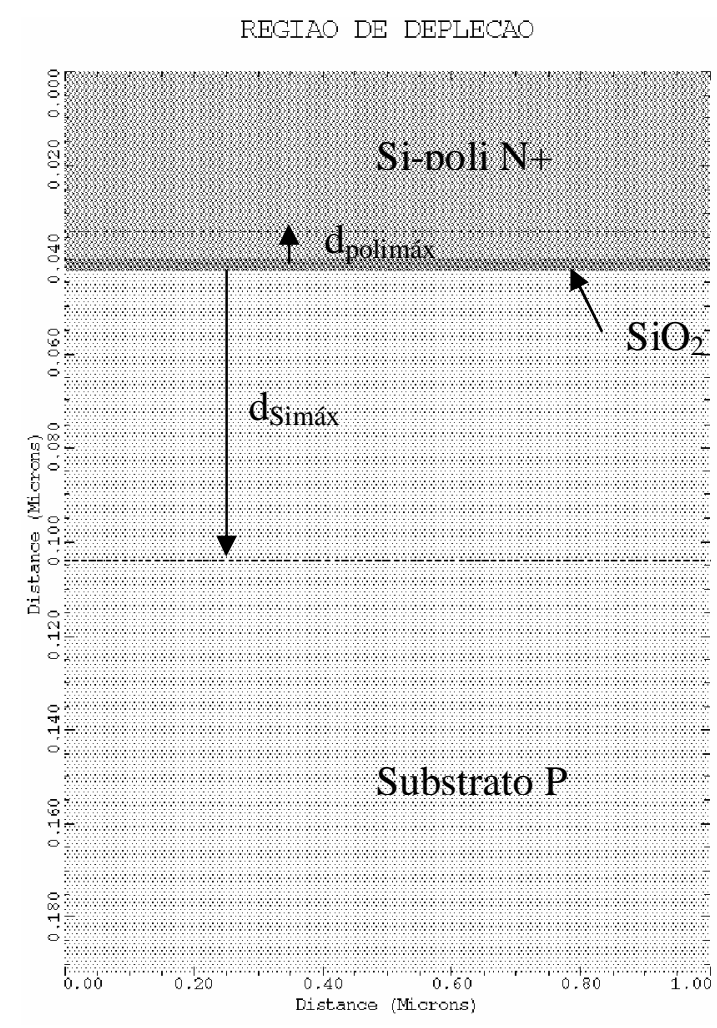

(b)

Figura 3.13 - Simulação do perfil bidimensional de uma estrutura Sipoli N+/SiO2/Substrato P, onde (a) é sem corrente de tunelamento direto e (b) é com tunelamento, para $\mathrm{V}_{\mathrm{G}}=3 \mathrm{~V}$.

A Figura 3.14 apresenta a variação de $d_{\text {Simáx }}$ e $d_{\text {polimáx }}$ em função da concentrações de dopantes do Si-poli, para capacitores MOS tipo $P$ com $N_{a}=1 \times 10^{18} \mathrm{~cm}^{-3}, t_{o x}=2,2 \mathrm{~nm} \mathrm{e} V_{G}=3 V$, simulados com e sem tunelamento. As larguras das regiões de depleção foram extraídas através dos perfis bidimensionais simulados semelhantes ao apresentado na Figura 3.13. A partir das curvas apresentadas, pode-se notar a diminuição da largura máxima da região de depleção no Si-poli $\left(\mathrm{d}_{\text {polimáx }}\right)$ quando o modelo de tunelamento direto (TD) é inserido na simulação; entretanto, quando a concentração do Si-poli aproxima-se da concentração do substrato, há uma inversão de comportamento, e $\mathrm{d}_{\text {polimáx }}$ passa a ser maior com TD. Por outro lado, a diferença entre a largura máxima da região de depleção no silício com e sem o efeito de TD, é maior para altas concentrações no Si-poli. A fina largura da região de depleção do Si-poli, observada com alta dopagem, é mais afetada pelo tunelamento, e em alguns casos pode vir a desaparecer. Sem a presença da barreira formada pela região de depleção no Si-poli a queda de tensão no óxido cresce, aumentando a corrente de tunelamento, o que resulta no acréscimo de $\mathrm{d}_{\text {Simáx. }}$ 


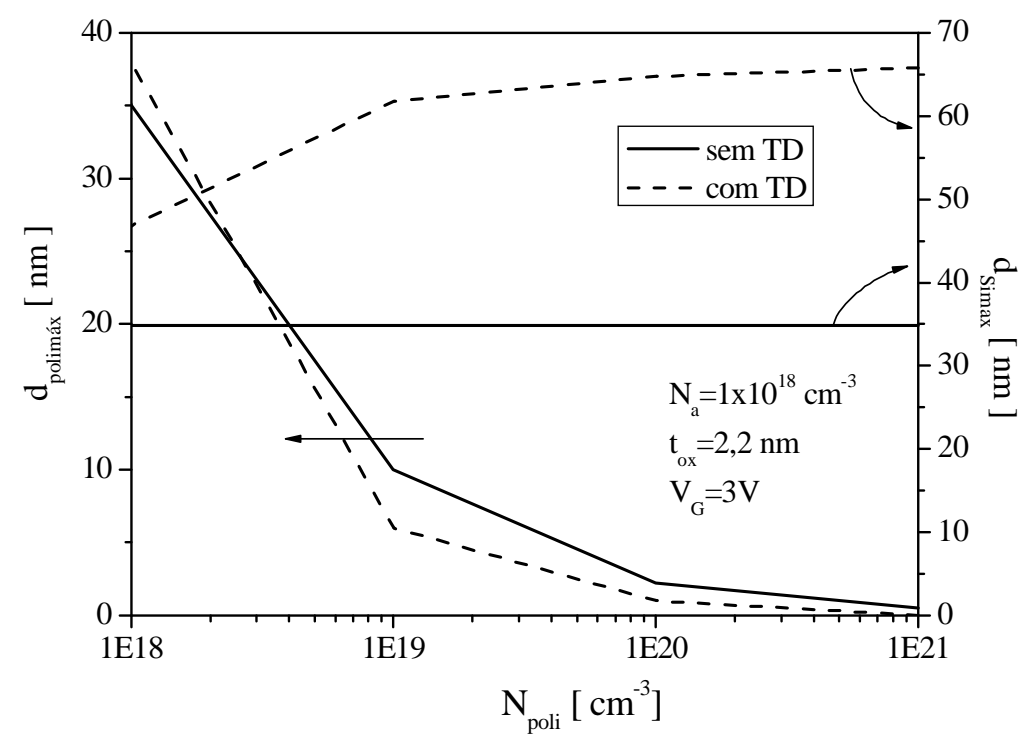

Figura 3.14 - Curvas da largura da região de depleção máxima no Si-poli ( $\left.\mathrm{d}_{\text {polimáx }}\right)$ e no silício $\left(\mathrm{d}_{\text {Simáx }}\right)$ em função da concentração de dopantes no Si-poli $\left(\mathrm{N}_{\text {poli }}\right)$ com e sem tunelamento TD.

Para se estudar a influência da espessura do óxido de porta em $\mathrm{d}_{\text {Simáx }}$, foram simulados perfis bidimensionais para capacitores MOS tipo $\mathrm{P}$ com $\mathrm{N}_{\mathrm{a}}=1 \times 10^{18} \mathrm{~cm}^{-3}, \mathrm{~V}_{\mathrm{G}}=3 \mathrm{~V}$, porta de Sipoli $\mathrm{N}+$ com diferentes concentrações e $\mathrm{t}_{\mathrm{ox}}=3,0 ; 2,2$ e 1,5 nm. Após extração das larguras da região de depleção, foi montado o gráfico de $\mathrm{d}_{\text {Simáx }}$ (máximo porque para $\mathrm{V}_{\mathrm{G}}=3 \mathrm{~V}$ considerouse que $d_{S i}$ atingiu seu máximo) em função de $\mathrm{N}_{\text {poli }}$, como mostra a Figura 3.15. Sem o efeito do tunelamento $\mathrm{d}_{\text {Simáx }}$ continua constante e no valor de $37 \mathrm{~nm}$ independente de $\mathrm{N}_{\text {poli. }}$. Mas quando inserido o modelo de $\mathrm{TD}, \mathrm{d}_{\text {Simáx }}$ apresenta um aumento e que é mais pronunciado para altas concentrações de dopantes no Si-poli e baixas espessuras do óxido.

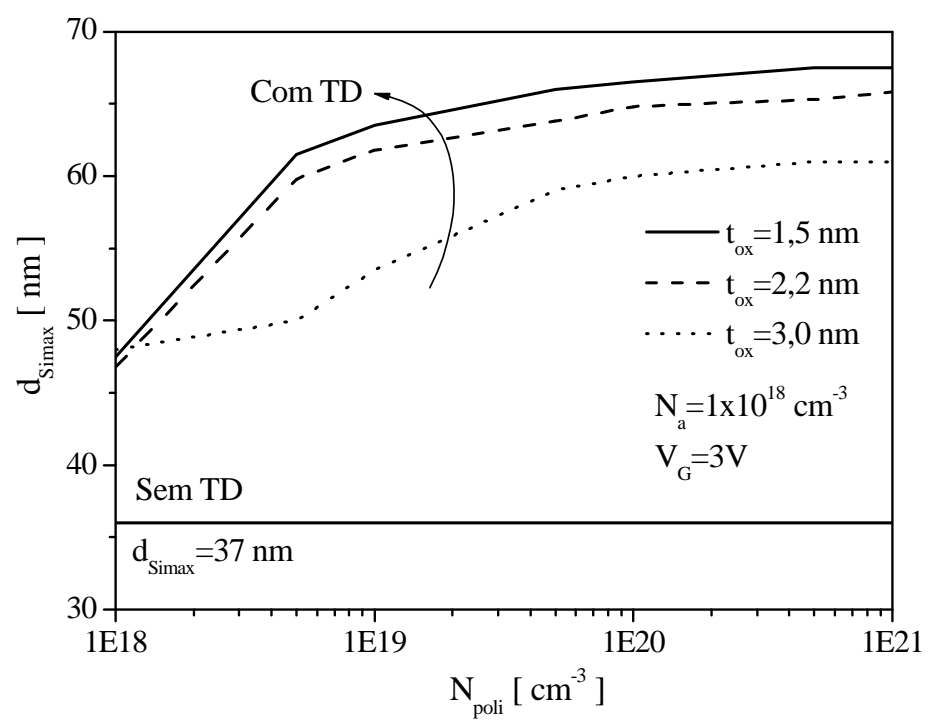

Figura 3.15 - Curvas da largura da região de depleção máxima no silício em função de $\mathrm{N}_{\text {poli, }}$, para diferentes espessuras de óxido de porta. 
$\mathrm{Na}$ Figura 3.16 são apresentadas as curvas $\mathrm{C}-\mathrm{V}$ simuladas de capacitores MOS tipo $\mathrm{P}$ com $\mathrm{N}_{\mathrm{a}}=1 \times 10^{18} \mathrm{~cm}^{-3}, \mathrm{t}_{\mathrm{ox}}=2,2 \mathrm{~nm}$, operando em alta freqüência, onde na curva (a) foi utilizado alumínio na porta (pois não há efeito de depleção no Si-poli), na curva (b) porta de Si-poli N+ com uma concentração de $\mathrm{N}_{\text {poli }}=1 \times 10^{19} \mathrm{~cm}^{-3}$, considerando a presença de depleção no Si-poli, e finalmente na curva (c) porta de Si-poli N+ com a mesma concentração da anterior, mas agora inserindo-se o modelo de tunelamento.

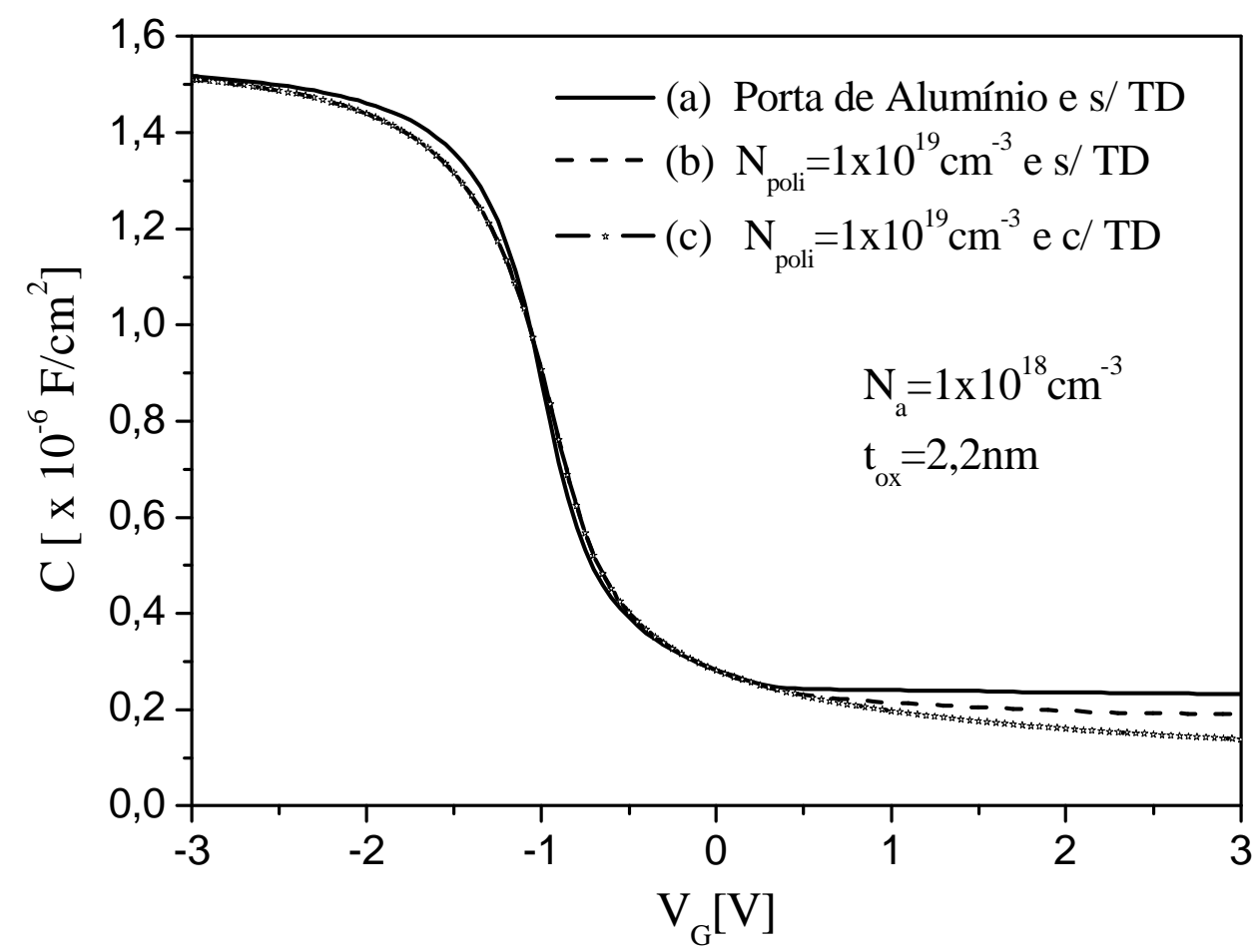

Figura 3.16 - Curvas C-V com (a) porta de alumínio, (b) porta Si-poli N+e (c) porta Si-poli $\mathrm{N}+$ e modelo de tunelamento, com $\mathrm{t}_{\mathrm{ox}}=2,2 \mathrm{~nm}, \mathrm{~N}_{\mathrm{a}}=1 \times 10^{18} \mathrm{~cm}^{-3}$ e alta freqüência de operação.

Ampliando-se a Figura 3.16 na região de inversão, tem-se a Figura 3.17, onde na curva (a) a capacitância mínima $\left(\mathrm{C}_{\min }\right)$ é expressa pela associação série de $\mathrm{C}_{\mathrm{ox}}$ e $\mathrm{C}_{\mathrm{Si}}$, e na curva (b) a baixa dopagem da porta acrescenta a capacitância do Si-poli $\left(\mathrm{C}_{\text {poli }}\right)$ a associação série, reduzindo $\mathrm{C}_{\min }$. $\mathrm{E}$ na curva (c) a capacitância mínima $\mathrm{C}_{\min }$ diminui mais ainda, aparentando ser devido ao acréscimo do efeito da corrente de tunelamento. A impressão que se tem é que o efeito da depleção do Si-poli e o efeito da corrente de tunelamento direto se somam. 


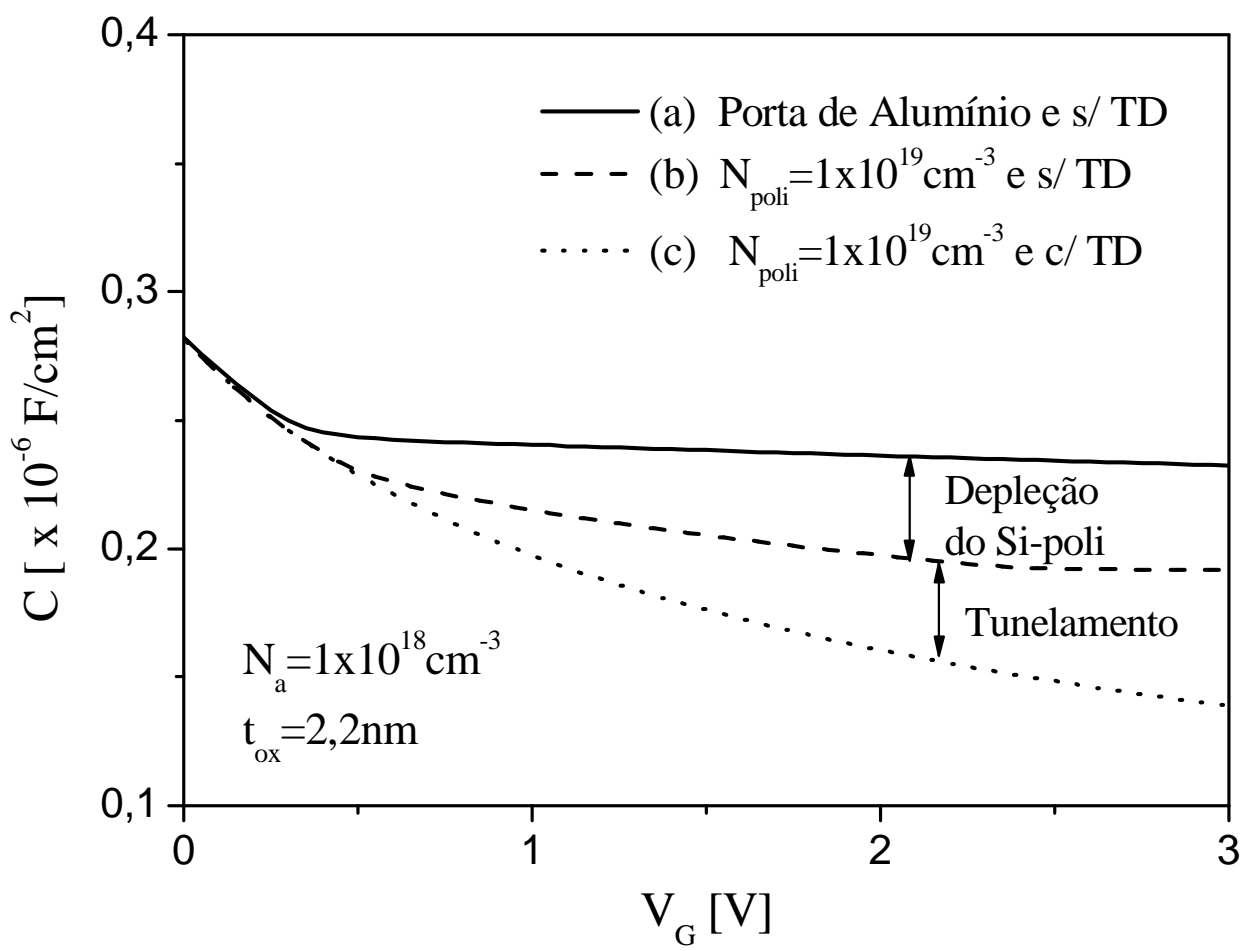

Figura 3.17 - Ampliação da curva C-V da Figura 3.16 na região de inversão.

Mas como foi analisado, as regiões de depleção do Si-poli e do silício são alteradas pela corrente de tunelamento direto, assim como $\mathrm{C}_{\text {poli }}$ e $\mathrm{C}_{\mathrm{Si}}$. Logo o menor valor de $\mathrm{C}_{\min } \mathrm{da}$ curva (c) visto na Figura 3.17, não pode ser dito que é o resultado da soma dos efeitos, pois $\mathrm{C}_{\text {poli }}$ aumenta e $\mathrm{C}_{\mathrm{Si}}$ diminui. Como $\mathrm{C}_{\mathrm{Si}}$ é muito menor que $\mathrm{C}_{\mathrm{poli}}$ e $\mathrm{C}_{\mathrm{ox}}$, pode-se concluir que a redução em $\mathrm{C}_{\min }$ de uma curva $\mathrm{C}-\mathrm{V}$ que sofre de ambos os efeitos, deve-se grande parte à diminuição de $\mathrm{C}_{\mathrm{Si}}$.

$\mathrm{Na}$ Figura 3.18 foram simuladas curvas $\mathrm{C}-\mathrm{V}$ de capacitores MOS tipo P, com $\mathrm{N}_{\mathrm{a}}=1 \times 10^{18} \mathrm{~cm}^{-3}, \mathrm{t}_{\mathrm{ox}}=2,2 \mathrm{~nm}$ e diferentes concentrações de dopantes do Si-poli $\left(\mathrm{N}_{\text {poli }}\right)$. Como pode ser observado, a mudança na concentração de dopantes no Si-poli quase não interfere em $\mathrm{C}_{\text {min }}$, apenas para $\mathrm{N}_{\text {poli }}$ muito baixo (próximo de $\mathrm{N}_{\mathrm{a}}$ ) onde $\mathrm{d}_{\text {poli }}$ é espesso e resulta em uma capacitância no Si-poli pequena capaz de interferir na associação série de capacitâncias. 


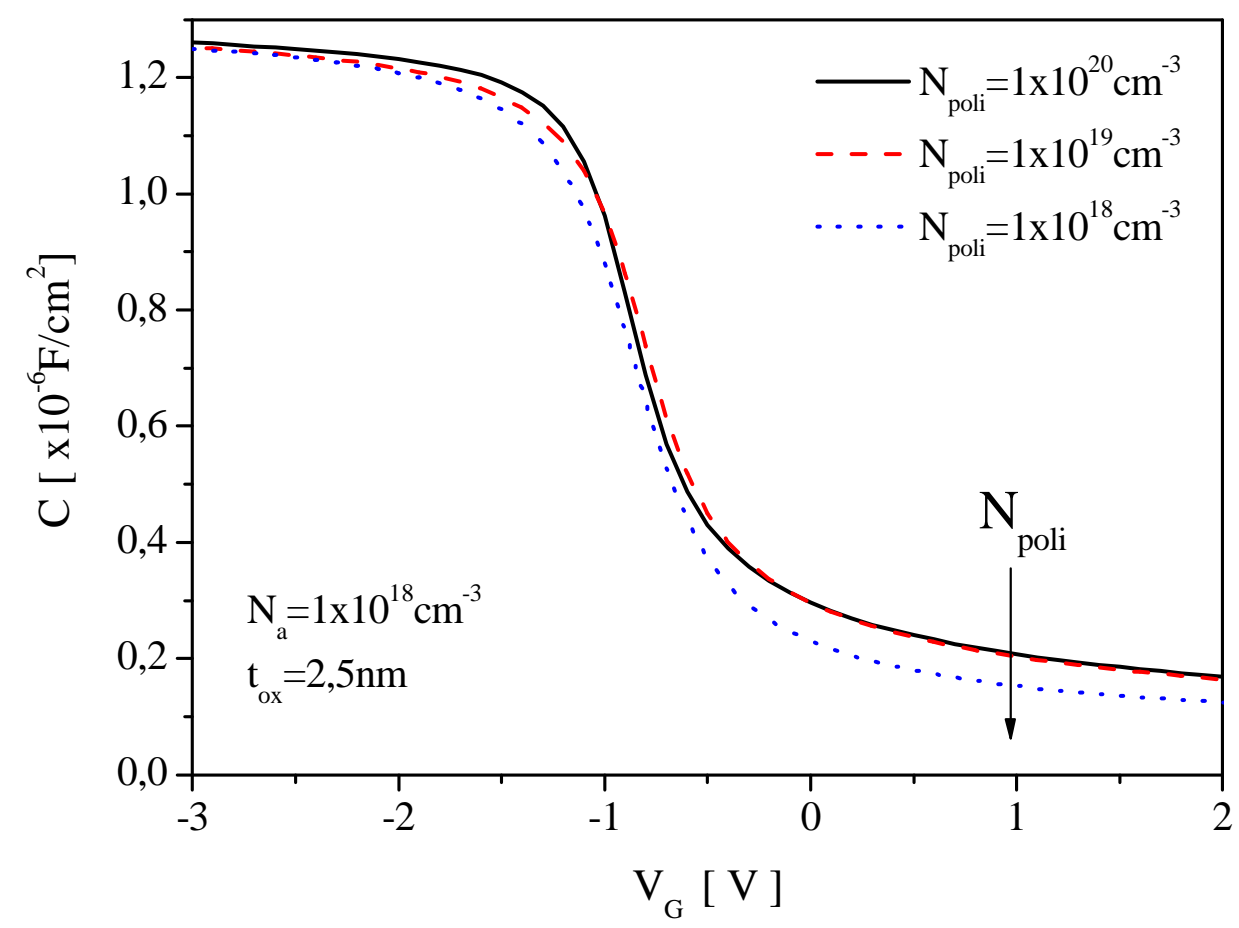

Figura 3.18 - Variação da curva C-V de alta freqüência, com a diminuição na concentração de dopantes do Si-poli N+e com a corrente de tunelamento.

A Figura 3.19 apresenta as curvas das capacitâncias presentes em uma estrutura

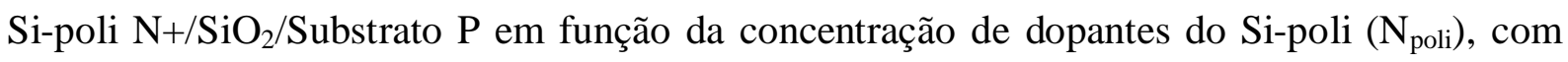
$\mathrm{Na}=1 \times 10^{18} \mathrm{~cm}^{-3}, \mathrm{t}_{\mathrm{ox}}=2,2 \mathrm{~nm}, \mathrm{~V}_{\mathrm{G}}=3 \mathrm{~V}$ e com tunelamento. Com as larguras das regiões de depleção extraídas dos perfis bidimensionais, foram calculadas as capacitâncias do Si-poli $\left(\mathrm{C}_{\text {poli }}\right)$ e do silício $\left(\mathrm{C}_{\mathrm{Si}}\right)$. A capacitância do óxido de porta $\left(\mathrm{C}_{\mathrm{ox}}\right)$ foi estimada para uma espessura de $t_{o x}=2,2 \mathrm{~nm}$, e a capacitância mínima foi calculada através da associação série das três capacitâncias $\left(\mathrm{C}_{\mathrm{poli}}, \mathrm{C}_{\mathrm{ox}}\right.$ e $\left.\mathrm{C}_{\mathrm{Si}}\right)$. Era esperado uma maior variação em $\mathrm{C}_{\min }$ conforme $\mathrm{N}_{\text {poli }}$ diminui-se. Mas como $\mathrm{C}_{\mathrm{Si}}$ é muito pequeno devido ao tunelamento, a capacitância mínima tenderá para a menor capacitância, independente da concentração de dopantes no Si-poli. 


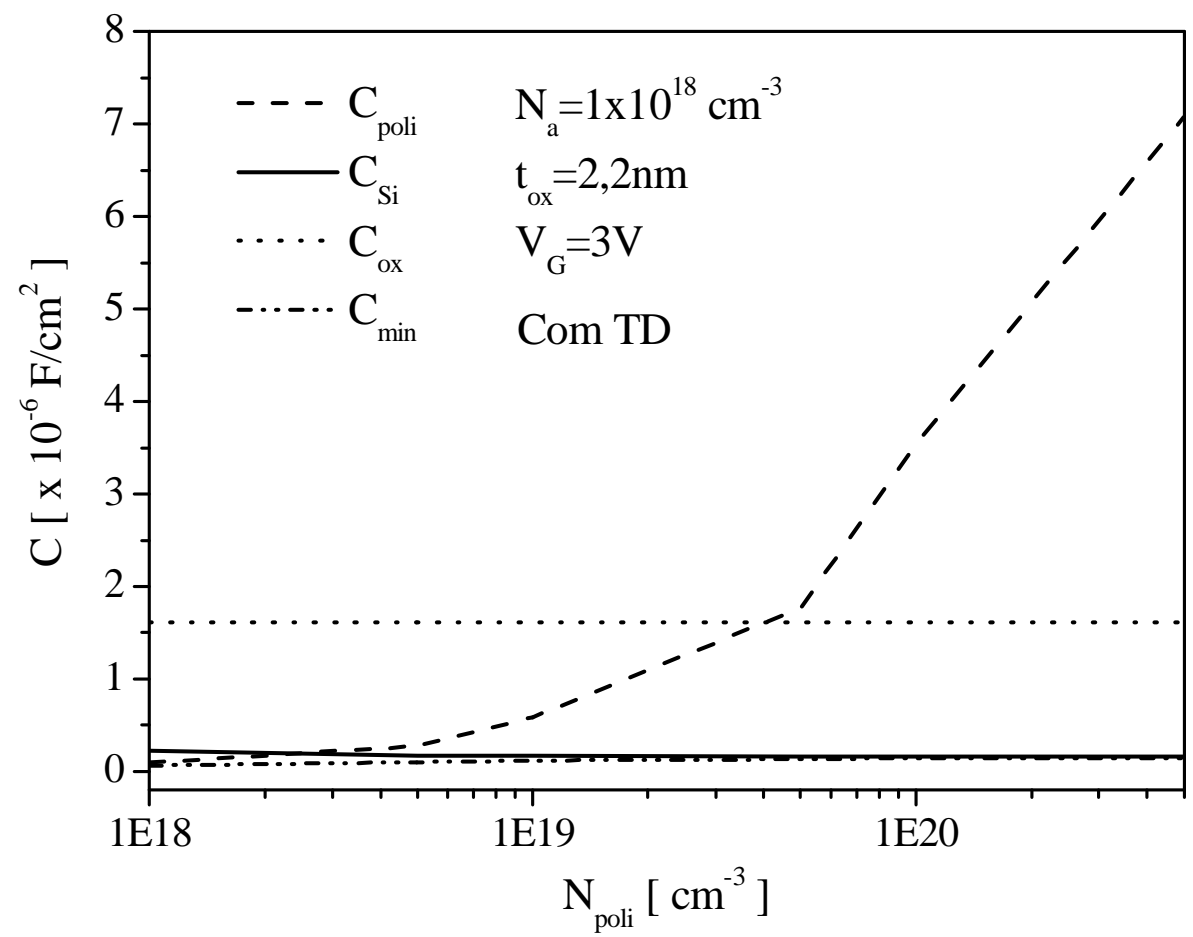

Figura 3.19 - Curvas das capacitância presentes em uma estrutura Si-poli N+/ $\mathrm{SiO}_{2} /$ Substrato $\mathrm{P}$ em função de $\mathrm{N}_{\text {poli }}$, sob o efeito da corrente de tunelamento direto.

A Figura 3.20 apresenta as curvas do potencial em função da profundidade para o mesmo dispositivo simulado acima e com $\mathrm{N}_{\text {poli }}=1 \times 10^{19} \mathrm{~cm}^{-3}$. Na Figura 3.20a foi utilizada uma tensão de $\mathrm{V}_{\mathrm{G}}=0,5 \mathrm{~V}$, e neste caso a região da porta inicia a depleção, e o substrato já encontra-se invertido. A uma tensão de $\mathrm{V}_{\mathrm{G}}=1,5$ (Figura 3.20b), o Si-poli está depletado, enquanto que no substrato uma deformidade é observada no nível de Fermi (devido ao tunelamento de portadores e conseqüente mudança da energia média de elétrons na região próxima a interface) e um subsequente aumento no potencial. Já quando a tensão alcança $\mathrm{V}_{\mathrm{G}}=3 \mathrm{~V}$, o Si-poli inicia a inversão e no substrato o aumento do potencial continua sendo observado (Figura 3.20c). Vale ressaltar que para $\mathrm{V}_{\mathrm{G}}=3 \mathrm{~V}$, a interface Si-poli/óxido já deveria estar invertida. Isso comprova que, a corrente de tunelamento ao reduzir $\mathrm{d}_{\text {poli }}$ atrasa a inversão do Si-poli, pois uma maior tensão é necessária. Como para as estruturas de agora uma menor tensão de polarização é requerida (para evitar o rompimento do dispositivo), pode ser que o Si-poli não venha a inverter. 


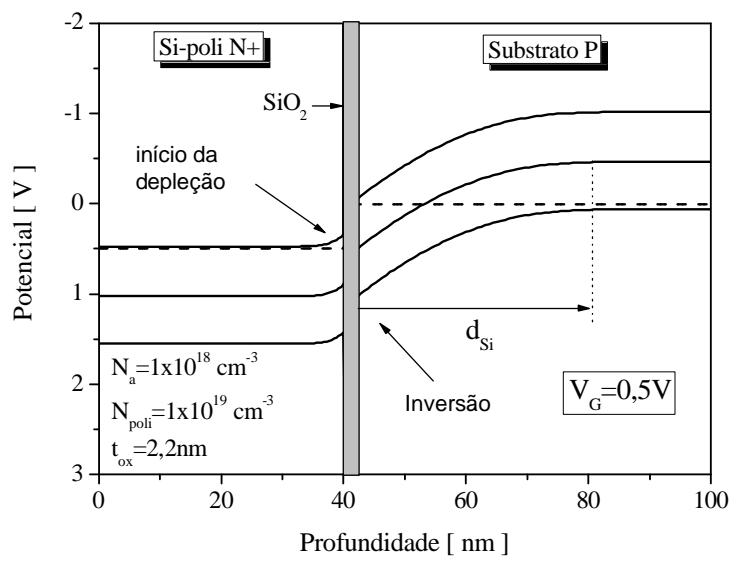

(a)

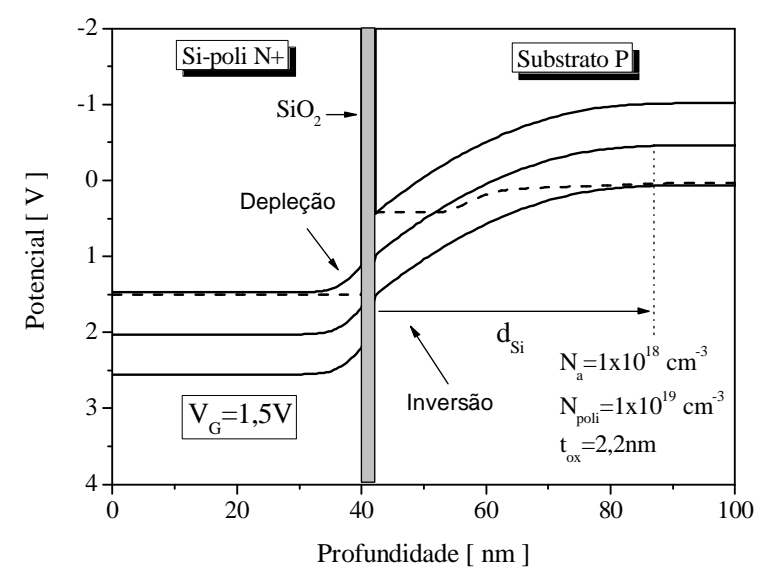

(b)

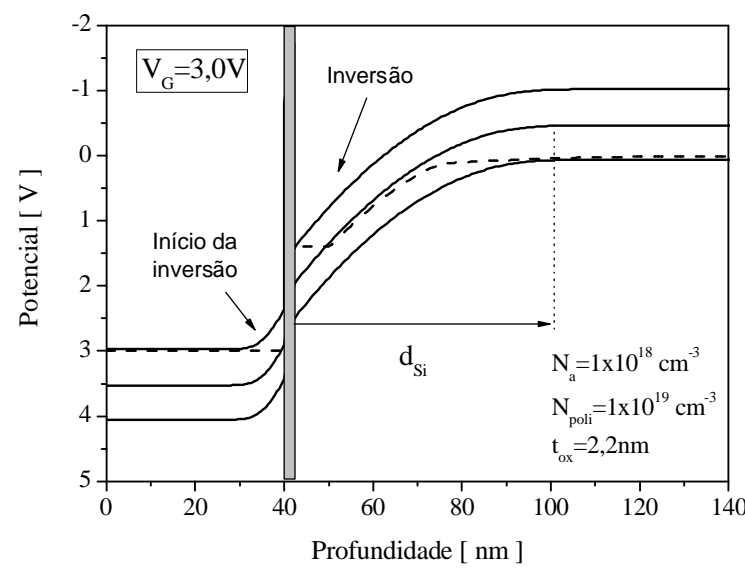

(c)

Figura 3.20 - Curvas do Potencial em função da profundidade, para uma estrutura Sipoli $\mathrm{N}+/ \mathrm{SiO} 2 /$ Substrato $\mathrm{P}$, com tensões de porta de (a) $\mathrm{V}_{\mathrm{G}}=0,5 \mathrm{~V}$, (b) $\mathrm{V}_{\mathrm{G}}=1,5 \mathrm{~V}$ e (c)

$$
\mathrm{V}_{\mathrm{G}}=3,0 \mathrm{~V} \text {. }
$$

Como foi dito, esta deformidade observada no Nível de Fermi $\left(\mathrm{E}_{\mathrm{F}}\right)$, causada pela ausência de portadores no substrato pela corrente de tunelamento, faz com que o potencial de superfície do silício aumente, mantendo-se assim a mesma condição de funcionamento. A Figura 3.21 mostra as curvas do potencial em função da profundidade, para um capacitor tipo P com as mesmas características da Figura 3.20. Observa-se que a curva com modelo de tunelamento direto (TD) apresenta um aumento de aproximadamente $0,4 \mathrm{~V}$ no potencial de superfície no silício $\left(\phi_{S}\right)$. 


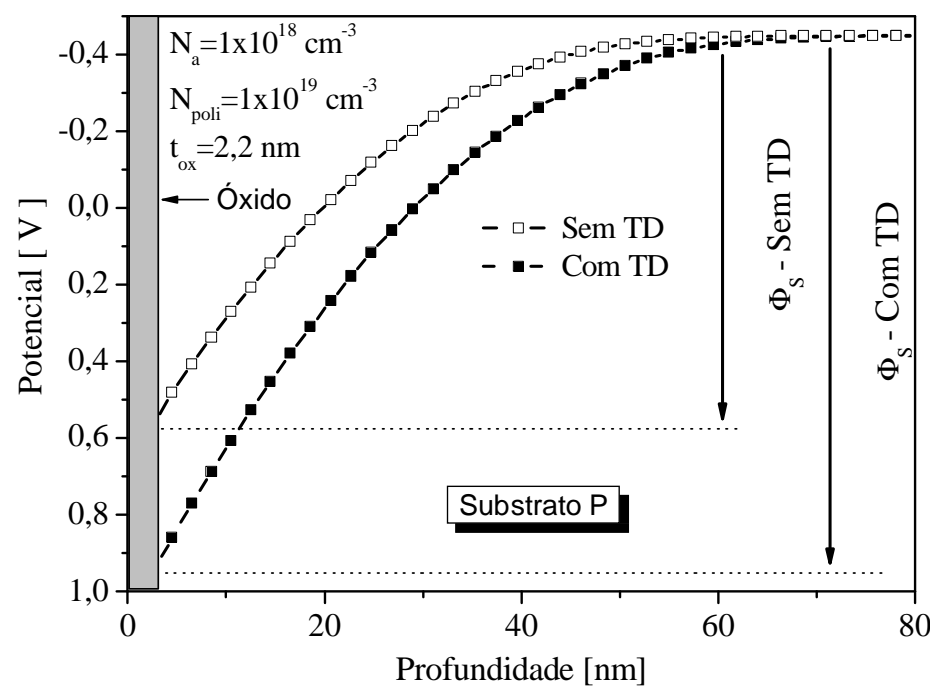

Figura 3.21 - Curva do Potencial em função da Profundidade, demonstrando a influência da corrente de tunelamento direto no potencial de superfície do silício $\left(\phi_{\mathrm{S}}\right)$.

Mas quando simulada uma curva $\mathrm{C}-\mathrm{V}$ de baixa freqüência o causador da queda na capacitância total na região de inversão deixa de ser a região de depleção no silício, e passa a ser a capacitância de inversão $\left(C_{\text {inv }}\right)$ que sofre uma redução. A Figura 3.22 mostra curvas $C-V$ operando em baixa frequiência para capacitores MOS tipo $P$, com $t_{o x}=2,2 n m, N_{a}=1 \times 10^{18} \mathrm{~cm}^{-3}$ e porta de Si-poli N+ com diferentes concentrações de dopantes.

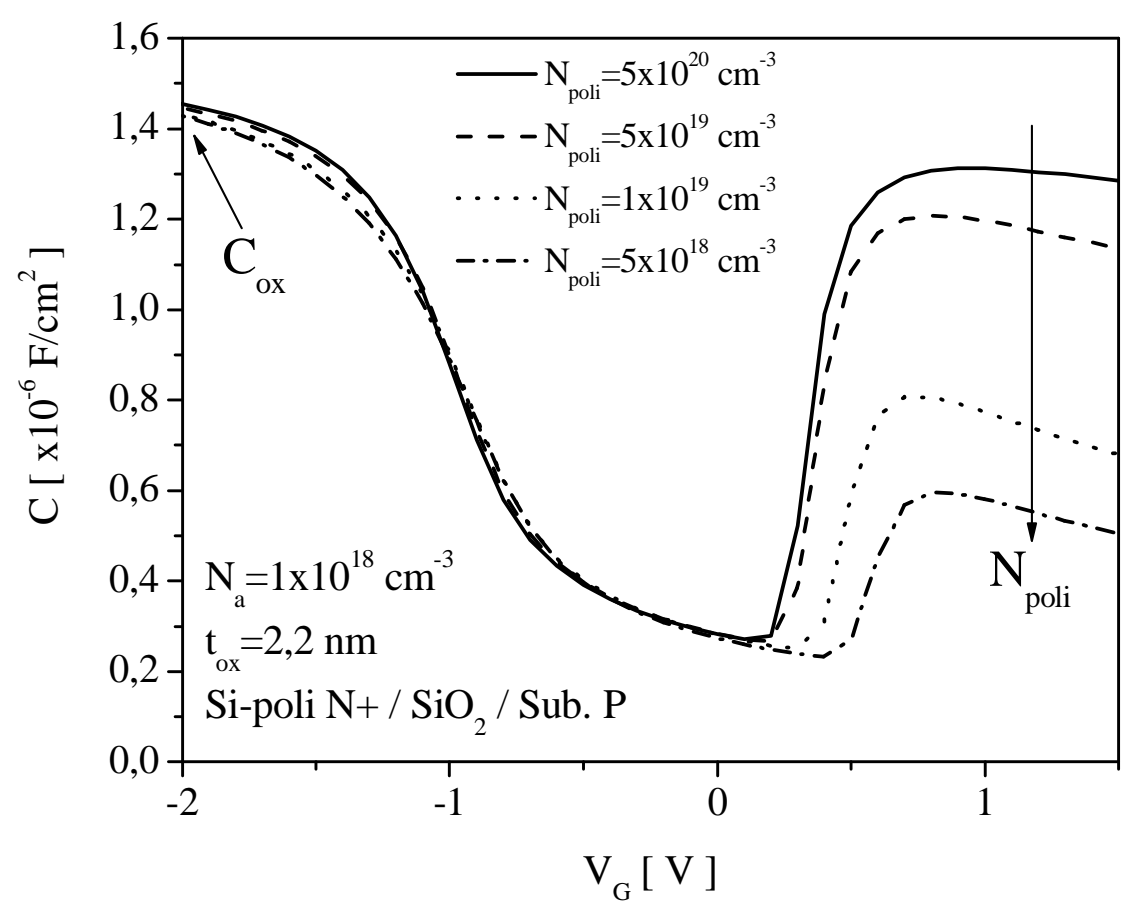

Figura 3.22 - Variação da curva C-V de baixa freqüência, com a diminuição na concentração de dopantes do Si-poli N+ e com a corrente de tunelamento. 


\section{PROPOSTA DE UM MÉTODO PARA EXTRAÇÃO DA CONCENTRAÇÃO EFETIVA DE DOPANTES DO SI-POLI $\left(\mathrm{N}_{\text {POLI }}\right)^{41}$}

Neste capítulo é apresentado um novo método para extração da concentração efetiva de dopantes do Si-poli $\left(\mathrm{N}_{\text {poli }}\right)$, desenvolvido através da curva característica $(\mathrm{C}-\mathrm{V})$ operando em alta freqüência, de um capacitor MOS. Simulações numéricas foram executadas para a avaliação da validade do método proposto, assim como medidas experimentais.

\subsection{Proposta do método}

Conforme abordado nos Capítulos 2 e 3, materiais de porta Si-poli com baixa dopagem, apresentam uma depleção na interface com o óxido de porta. Neste caso a curva $\mathrm{C}-\mathrm{V}$ operando em alta freqüência, apresenta uma redução na capacitância mínima $\left(\mathrm{C}_{\min }\right)$.

A Figura 4.1 apresenta a curva $\mathrm{C}-\mathrm{V}$ normalizada em função de $\mathrm{C}_{\mathrm{ox}}$ de uma estrutura Si-poli N+ / óxido / substrato P, operando em alta freqüência, com diferentes concentrações de dopantes no Si-poli.

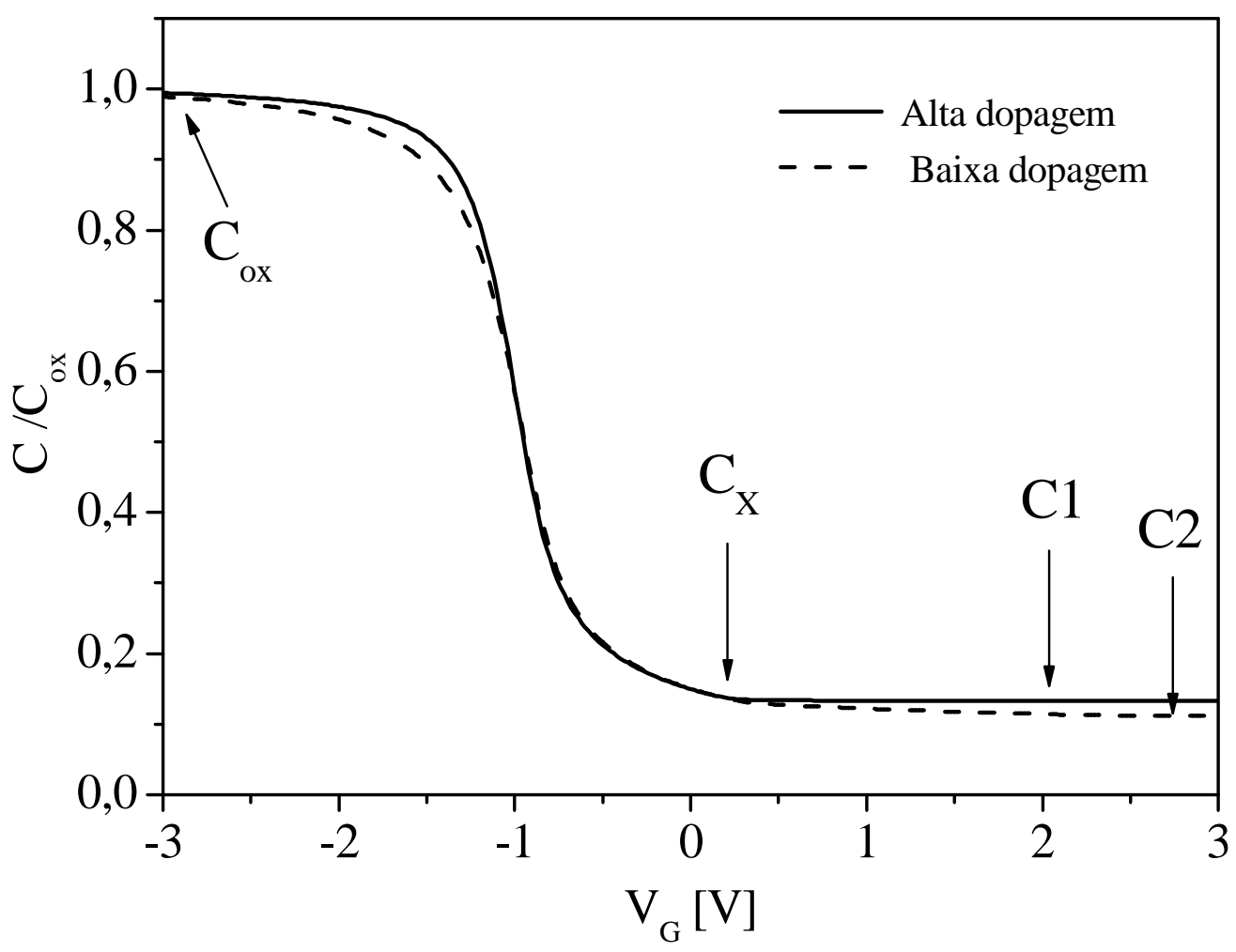

Figura 4.1 - Curva C-V normalizada em função de $\mathrm{C}_{\mathrm{ox}}$ de uma estrutura Si-poli N+ / óxido / substrato, operando em alta freqüência. 
Observa-se que as duas curvas tem um ponto em comum, chamado de $\mathrm{C}_{\mathrm{x}}$, e que corresponde a uma tensão aplicada na porta $\left(\mathrm{V}_{\mathrm{G}}\right)$ que dá início a depleção na região do Sipoli. Na curva com alta dopagem no Si-poli, a capacitância $\mathrm{C} 1$ é a associação série da capacitância do óxido de porta $\left(\mathrm{C}_{\mathrm{ox}}\right)$ com a capacitância do silício $\left(\mathrm{C}_{\mathrm{Si}}\right)$, e o efeito de depleção no Si-poli não é observado. A curva com baixa dopagem tem a capacitância C2 como sendo a associação série das capacitâncias do Si-poli $\left(\mathrm{C}_{\text {poli }}\right)$, do óxido de porta $\left(\mathrm{C}_{\mathrm{ox}}\right)$ e do silício $\left(\mathrm{C}_{\mathrm{Si}}\right)$, conforme é visto na Figura 4.2a.

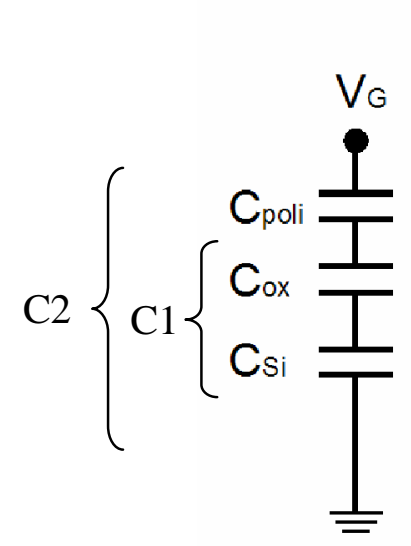

(a)

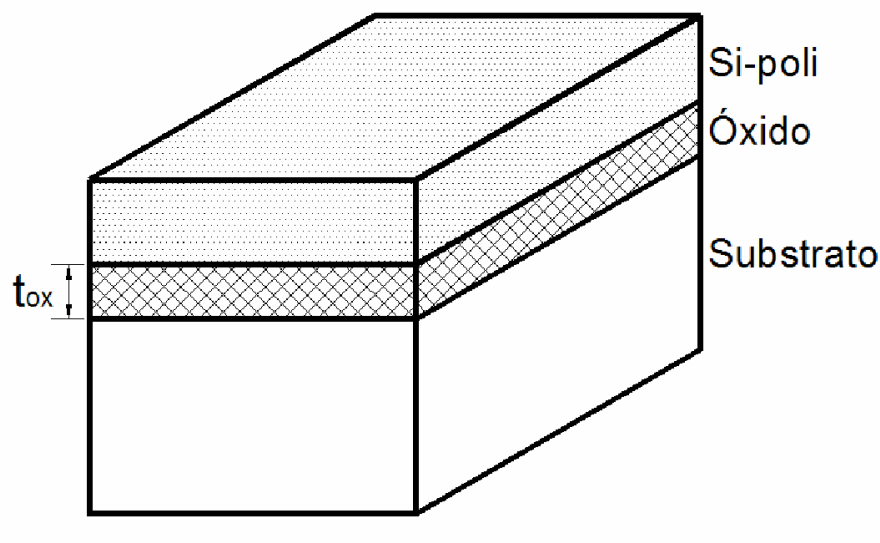

(b)

Figura 4.2 - (a) Modelo equivalente de capacitâncias e a representação de C1 e C2, e (b) o perfil de um capacitor MOS com porta de Si-poli.

$\mathrm{O}$ ponto $\mathrm{C}_{\mathrm{x}}$ pode ser considerando como sendo igual ao ponto $\mathrm{C} 1$, pois ambos são a associação série de $\mathrm{C}_{\mathrm{ox}}$ e $\mathrm{C}_{\mathrm{Si}}$. Da curva $\mathrm{C}-\mathrm{V}$ com alta dopagem no Si-poli, pode-se extrair $\mathrm{C}_{\mathrm{ox}}$ e $\mathrm{C} 1$, e utilizar no cálculo da capacitância máxima do silício $\left(\mathrm{C}_{\text {Simáx }}\right)$, como mostra a equação (14). Por consequiência a largura máxima da região de depleção no silício d $\mathrm{d}_{\text {Simáx }}$ pode ser calculada através da equação (15).

$$
\begin{gathered}
C_{\text {Simáx }}=\frac{C_{o x} C 1}{C_{o x}-C 1} \\
d_{\text {Simáx }}=\frac{\varepsilon_{S i}}{C_{\text {Simáx }}}
\end{gathered}
$$


Com a largura máxima da região de depleção $\left(\mathrm{d}_{\text {Simáx }}\right)$, a concentração efetiva de dopantes na região do silício $\left(\mathrm{N}_{\mathrm{a}}\right)$ é determinada iterativamente devido a equação ser transcendental, conforme equação (16).

$$
N_{a}=\frac{4 \varepsilon_{S i}}{q d_{\text {Simáx }}^{2}} \frac{k T}{q} \ln \frac{N_{a}}{n_{i}}
$$

sendo

$\mathrm{k}$ constante de Boltzmann

T temperatura

$\mathrm{n}_{\mathrm{i}}$ concentração intrínseca de portadores

Utilizando-se agora a curva com baixa dopagem no Si-poli, pode-se extrair o ponto C2, que juntamente com C1 extraído anteriormente, torna-se possível calcular a capacitância máxima do Si-poli $\left(\mathrm{C}_{\text {polimáx }}\right)$ e a largura máxima da região de depleção no Si-poli $\left(\mathrm{d}_{\text {polimáx }}\right)$, conforme as equações (17) e (18) respectivamente.

$$
\begin{gathered}
C_{p o \operatorname{limáx}}=\frac{C 1 C 2}{C 1-C 2} \\
d_{p o \lim a x}=\frac{\varepsilon_{S i}}{C_{p o l i}}
\end{gathered}
$$

Com $\mathrm{d}_{\text {polimáx }}$ e de maneira análoga, a concentração de dopantes do Si-poli $\left(\mathrm{N}_{\text {poli }}\right)$ também pode ser calcula iterativamente, através da equação (19).

$$
N_{p o l i}=\frac{4 \varepsilon_{S i}}{q d_{p o l i m a x}{ }^{2}} \frac{k T}{q} \ln \frac{N_{p o l i}}{n_{i}}
$$

Como não é possível obter experimentalmente uma curva $\mathrm{C}-\mathrm{V}$ com e sem depleção no Si-poli, o ponto $\mathrm{C} 1$ foi extraído da segunda derivada da curva $\mathrm{C}-\mathrm{V}\left(\delta C^{2} / \delta V_{G}{ }^{2}\right)$ através de um ponto máximo presente na região de inversão, conforme Figura 4.3. O ponto $\mathrm{V}_{\mathrm{Gx}}$ representa a tensão de porta que inicia a depleção no Si-poli. Considera-se também que a influência da 
corrente de tunelamento para extração de C2 é desprezível e que nesta condição o Si-poli já atingiu sua depleção máxima.

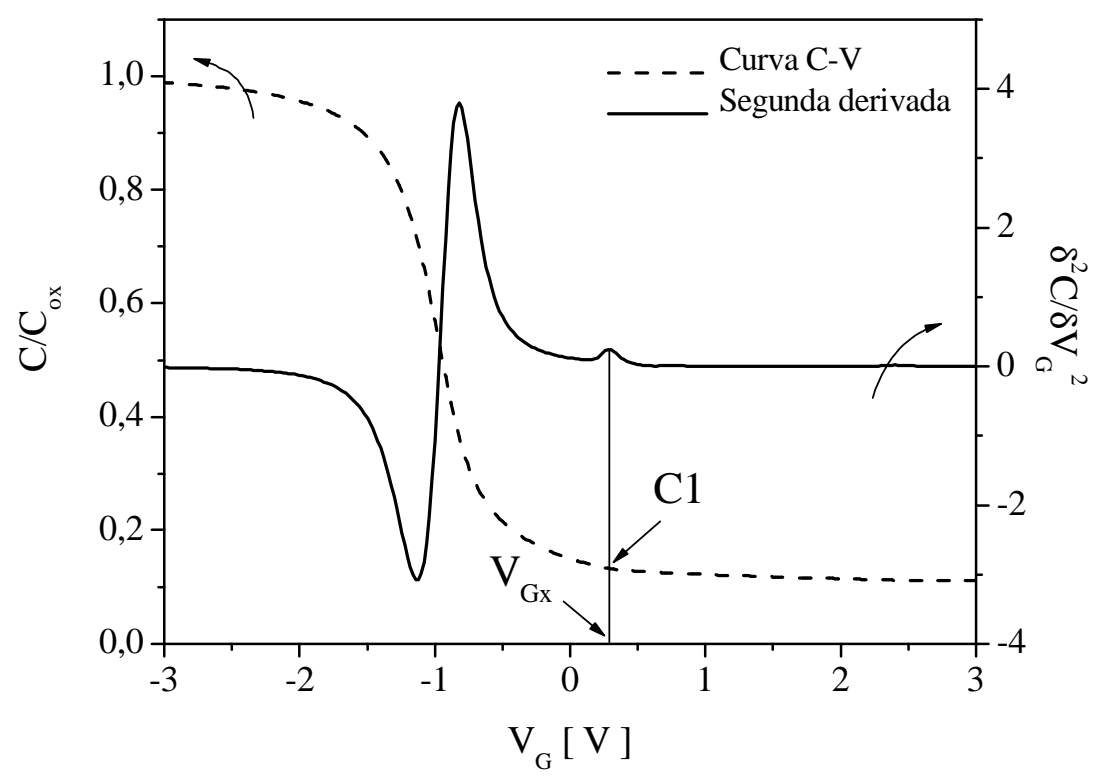

Figura 4.3 - Curva C-V normalizada em função de $\mathrm{C}_{\mathrm{ox}}$ e a respectiva segunda derivada de um capacitor MOS com porta de Si-poli N+.

A Figura 4.4 ilustra o digrama de blocos para determinação de $\mathrm{N}_{\mathrm{a}}$ e $\mathrm{N}_{\text {poli. }}$.

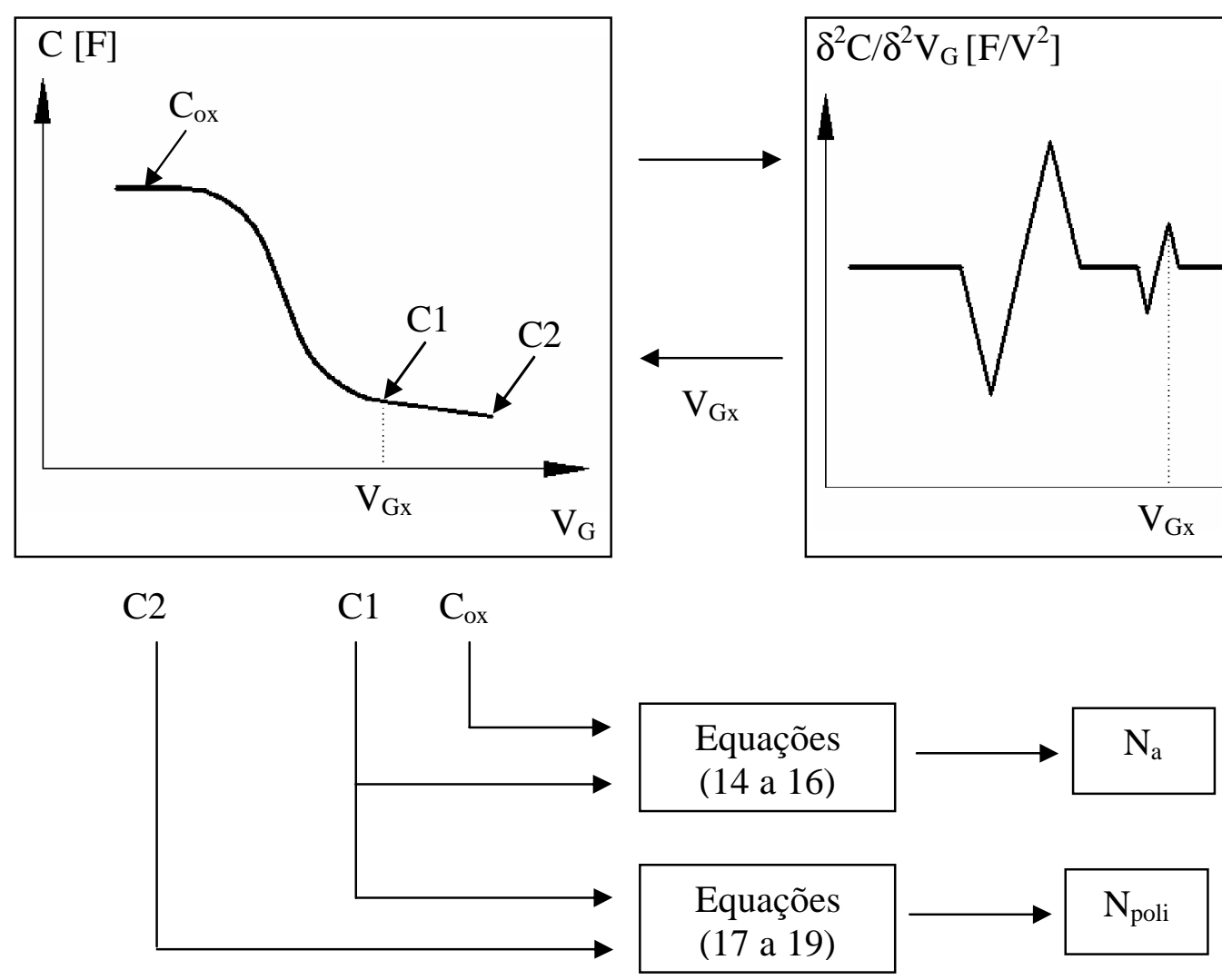

Figura 4.4 - Diagrama de blocos para determinação de $\mathrm{N}_{\mathrm{a}}$ e $\mathrm{N}_{\text {poli. }}$. 


\subsection{Simulação numérica}

Após a proposta do método de extração de $\mathrm{N}_{\mathrm{a}}$ e $\mathrm{N}_{\text {poli }}$, procedeu-se à simulação de curvas $\mathrm{C}-\mathrm{V}$ com o auxílio do simulador bidimensional MEDICI, a fim de se verificar a confiabilidade do método.

Foram simuladas curvas $\mathrm{C}-\mathrm{V}$ em alta freqüência $(1 \mathrm{MHz})$, de capacitores MOS convencionais com substrato $\mathrm{P}, \mathrm{t}_{\mathrm{ox}}=2,5 \mathrm{~nm}, 150 \mathrm{~nm}$ de espessura do substrato de silício $\left(\mathrm{t}_{\mathrm{Si}}\right), 40$ $\mathrm{nm}$ de espessura de Si-poli $\left(\mathrm{t}_{\text {poli }}\right), 1 \mu \mathrm{m}$ de comprimento e largura, diferentes concentrações de dopantes do Si-poli $\left(\mathrm{N}_{\text {poli }}=1 \times 10^{19}\right.$ e $\left.5 \times 10^{19} \mathrm{~cm}^{-3}\right)$ e diferentes concentrações de dopantes do substrato $\left(\mathrm{N}_{\mathrm{a}}=5 \times 10^{17}\right.$ e $\left.1 \times 10^{18} \mathrm{~cm}^{-3}\right)$.

Através das curvas C-V e suas respectivas derivadas, foram extraídas as capacitâncias $\mathrm{C}_{\mathrm{ox}}, \mathrm{C} 1$ e C2 e aplicado o método. A Tabela 4.1 apresenta uma comparação dos resultados de $\mathrm{N}_{\mathrm{a}}$ e $\mathrm{N}_{\text {poli }}$ obtidos pelo método proposto com os valores utilizados na simulação. A Tabela 4.2 mostra o erro percentual máximo encontrado na extração de $\mathrm{N}_{\mathrm{a}}$ e $\mathrm{N}_{\text {poli }}$ com o método proposto em função dos valores simulados.

Tabela 4.1 - Valores de C1, C2 e $\mathrm{C}_{\mathrm{ox}}$ extraídos das simulações e os valores de $\mathrm{N}_{\mathrm{a}}$ e $\mathrm{N}_{\text {poli }}$ determinados pelo método proposto.

\begin{tabular}{ccccccc}
\hline \multicolumn{2}{c}{ Simulados } & \multicolumn{3}{c}{$\begin{array}{c}\text { Resultados extraídos } \\
\text { da curva C-V }\end{array}$} & \multicolumn{2}{c}{ Método proposto } \\
\hline $\begin{array}{c}\mathrm{N}_{\mathrm{a}} \\
{\left[\mathrm{cm}^{-3}\right]}\end{array}$ & $\begin{array}{c}\mathrm{N}_{\mathrm{poli}} \\
{\left[\mathrm{Cm}^{-3}\right]}\end{array}$ & $\begin{array}{c}\mathrm{C} 1 \\
{\left[\mathrm{~F} / \mathrm{cm}^{2}\right]}\end{array}$ & $\begin{array}{c}\mathrm{C} 2 \\
{\left[\mathrm{~F} / \mathrm{cm}^{2}\right]}\end{array}$ & $\begin{array}{c}\mathrm{C}_{\mathrm{ox}} \\
{\left[\mathrm{F} / \mathrm{cm}^{2}\right]}\end{array}$ & $\begin{array}{c}\mathrm{N}_{\mathrm{a}} \\
{\left[\mathrm{cm}^{-3}\right]}\end{array}$ & $\begin{array}{c}\mathrm{N}_{\text {poli }} \\
{\left[\mathrm{cm}^{-3}\right]}\end{array}$ \\
\hline & $1 \times 10^{19}$ & $1,79 \times 10^{-7}$ & $1,50 \times 10^{-7}$ & $1,35 \times 10^{-6}$ & $4,65 \times 10^{17}$ & $1,13 \times 10^{19}$ \\
$5 \times 10^{17}$ & & & & & & \\
& $5 \times 10^{19}$ & $1,86 \times 10^{-7}$ & $1,69 \times 10^{-6}$ & $1,36 \times 10^{-6}$ & $5,06 \times 10^{17}$ & $4,79 \times 10^{19}$ \\
\hline & $1 \times 10^{19}$ & $2,29 \times 10^{-7}$ & $1,88 \times 10^{-7}$ & $1,35 \times 10^{-6}$ & $0,85 \times 10^{18}$ & $1,44 \times 10^{19}$ \\
$1 \times 10^{18}$ & & & & & & \\
& $5 \times 10^{19}$ & $2,45 \times 10^{-6}$ & $2,18 \times 10^{-7}$ & $1,36 \times 10^{-6}$ & $1,01 \times 10^{18}$ & $5,60 \times 10^{19}$ \\
\hline
\end{tabular}


Tabela 4.2 - Erro percentual máximo na extração de $\mathrm{N}_{\mathrm{a}}$ e $\mathrm{N}_{\text {poli. }}$.

\begin{tabular}{cccc}
\hline \multicolumn{2}{c}{ Parâmetros simulados } & $\begin{array}{c}\mathbf{N}_{\mathbf{a}} \\
{[\%]}\end{array}$ & $\begin{array}{c}\mathbf{N}_{\text {poli }} \\
{[\%]}\end{array}$ \\
\cline { 1 - 2 } $\mathrm{N}_{\mathrm{a}}\left[\mathrm{cm}^{-3}\right]$ & $\mathrm{N}_{\text {poli }}\left[\mathrm{cm}^{-3}\right]$ & 7 & 13 \\
$5 \times 10^{17}$ & $1 \times 10^{19}$ & 1,2 & 4,2 \\
\hline $1 \times 10^{18}$ & $5 \times 10^{19}$ & 15 & 44 \\
& $5 \times 10^{19}$ & 1 & 12 \\
\hline
\end{tabular}

Em todas as curvas simuladas, a capacitância C2 foi extraída para um tensão de porta de $\mathrm{V}_{\mathrm{G}}=3 \mathrm{~V}$, pois foi considerado que a região da interface Si-poli/óxido já estaria invertida. Com o intuito de se verificar este dado, foram simuladas curvas do potencial em função da profundidade para um capacitor com substrato tipo $\mathrm{P}$, porta de Si-poli $\mathrm{N}+, \mathrm{t}_{\mathrm{ox}}=2,5 \mathrm{~nm}$, $\mathrm{N}_{\mathrm{a}}=1 \times 10^{18} \mathrm{~cm}^{-3}, \mathrm{~N}_{\text {poli }}=1 \times 10^{19} \mathrm{~cm}^{-3}$ e com diferentes tensões de polarização. Na Figura 4.5a foi utilizada a tensão $\mathrm{V}_{\mathrm{Gx}}$ extraída da segunda derivada da curva $\mathrm{C}-\mathrm{V}$, onde neste caso confirmase que a região do Si-poli iniciou a depleção. A Figura $4.5 b$ foi simulada para $V_{G}=3 V$, e nota-

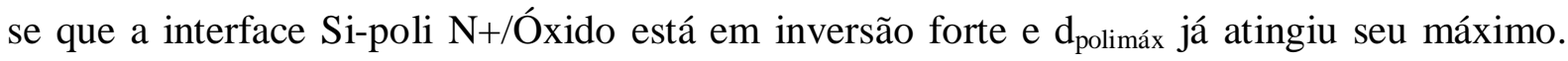
Pode-se dizer então que no ponto $\mathrm{C} 2$ a associação série de capacitâncias é dada por $\mathrm{C}_{\mathrm{poli}}, \mathrm{C}_{\mathrm{ox}} \mathrm{e}$ $\mathrm{C}_{\mathrm{Si}}$.

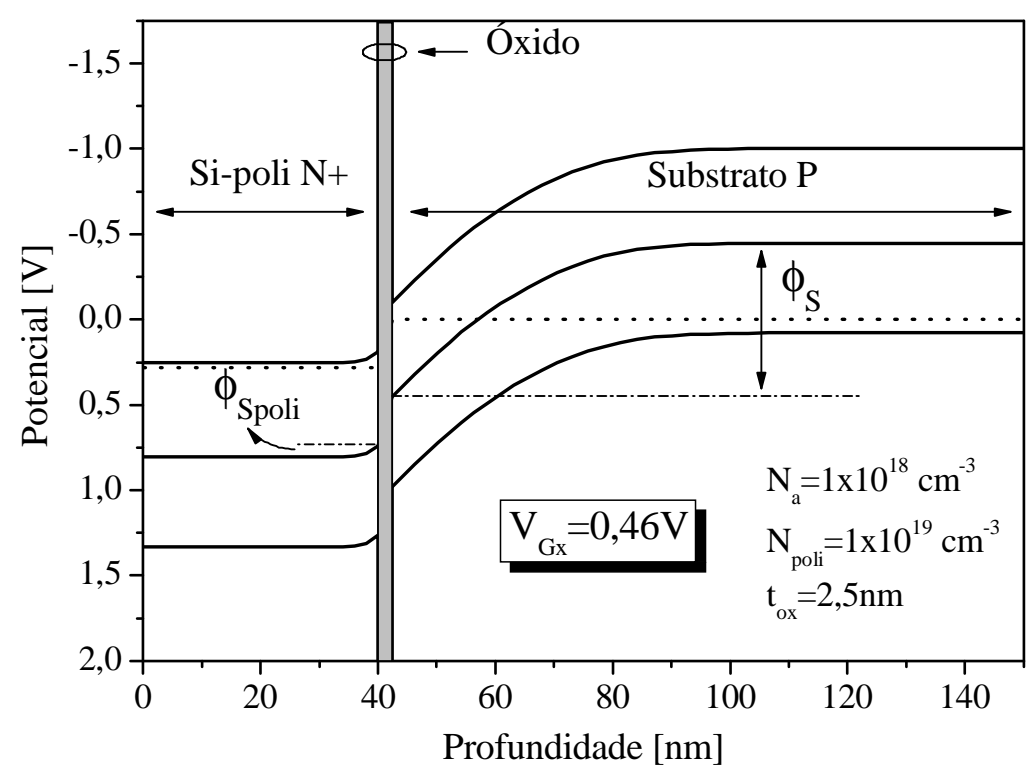

(a) 


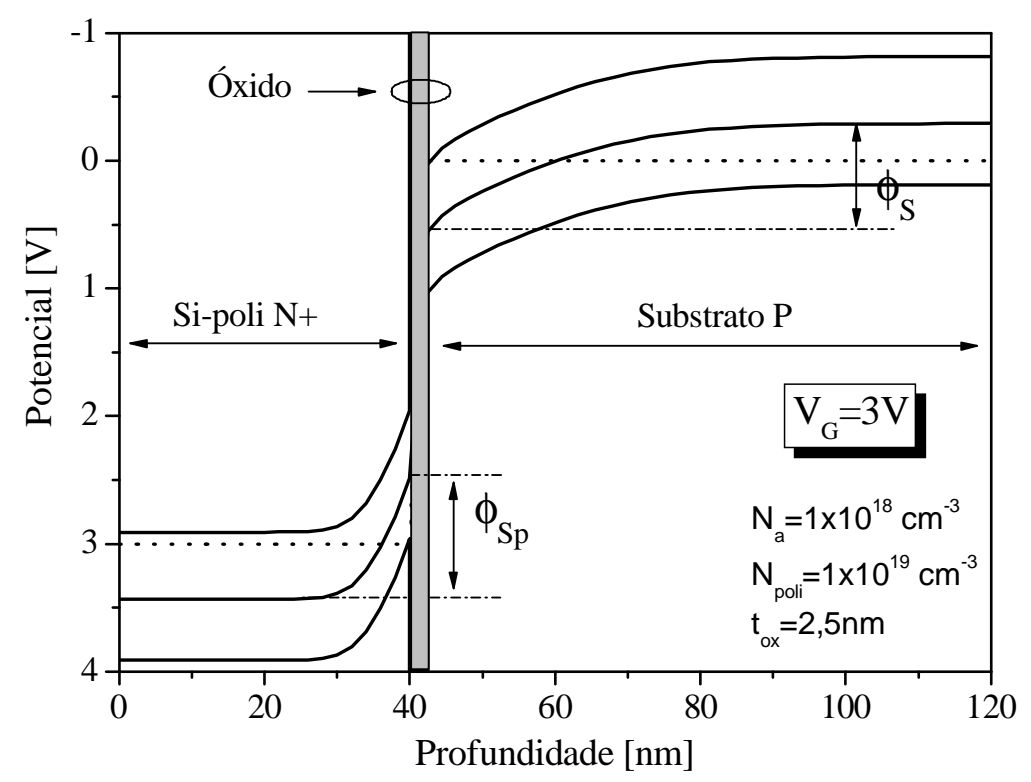

(b)

Figura 4.5 Curvas simuladas do potencial em função da profundidade, onde para (a) $\mathrm{V}_{\mathrm{G}}=\mathrm{V}_{\mathrm{Gx}}=0,46 \mathrm{~V}$ e para (b) $\mathrm{V}_{\mathrm{G}}=3 \mathrm{~V}$.

Das curvas do potencial em função da profundidade, foram extraídos os valores do potencial de superfície no silício $\left(\phi_{\mathrm{S}}\right)$ e no $\mathrm{Si}$-poli $\left(\phi_{\mathrm{Sp}}\right)$, e do nível de Fermi no silício $\left(\phi_{\mathrm{F}}\right)$ e no Si-poli ( $\phi_{\mathrm{Fpoli}}$ ), para uma tensão de porta $\mathrm{V}_{\mathrm{Gx}}$, e para os mesmos dispositivos da Tabela 4.1, e estão apresentados na Tabela 4.3. Pode-se observar que para uma tensão aplicada à porta igual $\mathrm{V}_{\mathrm{Gx}}$, o potencial de superfície no silício $\left(\phi_{\mathrm{S}}\right)$ está por volta de $2 \phi_{\mathrm{F}}$, demonstrando o início da inversão. Já o potencial de superfície no Si-poli $\left(\phi_{\mathrm{Sp}}\right)$ está iniciando a depleção.

Tabela 4.3 - Comparação entre os potenciais de superfície no silício e no Si-poli, para diferentes valores de $\mathrm{N}_{\mathrm{a}}$ e $\mathrm{N}_{\text {poli }}$.

\begin{tabular}{ccccccccc}
\hline \multicolumn{2}{c}{ Simulada } & \multicolumn{2}{c}{ C-V } & \multicolumn{2}{c}{ óxido/substrato } & \multicolumn{3}{c}{ Si-poli /óxido } \\
\hline $\begin{array}{c}\mathrm{N}_{\mathrm{a}} \\
{\left[\mathrm{cm}^{-3}\right]}\end{array}$ & $\begin{array}{c}\mathrm{N}_{\mathrm{poli}} \\
{\left[\mathrm{cm}^{-3}\right]}\end{array}$ & $\begin{array}{c}\mathrm{V}_{\mathrm{Gx}} \\
{[\mathrm{V}]}\end{array}$ & $\begin{array}{c}\phi_{\mathrm{F}} \\
{[\mathrm{V}]}\end{array}$ & $\begin{array}{c}\phi_{\mathrm{S}} \\
{[\mathrm{V}]}\end{array}$ & $\phi_{\mathrm{S}} / \phi_{\mathrm{F}}$ & $\begin{array}{c}\phi_{\mathrm{Fpoli}} \\
{[\mathrm{V}]}\end{array}$ & $\begin{array}{c}\phi_{\mathrm{Sp}} \\
{[\mathrm{V}]}\end{array}$ & $\begin{array}{c}\phi_{\mathrm{Sp}} / \\
\phi_{\mathrm{Fpoli}}\end{array}$ \\
\hline $5 \times 10^{17}$ & $1 \times 10^{19}$ & 0,28 & 0,45 & 0,90 & 2,01 & 0,53 & 0,07 & 0,13 \\
& $5 \times 10^{19}$ & 0,20 & 0,45 & 0,91 & 2,02 & 0,55 & 0,02 & 0,04 \\
\hline \multirow{2}{*}{$1 \times 10^{18}$} & $1 \times 10^{19}$ & 0,46 & 0,47 & 0,93 & 1,99 & 0,53 & 0,12 & 0,22 \\
& $5 \times 10^{19}$ & 0,34 & 0,47 & 0,94 & 2,01 & 0,57 & 0,02 & 0,04 \\
\hline
\end{tabular}




\subsection{Resultados experimentais}

Para obtenção das curvas C-V foi utilizado um analisador de parâmetros LCR HP4280 com uma freqüência de $1 \mathrm{MHz}$, onde o substrato foi aterrado. Um degrau lento foi aplicado para a polarização estática (DC) do capacitor MOS e um sinal alternado de alta frequiência e baixa amplitude de $10 \mathrm{mV}$, para se extrair a capacitância diferencial da estrutura nas diversas condições de polarização (acumulação, depleção e inversão). A medida foi realizada da inversão para a acumulação e em ambiente escuro.

As medidas foram realizadas em capacitores com substrato $\mathrm{P}$ e porta de Si-poli $\mathrm{N}+$, área de $A=12 \times 10^{-6} \mathrm{~cm}^{2}$, espessura equivalente do óxido de porta de EOT=2,5 $\mathrm{nm}$, uma concentração pelicular na interface do substrato com o óxido de porta de $1 \times 10^{18} \mathrm{~cm}^{-3}$ e no corpo de $5 \times 10^{17} \mathrm{~cm}^{-3}$, aproximadamente.

Da curva experimental foi obtida a capacitância do óxido de porta $C_{o x}=1,34 \times 10^{-6}$ $\mathrm{F} / \mathrm{cm}^{2}$ e uma capacitância mínima $\mathrm{C} 2=0,21 \times 10^{-6} \mathrm{~F} / \mathrm{cm}^{2}$. A partir da segunda derivada da mesma foi extraída a tensão $V_{\mathrm{Gx}}=0,50 \mathrm{~V}$ e sua referente capacitância $\mathrm{C} 1=0,24 \times 10^{-6} \mathrm{~F} / \mathrm{cm}^{2}$, conforme mostra a Figura 4.6.

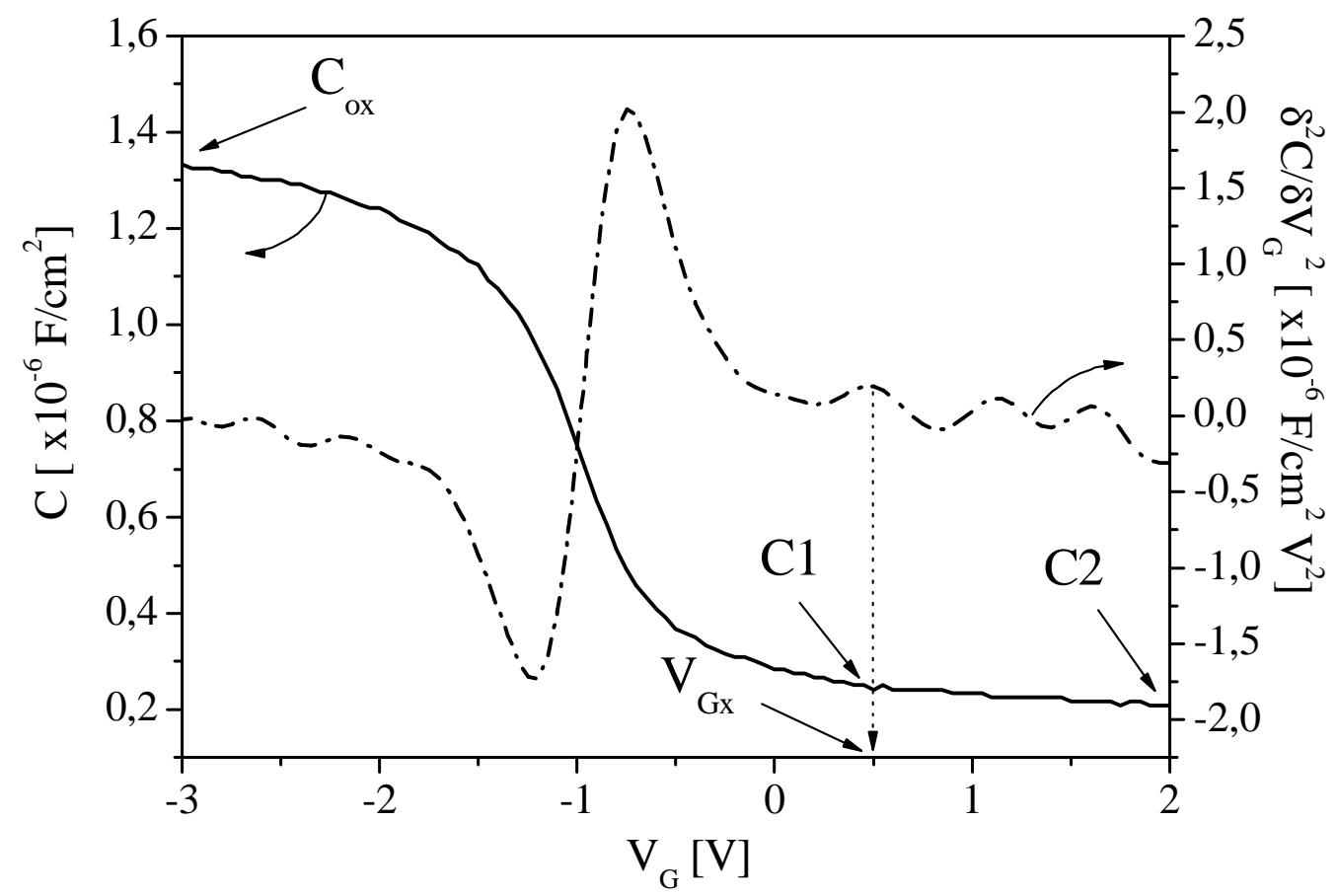

Figura 4.6 - Curva C-V experimental e sua respectiva segunda derivada. 
Aplicando-se o método proposto obteve-se uma espessura equivalente no óxido de porta de EOT=2,57 nm, uma concentração de dopantes no silício $\mathrm{N}_{\mathrm{a}}=0,98 \times 10^{18} \mathrm{~cm}^{-3}$ e uma concentração de dopantes no Si-poli $\mathrm{N}_{\text {poli }}=3,06 \times 10^{19} \mathrm{~cm}^{-3}$. Com o objetivo de diminuir o ruído, a curva experimental passou por um filtro FFT (Fast Fourier Transform) e nenhuma mudança no valor da tensão $\mathrm{V}_{\mathrm{Gx}}$ foi observada, apenas na amplitude do pico. Todos os resultados obtidos estão coerentes para esta tecnologia.

\subsubsection{Limites do método}

Sabe-se que quando a espessura do óxido de porta diminui, a corrente de tunelamento passa a interferir nas características dos dispositivos. Foi analisado no Capítulo 3, que a capacitância degrada não só pela depleção do Si-poli (diminuindo a capacitância na região de inversão), mas também pela corrente de tunelamento (onde uma maior diminuição foi observada). Contudo, para óxidos menores que 2,5nm o método proposto acima não pode ser aplicado por dois motivos que estão descritos abaixo:

1. Quando inserido o modelo da corrente de tunelamento direto o pico máximo na região de inversão, extraído da segunda derivada da curva $\mathrm{C}-\mathrm{V}$, desaparece. Acredita-se que como o tunelamento faz a capacitância mínima $\left(\mathrm{C}_{\min }\right)$ não apresentar uma estagnação na sua queda, a estimativa do início da região de depleção no Si-poli torna-se inadequada.

2. A capacitância C2 utilizada no método, e que representa a associação série de $\mathrm{C}_{\text {poli, }}$, $\mathrm{C}_{\mathrm{ox}}$ e $\mathrm{C}_{\mathrm{Si}}$, agora deveria contar com a capacitância de inversão no silício $\mathrm{C}_{\mathrm{inv}}$, pois sabe-se que o tunelamento interfere nas cargas de inversão. Logo a obtenção da capacitância $\mathrm{C}_{\text {poli }}$ estaria inadequada. 


\section{CONCLUSÃO}

Neste trabalho apresentou-se um estudo da influência dos efeitos da depleção no Silício policristalino (Si-poli) e da corrente de tunelamento em capacitores obtidos através de tecnologia ultra-submicrométrica, com o auxílio de curvas características da capacitância em função da tensão de porta $(\mathrm{C}-\mathrm{V})$.

A análise destes efeitos foi realizada através de simulações numéricas bidimensionais, utilizando o programa MEDICI, uma vez que a realização de medidas experimentais mostrouse bastante complicada em dispositivos com óxido fino. Além disso, o simulador possibilita a simulação isolada de cada um destes efeitos.

Com o intuito de verificar o efeito da depleção no Si-poli nas características elétricas dos capacitores MOS foram realizadas, inicialmente, simulações numéricas das curvas $\mathrm{C}-\mathrm{V}$ de estruturas com substrato tipo $\mathrm{P}$ e porta de Si-poli com dopagens $\mathrm{P}+\mathrm{e} \mathrm{N}+$. A partir dos resultados obtidos, observou-se que a capacitância total na região de inversão, tanto para curvas de alta como de baixa freqüência, sofre uma redução à medida que a concentração do Si-poli diminui. A degradação verificada na curva C-V impossibilita a aplicação de métodos convencionais para a extração de parâmetros da tecnologia, como por exemplo, a concentração de dopantes no substrato.

Utilizando-se os resultados das simulações, foram obtidos gráficos do potencial e da concentração de portadores em função da profundidade, a fim de demonstrar a ocorrência da depleção na interface Si-poli/óxido. A análise destes gráficos permitiu observar que, caso a tensão de porta seja suficientemente alta, a região do Si-poli pode atingir a inversão. Neste caso, a curva $\mathrm{C}-\mathrm{V}$ de baixa freqüência voltou a apresentar seu aspecto normal sem degradação, pois a capacitância de inversão tende ao infinito e torna-se desprezível na associação série de capacitâncias.

Após esta primeira análise, foi estudada a influência da corrente de tunelamento, presente em óxidos finos, nas curvas C-V. Para este estudo, foram realizadas simulações numéricas bidimensionais de estruturas com óxido de porta menores que $3 \mathrm{~nm}$, tornando necessária a inclusão do modelo de tunelamento direto nas simulações. Inicialmente foram simulados capacitores MOS com porta de alumínio, com o objetivo de se analisar o efeito de tunelamento independentemente da depleção que pode ocorrer quando o Si-poli é utilizado como material de porta.

Através das simulações realizadas, foram obtidos perfis bidimensionais da estrutura, a partir dos quais extraiu-se a largura da região de depleção no silício. Com os resultados 
obtidos, foi verificada a influência da corrente de tunelamento direto na largura da região de depleção no silício, a qual aumenta, ao invés de estabilizar em um único valor, à medida que a tensão de porta aumenta. Notou-se também que este aumento é mais pronunciado para óxidos de porta menores, nos quais a corrente de tunelamento é maior. Foram ainda simuladas curvas da densidade de corrente de tunelamento em função da tensão de porta, onde pôde ser observado que ocorre um aumento da corrente nos capacitores com óxidos de porta mais finos e com tensões de porta maiores.

Foram simuladas também curvas da capacitância em função da tensão de porta operando em alta e baixa freqüências. As curvas obtidas em alta freqüência apresentaram uma redução na capacitância mínima, na região de inversão. Tal fato deve-se à redução da capacitância do silício, provocada pelo aumento na largura de depleção no silício. Por outro lado, para as curvas de baixa freqüência esta queda da capacitância (na região de inversão) também foi observada, mas deve-se agora ao fato de que as cargas de inversão sofrerem uma redução pela corrente de tunelamento. Logo a capacitância de inversão $\left(\mathrm{C}_{\text {inv }}\right)$ deixa de ser desprezada na associação série de capacitâncias e a capacitância total sofre uma redução. Estas deformidades geradas pela corrente de tunelamento nas curvas $\mathrm{C}-\mathrm{V}$, dificultam seu uso na extração de parâmetros.

Após a análise dos dois efeitos isoladamente, foram realizadas simulações considerando tanto a depleção do Si-poli quanto a existência da corrente de tunelamento. Foi observado que, para altas concentrações de dopantes no Si-poli, há uma maior densidade de corrente de tunelamento à medida que a tensão de porta aumenta. Neste caso, a região de depleção no Si-poli é muito fina, e quase toda a tensão de porta sobrecai no óxido de porta.

Como mencionado anteriormente, verificou-se o aumento na largura da região de depleção no silício; entretanto, considerando-se os dois efeitos, uma redução na largura da região de depleção no Si-poli também foi vista, decorrente do excesso de portadores que tunelam do substrato para a porta. Novamente foram utilizados perfis bidimensionais para extração das larguras das região de depleção, tanto no silício como no Si-poli. Foi observado que, conforme a concentração de dopantes do Si-poli se aproxima da concentração de dopantes do silício, a largura da região de depleção no Si-poli passa a aumentar. Foi ainda verificado que óxidos de porta finos apresentam maior variação na largura da região de depleção do silício com o aumento da concentração de dopantes no Si-poli.

Curvas C-V de alta frequiência foram novamente simuladas, e uma maior redução na capacitância mínima foi observada. Foi verificado que a concentração de dopantes no Si-poli 
praticamente não interfere na queda da capacitância mínima, sendo a capacitância do silício a maior responsável por esta redução pois, como a largura da região de depleção no silício aumenta muito, a capacitância do silício torna-se muito pequena e predominante na capacitância mínima. Também foram simuladas curvas $\mathrm{C}-\mathrm{V}$ de baixa freqüência, nas quais tornou-se mais notório o fato de que a depleção do Si-poli não tem influência significativa nas curvas da capacitância quando o efeito da corrente de tunelamento também está presente, pois há uma sobreposição de efeitos.

Finalmente, o estudo realizado sobre o comportamento das curvas C-V de capacitores MOS, sob influência do efeito de depleção no Si-poli, possibilitou a elaboração de um novo método de extração da concentração de dopantes no substrato $\left(\mathrm{N}_{\mathrm{a}}\right)$ e no Si-poli $\left(\mathrm{N}_{\text {poli }}\right)$, uma vez que os métodos conhecidos para a extração destes parâmetros é impossibilitado pela presença dos efeitos estudados. O método proposto baseia-se na extração de alguns pontos notáveis da curva $\mathrm{C}-\mathrm{V}$ e de sua segunda derivada.

Simulações numéricas bidimensionais foram realizadas para validação do método proposto. Os resultados obtidos através do método proposto foram comparados ao valores de concentração simulados, sendo que o erro máximo obtido na determinação da concentração de dopantes do substrato $\left(\mathrm{N}_{\mathrm{a}}\right)$ e do Si-poli $\left(\mathrm{N}_{\text {poli }}\right)$ foi de $15 \%$ e $44 \%$, respectivamente. Tais erros devem-se às imprecisões típicas das extrações das capacitâncias que são utilizadas no método.

O método proposto também foi aplicado à curvas obtidas experimentalmente, e os resultados obtidos foram: espessura equivalente do óxido de porta (EOT) de 2,57 nm, $\mathrm{N}_{\mathrm{a}}=0,98 \times 10^{18} \mathrm{~cm}^{-3}$ e $\mathrm{N}_{\text {poli }}=3,06 \times 10^{19} \mathrm{~cm}^{-3}$, sendo estes valores coerentes para a tecnologia analisada.

Uma das principais vantagens do método proposto é sua simplicidade de aplicação e a obtenção de importantes parâmetros da tecnologia MOS. Contudo, o método mostrou-se ineficiente para a extração da espessura de óxido de porta muito finos, uma vez que a presença da corrente de tunelamento mascara o valor real da concentração de dopantes no Sipoli. 


\section{REFERÊNCIAS}

1 MOORE'S LAW MADE REAL BY INNOVATION. Produced by Intel Corporation. Disponível em: <http://www.intel.com/technology/silicon/mooreslaw/>. Acesso em: 29 maio 2006.

2 INTEL SILICON INNOVATION FUELING NEW SOLUTIONS FOR THE DIGITAL PLANET. Produced by Intel Corporation. Disponível em: <ftp://download.intel.com/technology/silicon/mooreslaw/download/silicon_brochure_05.pdf> .Acesso em: 29 maio 2006.

3 CHAU, R.; DOYLE, B.; DOCZY, M.; DATTA, S.; HARELAND, S.; JIN, B.; KAVALIEROS, J.; METZ, M. Silicon nano-transistors and breaking the $10 \mathrm{~nm}$ physical gate length barrier. Device Research Conference, p.123-126, 2003.

4 THOMPSON, S.; PACKAN, P.; BOHR, M. MOS Scaling: Transistor challenges for the $21^{\text {st }}$ century. Intel Technology Journal, v.2, n.3, 1998.

5 GHIBAUDO, G.; CLERC, R.; VINCENT, E.; BRUYÈRE, S.; AUTRAN, J.L. Gate dielectrics for ultimate CMOS technologies - Limitations and alternative solutions. ComptesRendus de l'Académie des Sciences Paris, v.1, n.7, p.911-927, 2000.

6 STREETMAN, B. G. Solid States Eletronic devices. 4.ed. Ed. New Jersey: Prentice Hall, 2000 .

7 TEIXEIRA, R. C.; DOI, I.; ZAKIA, M. B.; SWART, J. W.; DINIZ, J. A. Deposition and characterization of LPCVD Polycrystalline Silicon. Proceedings of COBEM, v.19, p.62-70, 2001

8 LIOU, J. J.; SHIREEN, R.; ORTIZ-CONDE, A.; SÁNCHEZ, F. J. G.; CERDEIRA, A.; GAO, X. Influence of polysilicon-gate depletion on the subthreshold behavior of submicron MOSFETs. Microelectronics Reliability, v.42, n.3, p.343-347, 2002.

9 LU, C. Y.; SUNG, J. M.; KIRSCH, H. C.; HILLENIUS, S. J.; SMITH, T. E.; MANCHANDA, L. Anomalous C-V characteristics of implanted poly MOS structure in n+/p+ dual-gate CMOS technology. IEEE Electron Device Letters, v.10, n.5, p.192-194, 1989. 
10 HABAS, P.; FARICELLI, J. V. Investigation of the physical modeling of the gatedepletion effect. IEEE Transactions on Electron Devices, v.38, n.6, p.1496-1500, 1992.

11 YARON, G.; FROHMAN-BENTCHKOWSKY, D. Capacitance voltage characterization of poly $\mathrm{Si}_{-} \mathrm{SiO}_{2}$-Si structures. Solid-State Electronics, v.23, n.5, p.433-439, 1980.

12 ARORA, N. D.; RIOS, R.; HUANG, C. L. Modeling the polysilicon depletion effect and its impact on submicrometer CMOS circuit performance. IEEE Transactions on Electron Devices, v.42, n.5, p.935-943, 1995.

13 HUANG, C. L.; ARORA, N. D. Measurements and modeling of MOSFET I-V characteristics with polysilicon depletion effect. IEEE Transactions on Electron Devices, v.40, n.12, p.2330-2337, 1993.

14 RIOS, R.; ARORA, N. D.; HUANG, C. L. An analytic polysilicon depletion effect model for MOSFET's. IEEE Electron Device Letters, v.15, n.4, p.129-131, 1994.

15 LO, S.-H; BUCHANAN, D. A.; TAUR, Y. Modeling and characterization, of quantization, polysilicon depletion and direct tunneling effects in MOSFETs with ultrathin oxides. IBM Journal of Research and Development, v.43, n.3, p.327-337, 1999.

16 LARCHER, L.; PAVAN, P.; PELLIZZER, F.; GHIDINI, G. A new model of gate capacitance as a simple tool to extract MOS parameters. IEEE Transactions on Electron Devices, v.48, n.5, p.935-945, 2001.

17 ClERC, R.; DEVOIVRE, T.; GHIBAUDO, C; CAILlAT, C; GUÉGAN, G; REIMBOLD, G.; PANANAKAKIS, G. Capacitance-Voltage (C-V) characterization of 20thick gate oxide: parameter extraction and modeling. Microelectronics Reliability, v.40, n. $4-5$, p.571-575, 2000.

18 HABAS, P.; SELBERHERR, S. On the effect of non-degenerate doping of polysilicon gate in thin oxide MOS-devices - analytical modeling. Solid-State Electronics, v.33, n.12, p.1539-1544, 1990. 
19 CHOI, CHANG-HOON; CHIDAMBARAM, P.R.; KHAMANKAR, R.; MACHALA, C. F.; ZHIPING YU; Dutton, R.W. Gate length dependent polysilicon depletion effects. IEEE Electron Device Letters, v.23 n.4 p.224-226, 2002.

20 HUANG, C. L.; ARORA, N. D.; NASR, A. I.; BELL, D. A. Effect of polysilicon depletion on MOSFET I-V characteristics. IEEE Electronics Letters, v.29, n.13, p.1208-1209, 1993.

21 XUAN, P.; BOKOR, J. Investigation of NiSi and TiSi as CMOS gate materials. IEEE Electron Device Letters, v.24, n.10, p.634-636, 2003.

22 SHIMADA, H.; HIRANO, Y.; USHIKI, T.; OHMI, T. Threshold voltage adjustment in SOI MOSFETs by employing tantalum for gate material. International Electron Devices Meeting, p.881-884, 1995.

23 LU, Q.; LIN, R.; RANADE, P.; YEO, Y. C.; MENG, X.; TAKEUCHI, H.; KING, T.-J.; HU, C.; LUAN, H.; LEE, S.; BAI, W.; LEE, C.-H.; KWONG, D.-L.; GUO, X.; WANG, X.; MA, T.-P. Molybdenum metal gate MOS technology for post- $\mathrm{SiO}_{2}$ gate dielectrics. Technical Digest of the IEDM, p.641-644, 2000.

24 NORDHEIM, L. Zur Theorie der thermischen Emission und der Reflexion von Elektronen an Metallen. Zeits. für Phys, v.46, n.11-12 p. 833-855, 1928.

25 ESAKI, L.; TSU, R. Superlattice and negative differential conductivity in semiconductors. IBM Journal of Research and Development, v.14, n.4, p.61-65, 1970.

26 LARCHER, L.; PACCAGNELLA, A.; GHIDINI, G. Gate current in ultrathin MOS capacitors: A new model of tunnel current. IEEE Transactions on Electron Devices, v.48, n.2, p.271-278, 2001.

27 DEPAS, M.; VERMEIRE, B.; MERTENS, P. W.; VAN MEIRHAEGHE, R. L.; HEYNS, M. M. Determination of tunnelling parameters in ultra-thin oxide layer poly-Si/SiO$/ 2 / S i$ structures. Solid-State Electronics, v.38, n.8, p.1465-1471, 1995. 
28 GUPTA, M.; WOO, J. Device design for sub 90nm MOSFET's for sample and hold circuits. Proceeding of the 34th European Solid-State Device Research Conference, p.377380, 2004.

29 VASILESKA, D.; SCHRODER, D. K.; FERRY, D. K. Scaled silicon MOSFET's: Degradation of the total gate capacitance. IEEE Transactions on Electron Devices, v.44, n.4, p.584-587, 1997.

30 TAKAGI, S.; TORIUMI, A. Quantitative undestanding of inversion-layer capacitance in Si MOSFETS's. IEEE Transactions on Electron Devices, v.42, n.12, p.2125-2130, 1995.

31 HARTSTEIN, A.; ALBERT, N. F. Determination of the inversion-layer thickness from capacitance measurements of metal-oxide-semiconductor field-effect transistors with ultrathin oxide layers. Physical Review B, v.38, n.2, p.1235-1240, 1988.

32 LEE, W.; HU, C. Modeling CMOS tunneling currents through ultrathin gate oxide due to conduction- and valence-band electron and hole tunneling. IEEE Transactions on Electron Devices, v.48, n.7, p.1366-1373, 2001.

33 YANG, N.; HENSON, W. K.; HAUSER, J. R. Modeling study of ultrathin gate oxides using direct tunneling current and capacitance-voltage measurements in MOS devices. IEEE Transactions on Electron Devices, v.46, n.7, p.1464-1471, 1999.

34 WILK, G. D.; WALlACE, R. M.; ANTHONY, J. M. High-k gate dielectrics: Current status and materials properties considerations. Journal of Applied Physics, v.89, n.10, p.52435275, 2001.

35 HUFF, H. R.; GILMER, D. C.. High Dielectric Constant Materials: VLSI MOSFET Applications. 1. ed. Berlim: Springer, 2005.

36 NO EXPONENTIAL IS FOREVER. Produced by Intel Corporation - Gordon E. Moore. Disponível em: < ftp://download.intel.com/research/silicon/Gordon_Moore_ISSCC_021003.pdf>. Acesso em: 01 maio 2006.

37 HUBER, F. Properties of hafnium dioxide thin-film capacitors. IEEE Transaction on parts, hybrids and packaging, v. PHP-7, n. 4, p.141-147, 1971. 
38 TMA MEDICI, version 4.0, 1997.

39 TARIK, K.; VASILESKA, D.; THORNTON, T.J. Quantum mechanical tunneling phenomena in metal-semiconductor junctions. Superlattices and Microstructures, v.34 n.3-6, p.335-339, 2003.

40 SINHA, A.; ROYCHOUDHURY, R.; VARSHNI, Y. P. Wentzel-Kramers-Brillouin quantization rules for two-dimensional quantum dots. Physica B: Condensed Matter, v.325, p.214-223, 2003.

41 RODRIGUES, M.; SONNENBERG, V.; MARTINO, J. A. Simple method to determine the poly gate doping concentration based on poly depletion effect. Microelectronics Technology and Devices SBMicro 2005, p. 180-187, 2005. 


\section{APÊNDICE A - Modelo do arquivo de simulação MEDICI para obtenção da curva $C-V$ de alta freqüência de um capacitor MOS.}

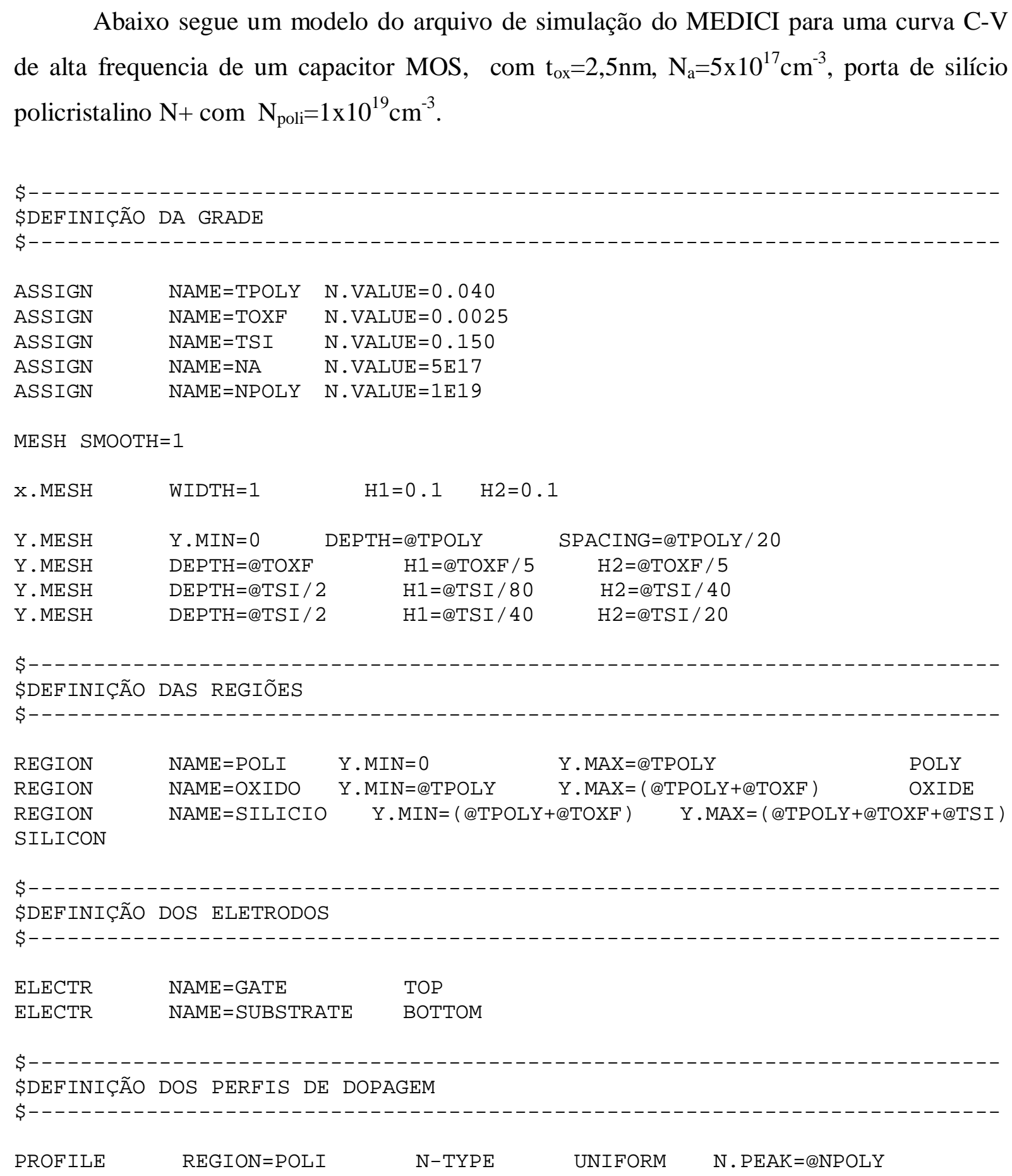




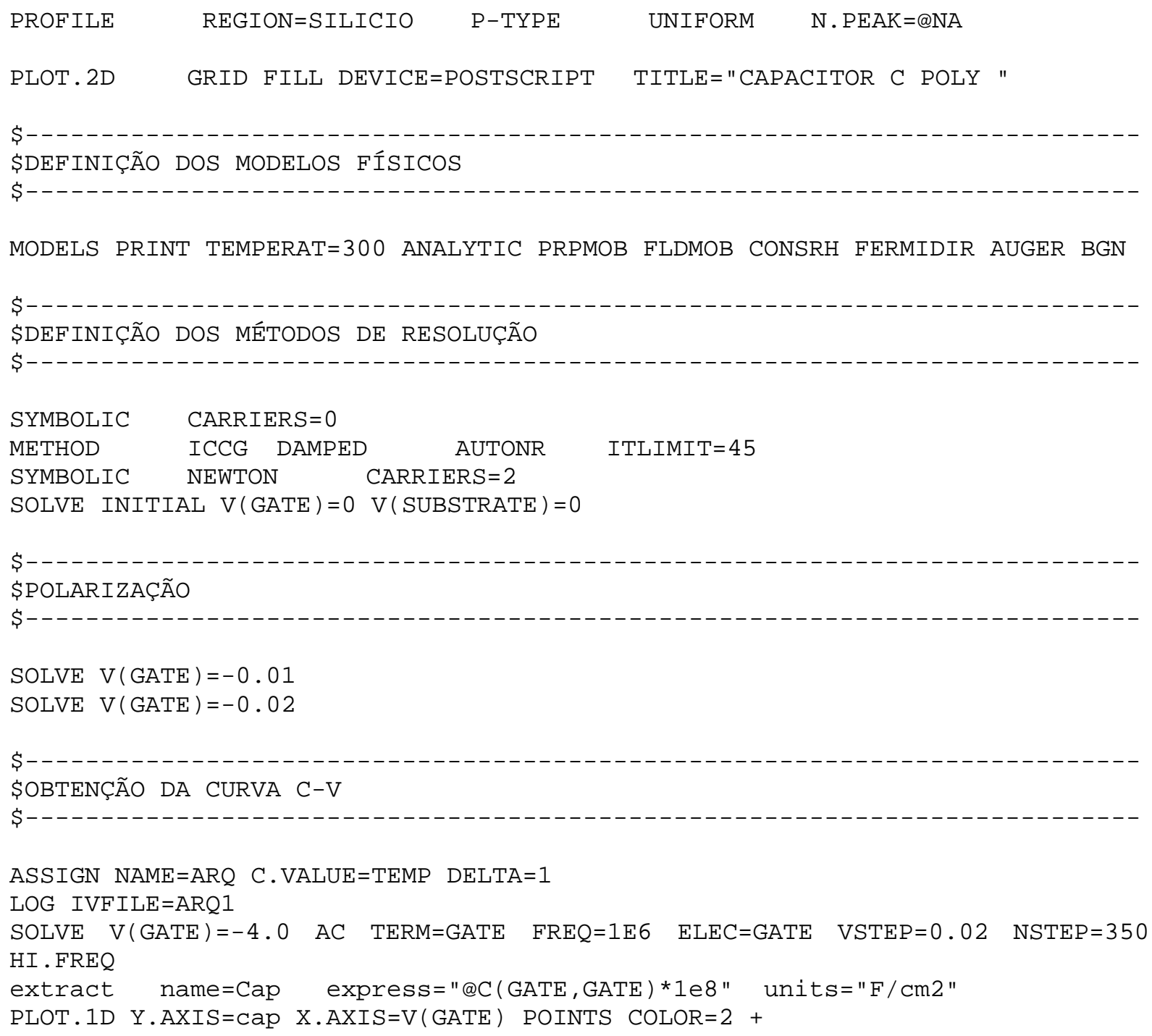




\section{APÊNDICE B - Modelo do arquivo de simulação MEDICI para obtenção da curva $C-V$ de baixa freqüência de uma capacitor MOS.}

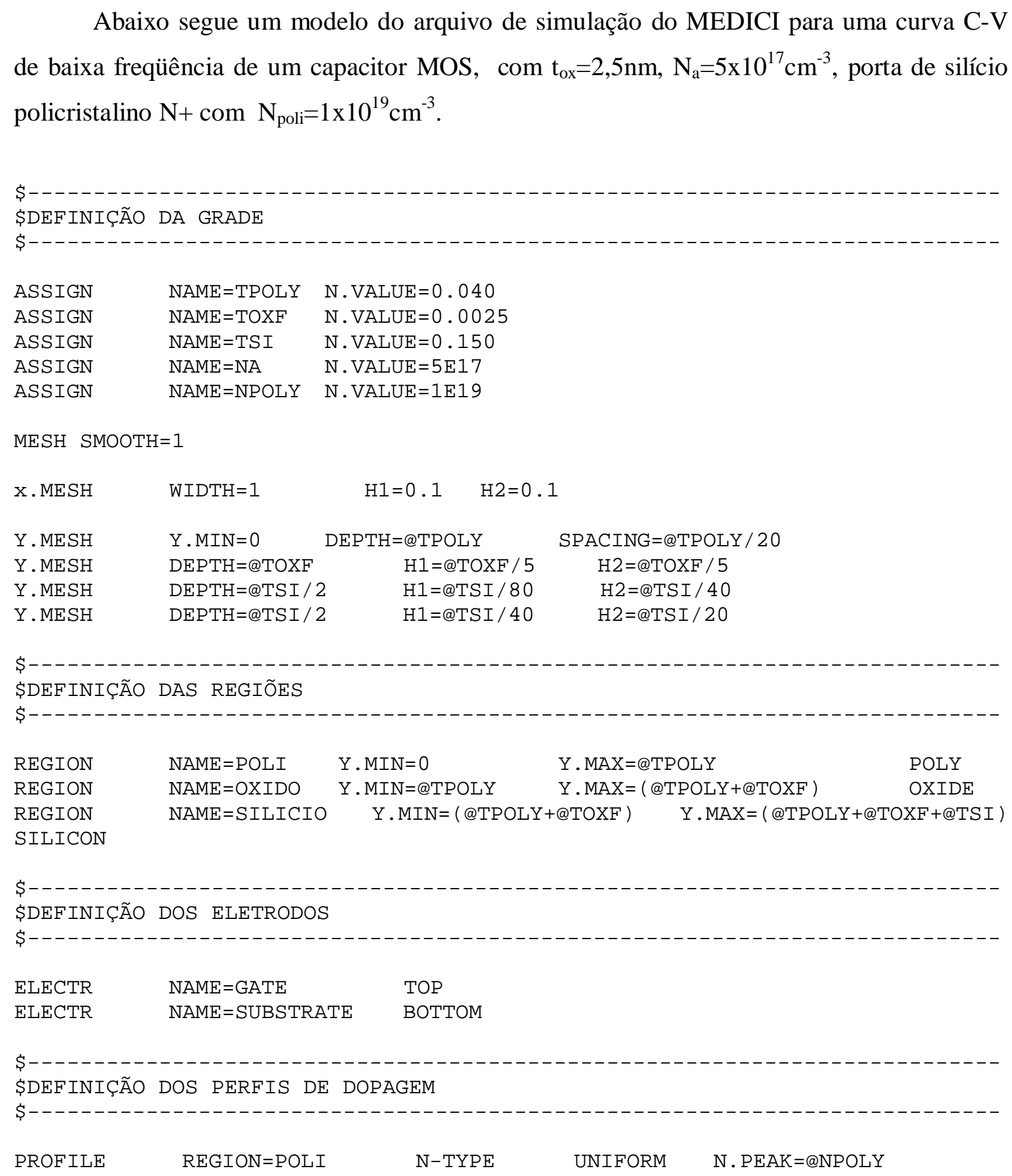




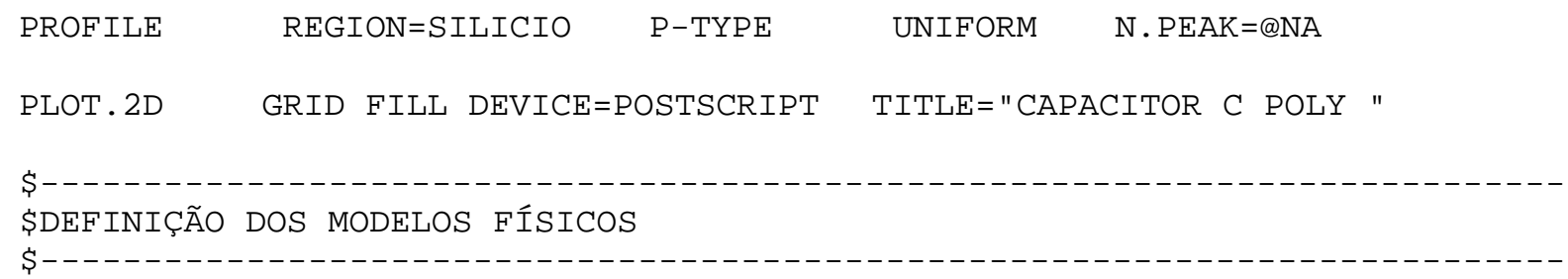
MODELS PRINT TEMPERAT=300 ANALYTIC PRPMOB FLDMOB CONSRH FERMIDIR AUGER BGN \$- 


\section{APÊNDICE C - Modelo do arquivo de simulação MEDICI para obtenção do diagrama de bandas de energia de um capacitor MOS.}

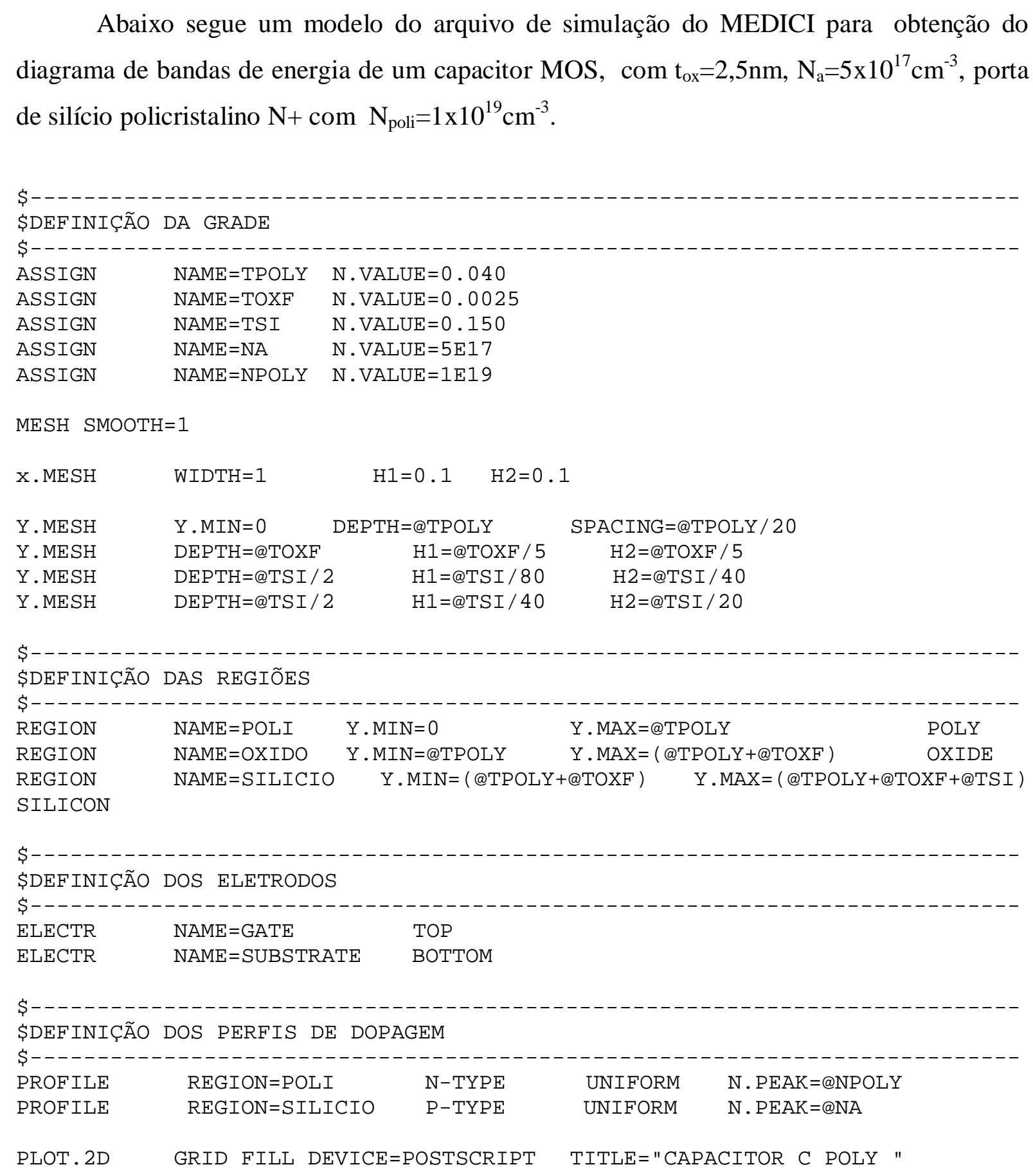




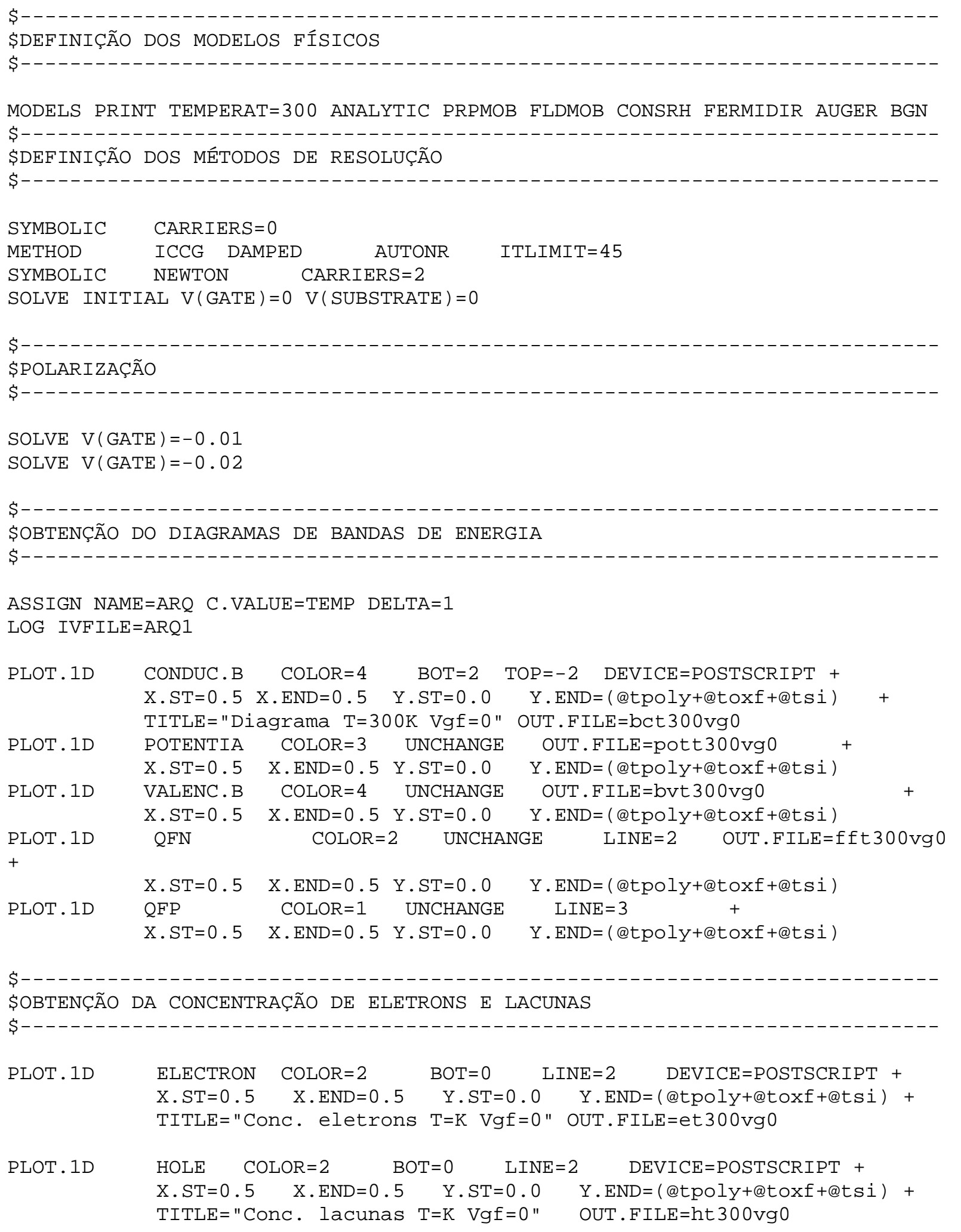




\section{APÊNDICE D - Modelo do arquivo de simulação MEDICI para obtenção de curva $\mathrm{C}-\mathrm{V}$ de alta freqüência e do perfil bidimensional da região de depleção de um capacitor MOS com modelo da corrente de tunelamento direto.}

Abaixo segue um modelo do arquivo de simulação MEDICI para obtenção da curva $\mathrm{C}-\mathrm{V}$ de alta freqüência e do perfil bidimensional da região de depleção (DEPLETIO) de um capacitor MOS, com $\mathrm{t}_{\mathrm{ox}}=2,5 \mathrm{~nm}, \mathrm{~N}_{\mathrm{a}}=5 \times 10^{17} \mathrm{~cm}^{-3}$, contato de porta Si-poli $\mathrm{n}+$ com alta dopagem, considerando modelo da corrente de tunelamento direto (DT.CUR).

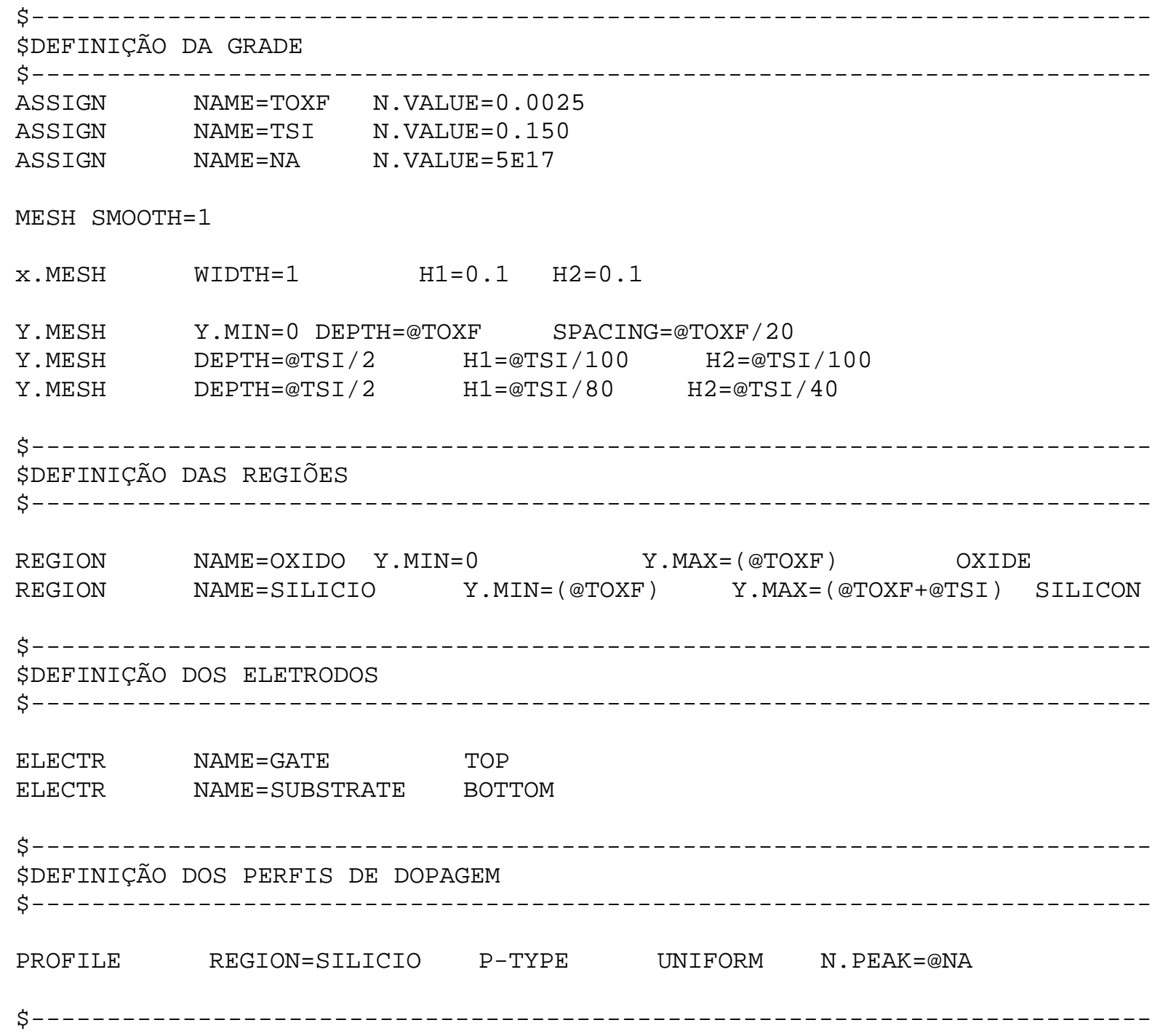


\$DEFINIÇÃO DOS MATERIAIS

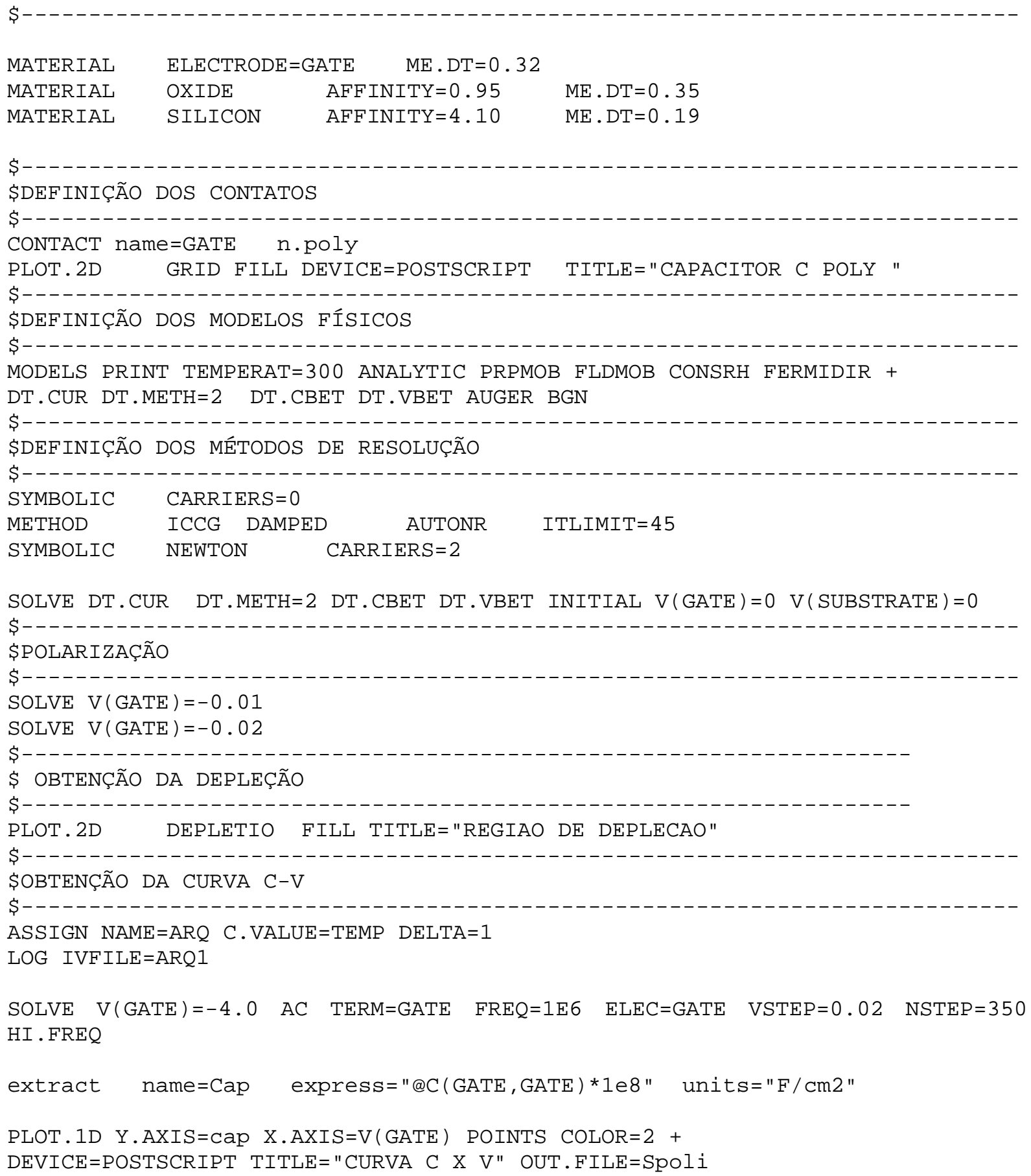

$\$-$ 


\section{APÊNDICE E - Modelo do arquivo de simulação MEDICI para obtenção da curva $I_{G} \times V_{G}$ de um capacitor MOS com modelo da corrente de tunelamento direto.}

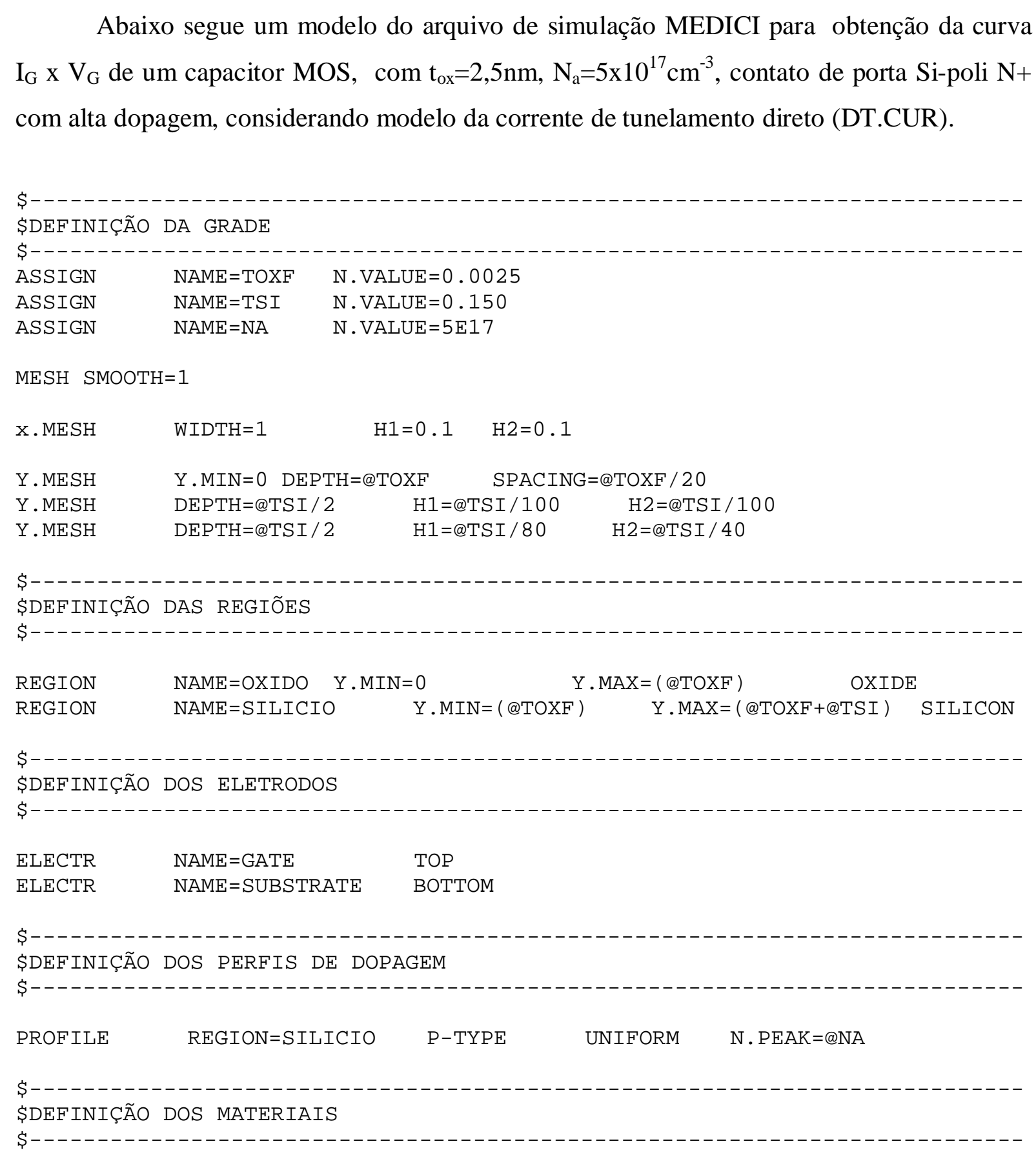




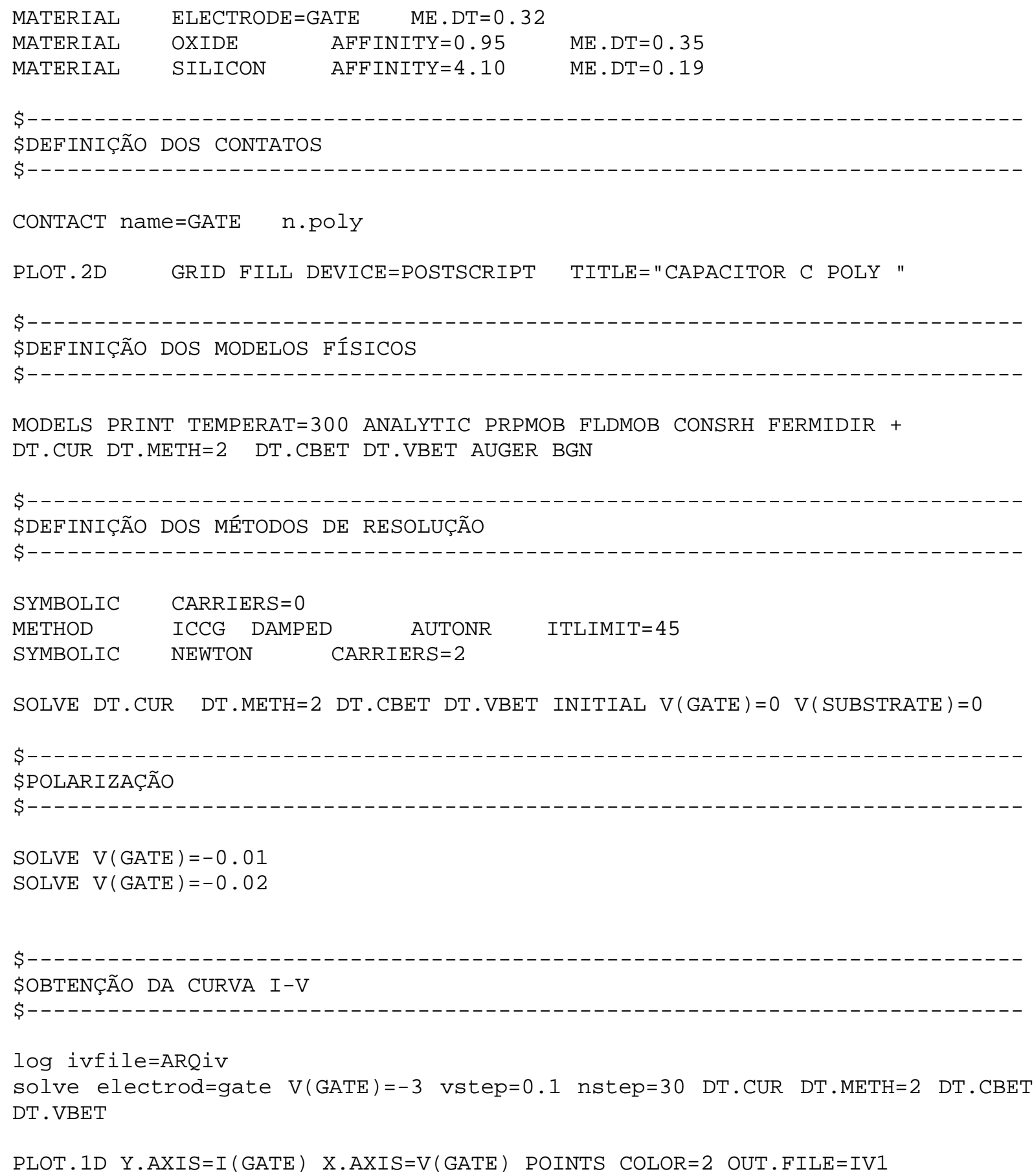

